NBER WORKING PAPER SERIES

\title{
GLOBAL MACRO-FINANCIAL CYCLES AND SPILLOVERS
}

\author{
Jongrim Ha \\ M. Ayhan Kose \\ Christopher Otrok \\ Eswar S. Prasad \\ Working Paper 26798 \\ http://www.nber.org/papers/w26798 \\ NATIONAL BUREAU OF ECONOMIC RESEARCH \\ 1050 Massachusetts Avenue \\ Cambridge, MA 02138 \\ February 2020
}

We thank Linda Goldberg, Andrej Sokol, and Mark Watson for their detailed suggestions. We appreciate helpful feedback from Stijn Claessens, Ambrogio Cesa-Bianchi, Thomas Drechsel, Ippei Fujiwara, Thomas Helbling, Raju Huidrom, Ergys Islamaj, Jinil Kim, Soyoung Kim, Naotaka Sugawara, Linda Tesar, and Kei-Mu Yi, and participants at the IMF 2017 Annual Research Conference, 2018 AEA Meetings, 2018 IMFC3 at Keio University, 2018 CEBRA Annual Meetings, and the Fall 2019 Midwest Macroeconomic Meetings. Meongsu Lee provided excellent research assistance. The authors gratefully acknowledge research support from NSF Grant SES 1156262. The findings, interpretations, and conclusions expressed in this paper are those of the authors and do not necessarily represent the views of the institutions they are affiliated with, nor of the National Bureau of Economic Research.

NBER working papers are circulated for discussion and comment purposes. They have not been peer-reviewed or been subject to the review by the NBER Board of Directors that accompanies official NBER publications.

(C) 2020 by Jongrim Ha, M. Ayhan Kose, Christopher Otrok, and Eswar S. Prasad. All rights reserved. Short sections of text, not to exceed two paragraphs, may be quoted without explicit permission provided that full credit, including ()$^{\text {notice, }}$ is given to the source. 
Global Macro-Financial Cycles and Spillovers

Jongrim Ha, M. Ayhan Kose, Christopher Otrok, and Eswar S. Prasad

NBER Working Paper No. 26798

February 2020

JEL No. C1,C32,E32,F4

\begin{abstract}
$\underline{\text { ABSTRACT }}$
We develop a new dynamic factor model that allows us to jointly characterize global macroeconomic and financial cycles and the spillovers between them. The model decomposes macroeconomic cycles into the part driven by global and country-specific macro factors and the part driven by spillovers from financial variables. We consider cycles in macroeconomic aggregates (output, consumption, and investment) and financial variables (equity and house prices, and interest rates). We find that the global macro factor plays a major role in explaining G-7 business cycles, but there are also spillovers from equity and house price shocks onto macroeconomic aggregates. These spillovers operate mainly through the global macro factor rather than the country-specific macro factors (i.e., these spillovers affect business cycles in all G-7 economies) and are stronger in the period leading up to and following the global financial crisis. We find little evidence of spillovers from macroeconomic cycles to financial cycles.

Jongrim Ha

World Bank

1818 H Street NW MC 2-511

Washington, DC 20433

jongrimha@worldbank.org

M. Ayhan Kose

World Bank

1818 H St NW

Washington, DC 20433

and Brookings institution and CEPR

akose@worldbank.org

Christopher Otrok

Department of Economics

University of Missouri

Columbia, MO 65211

and Federal Reserve Bank of St Louis

otrokc@missouri.edu

Eswar S. Prasad

Dyson School of Applied Economics and

Management

Cornell University

301A Warren Hall

Ithaca, NY 14853

and NBER

eswar.prasad@ cornell.edu
\end{abstract}




\section{Introduction}

Rising cross-border trade and financial flows, coupled with the increasing prominence of financial markets, appear to have intensified spillovers between financial markets and macroeconomic activity, both within and across economies. The 2007-09 global financial crisis dramatically highlighted these linkages. However, there was substantial heterogeneity across countries in how their financial markets and economies were affected by the crisis and ensuing global recession. Most advanced countries experienced deep contractions, but the timing and duration of the contractions and subsequent recovery have differed sharply across countries. The notion of a tightly linked global economy in which macroeconomic and financial disturbances are transmitted symmetrically, in terms of both speed and intensity, across countries is clearly not a suitable characterization.

This warrants a more nuanced analysis of business cycle transmission that accounts for various sources and channels of shock propagation across borders. A sharper distinction is also needed between macroeconomic aggregates (output, consumption, investment) and financial market variables (financial asset prices and house prices), both as sources of shocks and as channels of propagation. The empirical literature has tended to focus on only one of these channels at a time and often in the context of a single country, ignoring both the potentially large feedback effects between them and cross-border spillovers. Another important issue is whether comovement among macroeconomic and financial variables is the result of spillovers of countryspecific or variable-specific shocks, or simply reflects common shocks. Existing econometric models have not been able to make a convincing distinction.

In this paper, we attempt to provide an empirical characterization of macroeconomic and financial cycles in a setting that allows us to analyze the relationships between these two types of cycles, including potential spillovers between them. We begin by examining whether there is a common global cycle in financial variables, similar to the one that has been documented for macroeconomic aggregates. Our empirical analysis focuses on the G-7 economies over the period 1985-2019. The mid-1980s have been identified as the beginning of the recent wave of financial globalization (e.g., Kose, Otrok, and Prasad, 2012). Using a dynamic factor model that comprises three key financial variables - equity prices, house prices, and interest rateswe find no evidence of a common global cycle among these variables for the G-7 economies. Instead, we find evidence that there are global cycles specific to each financial variable (which are proxies for different asset classes) - there is a global equity price cycle, a separate global interest rate cycle, and a house price cycle. We then ask if there is a common cycle among real and financial variables - that is, do the shocks that drive cycles in macroeconomic aggregates also drive any of the financial cycles? The answer we find is again no.

Do these results imply that global macroeconomic and financial cycles evolve independently of each other? This question brings us to the heart of the model developed in this paper, which is designed to investigate cross-border spillovers across macroeconomic and financial cycles. During the global financial crisis, financial market spillovers appear to have been the main mechanism for transmission of shocks across advanced economies, but there is little formal evidence on this point. The crisis also suggests extensive feedback between these two types of cycles, making it imperative to study them in a unified setting. Our objective, therefore, is to study the dynamics of business and financial cycles in a unified model that allows us to characterize potential global macro-financial cycles and spillovers. 
We develop a new dynamic factor model to capture spillovers in both directions across the financial sector and macroeconomy. ${ }^{2}$ Existing factor models attribute the observed comovement among multiple macroeconomic aggregates to a small set of underlying shocks and help identify the relative importance of different driving forces for national and global business cyclesglobal shocks, shocks specific to certain groups of countries, and country-specific shocks. However, we are also interested in the global propagation of shocks originating in one sector (macroeconomic or financial) to other sectors. The model we develop explicitly captures spillovers from one type of factor to another. Specifically, our model allows us to analyze the quantitative importance of cross-border spillovers of shocks hitting different segments of financial markets onto macroeconomic variables through the global and country-specific macroeconomic factors.

We report four major findings. First, while the global macroeconomic (macro) factor plays an important role in explaining business cycle fluctuations, there are sizeable spillovers from specific financial variables - equity prices and house prices, in particular - to macroeconomic variables. Spillovers from the global interest rate factor also contribute to macroeconomic fluctuations but they are less important as sources of cross-border spillovers. Second, spillovers from the equity and housing markets operate mainly through the global macro factor rather than the country-specific macro factors. This means, for instance, that movements in global equity prices influence the global macroeconomic cycle (i.e., the spillovers affect overall business cycles in all G-7 economies), in turn affecting fluctuations in domestic macroeconomic variables in our sample. Third, common cycles among macroeconomic and financial variables, and also the spillovers from financial to macroeconomic variables, are stronger in the period leading up to and following the financial crisis.

Fourth, we find little evidence of spillovers from macroeconomic cycles to financial cycles. One exception is in the case of interest rates, which experience significant spillovers from the global macro factor. In addition to these new results we also confirm, consistent with the prior literature, that there are common business cycles, as reflected in the comovement of macroeconomic aggregates, among the G-7 economies. Our finding of common cycles in certain financial variables, especially equity prices and interest rates, also accords with the previous literature.

Our analysis straddles a number of related strands in the literature. There is a large body of work studying macro-financial linkages - the two-way interactions between the real economy and the financial sector. ${ }^{3}$ Shocks originating in the real economy can be propagated through asset prices, thereby amplifying business (macroeconomic) cycles. Imperfections in financial markets can intensify such propagation effects and, consequently, lead to more pronounced macroeconomic fluctuations. Conversely, shocks that hit financial markets can result in more pronounced asset price movements and macroeconomic fluctuations. Through cross-border linkages, these developments can lead to international spillovers.

\footnotetext{
${ }^{2}$ Our work builds on a large empirical literature using dynamic factor models to characterize business and financial cycles within and across countries (see Stock and Watson, 2011, 2016, and Breitung and Eickmeier, 2016 for surveys of methods and applications for this class of models). Using a dynamic factor model, Stock and Watson (2005) and Kose, Otrok, and Whiteman $(2003,2008)$ document the roles played by global and/or group-specific factors in driving business cycles. Using a factor model, Miranda-Agrippino and Rey (2015) argue that a common factor drives a sizeable portion of variation in equity prices, commodity prices, and bond indices. Hirata et al. (2012) report that common factors play an important role in explaining cycles in certain financial variables, including equity and house prices, and credit.

${ }^{3}$ Brunnermeier, Eisenbach, and Sannikov (2013), Cochrane (2017), and Claessens and Kose (2018) present surveys of different branches of the literature on macro-financial linkages.
} 
Fluctuations in financial markets are shown to have a significant impact on the real economy in a wide range of theoretical models (Bernanke, Gertler, and Gilchrist, 1999; Carlstrom and Fuerst, 1997; and Kiyotaki and Moore, 1997). In these models, wealth and substitution effects can be amplified by changes in access to external financing, including through the financial accelerator and related mechanisms operating through the balance sheets of firms, households, and countries. These mechanisms imply, for instance, that a decline in asset prices lowers an entity's net worth, reducing its capacity to borrow, invest, and spend (an increase in asset prices has the opposite effect). This process, in turn, can intensify fluctuations in asset prices and amplify macroeconomic fluctuations. A number of recent theoretical studies employ similar mechanisms to analyze the roles of leverage constraints, financial integration, global banks, and different types of financial shocks in explaining international business cycle comovement in the context of multi-country models with financial imperfections. ${ }^{4}$

A sizeable empirical literature studies macro-financial linkages at the country level but the research on global macro-financial cycles and spillovers is in its early stages. ${ }^{5}$ Our paper contributes to this nascent literature in multiple dimensions. Ours is the first study to explicitly distinguish between common shocks and cross-border spillovers in a systematic fashion that accounts for global and country-specific factors, along with spillovers. The models used in the previous literature are unable to disentangle spillovers from common shocks. Second, our model enables us to analyze linkages between business and financial cycles without requiring a strong a priori stand on the nature of spillovers between them. Finally, we consider common cycles and spillovers in an empirical model that encompasses both macroeconomic and financial variables in multiple countries (instead of focusing on a single country).

In Section 2, we employ a standard dynamic factor model to assess the evidence for a global financial cycle. In Section 3, we introduce our new dynamic factor model that is used to capture spillovers between the financial sector and macroeconomy. Next, we discuss the results of models that allow for spillovers from the financial sector to the macroeconomy. In Section 5, we describe the results of models that allow for spillovers from the macroeconomy to the financial sector. Section 6 concludes.

\section{Modelling Global Financial Cycles}

We first briefly analyze the evidence for a global financial cycle by using a standard dynamic factor model. Our concept of the global financial cycle is broad-based in the sense that it

\footnotetext{
${ }^{4}$ Some studies have focused on the role of asset prices in transmitting financial shocks to business cycles (Adrian, Colla, and Shin, 2013; Geanakoplos, 2010). For recent theoretical studies of international business cycle comovement in models with financial market imperfections, see Devereux and Sutherland (2011), Dedola and Lombardo (2012), Kollmann (2013), and Perri and Quadrini (2018). For a survey on the theory and empirics of macro-financial linkages, see Claessens and Kose (2018).

${ }^{5}$ For empirical research on macro-financial cycles and spillovers, see Helbling et al. (2011) and Eickmeier and Ng (2015). These studies document that global credit shocks have been influential in driving macroeconomic fluctuations. Ciccarelli, Ortega, and Valderrama (2016) find that both common and country-specific factors play important roles in explaining cross-border spillovers in real and financial variables. The literature examining interactions between business and financial cycles at the country level includes Claessens, Kose, and Terrones (2009, 2012), Borio (2014), Cesa-Bianchi (2013), Mian, Sufi, and Terebbi (2015), and Jordà, Schularick, and Taylor (2017). Meeks (2012) and Prieto, Eickmeier, and Marcellino (2016) employ time-series methods to analyze the roles played by financial markets in driving US business cycles. Others consider the linkages between financial sector and macreoconomy during financial crises (Reinhart and Rogoff, 2009, and Claessens et al., 2014).
} 
captures cyclical fluctuations that are common across multiple financial markets. ${ }^{6}$ Specifically, we analyze the existence of a global financial cycle based on prices in three major financial markets - stock markets, government securities markets, and housing markets. ${ }^{7}$ Our analysis covers the G-7 countries over the period 1985:Q1-2019:Q2. We focus on the G-7 economies since they account for a substantial fraction of world output and, given their levels of economic and financial integration, provide the best likelihood of finding significant spillover effects. These results will, therefore, provide a benchmark for future studies that could include a broader range of countries, including emerging market economies. It is worth emphasizing that, since our primary objective in this paper is to model spillovers between financial and macro variables rather than to precisely estimate a global financial cycle, we do not use a large array of financial variables. Rather, we focus on just a handful of variables that have been identified as relevant for macro fluctuations and also limit our analysis to relatively low (quarterly) frequencies rather than high-frequency (e.g., daily) financial market data.

\subsection{A Dynamic Factor Model with Common Financial Cycles}

In our initial empirical analysis of financial cycles, we employ a standard dynamic factor model. This class of empirical models is useful in identifying a few common factors that drive fluctuations in large multi-dimensional datasets. These factors can capture common fluctuations across the entire dataset (i.e., the world) or across subsets of the data (e.g., country-specific or variable-specific groupings). Our basic model contains: (i) a global financial factor common to all financial variables (and all countries) in the system; (ii) a factor common to each financial variable; (iii) a country factor common to all financial variables in each country; and (iv) an idiosyncratic component for each series.

We start by writing the dynamic factor model in a general matrix form:

$$
\begin{aligned}
& \mathrm{Y}_{\mathrm{t}}=\beta \mathrm{F}_{\mathrm{t}}+\Gamma_{\mathrm{t}} \\
& \Gamma_{\mathrm{t}}=\Psi(\mathrm{L}) \Gamma_{\mathrm{t}-1}+\mathrm{U}_{\mathrm{t}} \text { with } \quad \mathrm{E}\left(\mathrm{U}_{\mathrm{t}} \mathrm{U}_{\mathrm{t}}{ }^{\prime}\right)=\Omega, \\
& \mathrm{F}_{\mathrm{t}}=\Phi(\mathrm{L}) \mathrm{F}_{\mathrm{t}-1}+\mathrm{V}_{\mathrm{t}} \text { with } \mathrm{E}\left(\mathrm{V}_{\mathrm{t}} \mathrm{V}_{\mathrm{t}}{ }^{\prime}\right)=\mathrm{I}_{\mathrm{k}} .
\end{aligned}
$$

$Y_{t}$ is an $n$-dimensional vector of time series data. $\Gamma_{t}$ is an $(n \times 1)$ vector of idiosyncratic components that captures movement in each observable series that are specific to that time series. Each element of $\Gamma_{\mathrm{t}}$ is assumed to follow an independent $\operatorname{AR}(q)$ process as in equation (2). Hence, $\Psi(\mathrm{L})$ is a block diagonal lag polynomial matrix and $\Omega$ is a covariance matrix that is restricted to be diagonal. The latent factors are denoted by the vector $\mathrm{F}_{\mathrm{t}}{ }^{8}$. This vector contains contemporaneous values of the factors as well as lags. The lags of the factor enter the state equation (3) to allow for dynamics in each factor.

\footnotetext{
${ }^{6}$ This view of the global financial cycle follows the basic idea of studying business cycles in multiple aggregates, rather than focusing on cycles in a single variable such as output or industrial production (Kose and Terrones, 2015).

7 More details about our database are in Appendix Table A1. Financial and macroeconomic series are all at a quarterly frequency, seasonally adjusted, and deflated by the CPI for each country. We use growth rates of all variables and, following Stock and Watson (2012), remove low-frequency movements using the Local Mean method. 8 The set of equations (1)-(3) comprises a state space system where (1) and (2) combined correspond to the measurement equation and (3) corresponds to the state transition equation. This state space structure is exploited in the Gibbs sampling procedure when the model parameters are estimated.
} 
If we let $s$ be the number of factors $(s<n)$ and $p$ be the order of the autoregressive process that each factor follows, then we can define $m=s p$ as the dimension of the state vector. $\mathrm{F}$ is then an $(m \times 1)$ vector of unobservable factors (and its lags) and $\Phi(\mathrm{L})$ is a matrix lag polynomial governing the evolution of these factors. The variance covariance matrix of this equation, $I_{k}$, is assumed to be an identity matrix for normalization purposes. Typically, the matrix $\Phi(\mathrm{L})$ is restricted to be block diagonal. In Section 3, we will model spillovers by relaxing that restriction in a number of ways.

While, in principle, all variables can load on all factors in these models, we want to make a clear distinction in our model between global, country-specific, and financial variable-specific factors in this section. In order to identify such factors, we follow Kose, Otrok, and Whiteman (2003) and impose zero restrictions on some of the $\beta$ parameters. This implies that, for example, only the equity price variable in each country has a non-zero factor loading on the factor we label "equity prices". The zero restrictions of this sort that we impose on $\beta$ imply that the model can then be written as:

$$
\begin{aligned}
Y_{t}^{i, j, k} & =\beta_{\text {global }}^{i, j, k} f_{t}^{\text {global }}+\beta_{\text {fin variable }_{k}}^{i, j, k} f_{t}^{\text {fin variable }_{k}}+\beta_{\text {country }_{j}}^{i, j, k} f_{t}^{\text {country }_{j}}+\varepsilon_{t}^{i, j, k} \\
\varepsilon_{\mathrm{t}}^{\mathrm{i}, \mathrm{j}, \mathrm{k}} & =\phi^{\mathrm{i}, \mathrm{j}, \mathrm{k}}(\mathrm{L}) \varepsilon_{\mathrm{t}-1}^{\mathrm{i}, \mathrm{j}, \mathrm{k}}+v_{\mathrm{t}}^{\mathrm{i}, \mathrm{j}, \mathrm{k}} \\
\mathrm{f}_{\mathrm{t}}^{\mathrm{m}} & =\phi^{\mathrm{m}}(\mathrm{L}) \mathrm{f}_{\mathrm{t}-1}^{\mathrm{m}}+\mu_{\mathrm{t}}^{\mathrm{m}} \text { for } \mathrm{m}=1 \ldots(1+\mathrm{K}+\mathrm{J}) .
\end{aligned}
$$

We use this model to investigate common cycles in financial variables.

\subsection{Common Factors Driving Financial Cycles}

We begin with the most basic one-factor version of this model that allows for only a global factor common to all variables and countries. Panel A in Figure 1 shows the contributions of the global factor to the variance of each series. The variance contributions of the global factor are sizable for equity prices but small for the other variables. We then split the full sample into two overlapping sub-samples: a pre-crisis sample (1985-2007) and a recent sample (1998-2019). The first period excludes the global financial crisis while the second one includes part of the period of the Great Moderation and the subsequent crisis. The variance contributions of the global factor are on average higher in the second period for all three financial variables. For instance, the contribution of the global factor to the variance of equity price fluctuations rises from 51 percent in the first period to 62 percent in the latter period. For the other variableshousing prices, and interest rates - the variance contributions of the global factor are less than 10 percent in both periods. ${ }^{9}$

The residual variance in the above exercise could in principle be accounted for by other factors that could be common across specific groups of the data. In Table 1, we present results for the one-factor model as well as two other versions of our basic model that, in addition to the global factor, include (i) variable-specific factors that capture common cross-country fluctuations specific to each financial variable, and (ii) both variable-specific factors and country-specific factors that capture the comovement of all financial variables within a particular country. Since comovement of financial market variables appears to be stronger in the period 1998-2019, we show only the results for the models estimated over that period.

\footnotetext{
${ }^{9}$ We also examined the importance of different factors for the period 2008-2019. Relative to the period 1998-2019, the variance shares explained by the global factor increase for almost all financial variables.
} 
The results indicate that the contribution of the global factor to the variance of equity price fluctuations is smaller in the multi-factor models, accounting on average for 10-14 percent of the variance in the two extended versions of the model (Panel B in Figure 1). In the model with three factors, the variance contributions of the global factor to fluctuations in equity prices are sizeable for only a few countries. Instead, the bulk of fluctuations in each of the financial variables is explained by the variable-specific financial factors. For fluctuations in equity prices, for example, the common equity price factor is responsible on average for roughly 62 percent of variation across countries in the three-factor model. For house prices and interest rates, the variable-specific factor accounts on average for one-fifth to one-third of the variance and the global factor for less than 3 percent. Country-specific factors in general play a minor role in explaining fluctuations in the financial variables although they do play a more prominent role in explaining house price fluctuations in Canada and the United States and interest rate fluctuations in Japan and the United States.

The picture that emerges from these exercises is that the global financial factor does not play a major role in explaining the variance of fluctuations in any of these financial variables. Most of the literature on the presence of a global financial cycle is based on comovement of one financial variable across countries. Our findings are consistent with this view. ${ }^{10}$ Indeed, we find that there is strong evidence of cross-country comovement of equity prices and interest rates. For house prices, the variable-specific factor plays a smaller but still sizeable role in explaining cross-country comovement. But our results also highlight that there is limited empirical evidence to support the concept of a global financial cycle that encompasses multiple financial markets or asset classes, at least for the major financial market indicators of interest to us.

We acknowledge that there could be more cross-country financial market synchronization at higher frequencies, especially in response to unanticipated policy shocks, financial disruptions, and news shocks. ${ }^{11}$ However, the quarterly frequency that we focus on is more relevant for analyzing the linkages between the financial sector and the macroeconomy (we conduct some robustness exercises with monthly data in Section 6). The findings highlighted above - the absence of a broad-based global financial cycle that encompasses multiple asset markets - will play an important role in the construction of the empirical model that we use to capture spillovers between the financial sector and macroeconomy in the next section.

\section{A Dynamic Factor Model with Macro-Financial Spillovers}

We now provide a more general representation of the standard framework used in the previous section and use that as the basis for developing a new dynamic factor model. This new model

\footnotetext{
${ }^{10}$ Some recent studies document evidence in support of strong cross-country comovement of cycles in individual financial variables. See Claessens, Kose, and Terrones (2011) for highly synchronized cyclical phases of individual financial market segments, including equity and housing markets; Hirata et al. (2012) and Cesa-Bianchi, Cespedes, and Rebucci (2015) for the synchronization of cycles in equity and house prices and credit. Some of these studies also document that the degree of comovement of cycles in financial variables has increased over time (Claessens and Kose, 2018). Some other studies that examine the presence of a global financial cycle report mixed findings. For example, Miranda-Agrippino and Rey (2015) find that one global factor explains an important part of the variance of a large cross section of equity prices, commodity prices, and bond indices. Rey (2015) argues that there is a global financial cycle in capital flows, asset prices, and credit. By contrast, Cerutti, Claessens, and Rose (2017) conclude that there is no significant global financial cycle in capital flows. Avdjiev et al. (2017) and Buch et al. (2019) document that the importance of the global factor in global liquidity flows increases around and after the global financial crisis, largely due to the transmission of U.S. monetary policies.

${ }^{11}$ For example, a rich literature on contagion employs higher-frequency data to analyze the extent of comovement of different types of asset prices across countries (Forbes, 2013).
} 
allows us to study spillovers between financial and macroeconomic (macro) variables, and also permits us to disentangle such spillovers from common shocks. For the macro time series, we use quarterly real deseasonalized data on output, consumption, and investment.

\subsection{Modelling Macroeconomic and Financial Cycles}

We use the same zero restrictions as in Section 2 to first estimate a series of models where the factors can be identified as common, macro, or financial. We allow all variables to load on the same common factor. This addresses the question of whether or not there is a common cycle between financial and macroeconomic variables. A common cycle between the two types of variables would mean that they are driven in part by common shocks. We estimated such models combining in sequence macro series with (i) equity prices, (ii) house prices, and (iii) short-term interest rates. In no case did we find a common component. In other words, there is no common shock that jointly drives macroeconomic and financial variables.

This motivated us to treat the macro and financial blocks as separate in the specification of the factor model. Specifically, this means that the macro variables have zero factor loading on the financial factor, and the financial factors have zero factor loadings on the macro variables. A benefit of this approach is that we cleanly label "macro" and "financial" factors by imposing these zero restrictions. This implies that we can rewrite equation (1) as:

$$
\left[\begin{array}{c}
Y_{t}^{M} \\
Y_{t}^{F}
\end{array}\right]=\left[\begin{array}{cc}
\beta^{M} & 0 \\
0 & \beta^{F}
\end{array}\right]\left[\begin{array}{c}
F_{t}^{M} \\
F_{t}^{F}
\end{array}\right]+\left[\begin{array}{c}
\Gamma_{t}^{M} \\
\Gamma_{t}^{F}
\end{array}\right]
$$

where the $M$ superscript refers to a block of macroeconomic variables, the $F$ superscript represents the block of financial variables, and the zeros stand for appropriately sized matrixes of zeros.

The next step is to impose restrictions on the factor loading matrices within the macro and financial blocks. Based on the results in Section 2, which indicated that there is no common cycle across all financial variables, we estimate a sequence of macro-financial models where the financial block consists of one financial variable for each of the G-7 countries in our sample. This yields a financial block where $Y_{t}^{F}$ is a $7 \times 1$ vector with the financial data for each country at time $t, F_{t}^{F}$ is a single factor (but $F_{t}^{F}$ is not scalar because the lags of that factor appear in the state equation), and $\beta^{F}$ is non-zero for the relevant financial variable loading on the financial factor (note again that $\beta$ is not of dimension $1 \times 7$ because of the presence of lags of the factor). The financial factor is then interpreted as a global factor for the relevant financial variable.

For the macro block, we partition the data to allow for global and country-specific macro factors. With our dataset comprising output, consumption, and investment for G-7 countries, the block will have one common macro factor and seven country-specific macro factors. Identification of the country factors is obtained by allowing only variables within each country to load on a particular factor, which we then label that country's factor.

We do not have a country-specific financial factor because we did not find a common component across the financial variables within a country in our previous exercise. This is an empirical result, not an assumption. We do find that global and country-specific factors are both relevant for the macro block, which is consistent with the findings in the literature (Kose, Otrok, and Whiteman 2003, 2008). 


\subsection{Modeling Spillovers}

As noted above, a standard assumption in the factor literature is that the matrix governing the evolution of the factors, $\Phi(\mathrm{L})$, is block diagonal. This assumption imposes a structure on the model that the latent factors evolve independently of each other. We now seek to relax this assumption in some dimensions to allow spillovers across the factors. Since we have found that there are no common shocks across macro and financial variables, their comovement is driven only by spillovers. For example, a global financial shock may affect the global macro factor with a lag. To capture these effects, we relax the assumption that $\Phi(\mathrm{L})$ is strictly block diagonal. As with the $\beta$ matrix, we could in principle allow the entire matrix to be unrestricted. In practice, this would result in a proliferation of parameters that would add uncertainty to the estimates and make the results harder to interpret. Instead, we turn on spillovers in sequence from one factor to another. We focus on those spillovers that are "statistically" and "economically" interesting.

A spillover from one factor to another is captured by allowing one factor to load on lags of another factor as well as its own lags. For example, to measure spillovers from the world financial factor $\left(F_{t}^{F}\right)$ to the world macro factor $\left(F_{t}^{M, W}\right)$, we would model the factor evolution equation for the world macro factor as:

$$
F_{t}^{M, W}=\phi_{t}^{M, W}(L) F_{t}^{M, W}+\phi_{t}^{M, W, F}(L) F_{t}^{F}+u_{t}^{M, W}
$$

Generically speaking, when we say factor 'A' spills over to factor 'B', we are referring to a structure such as this one. Note that the only commonality across these variables comes from the spillovers that occur with a one (or more) period lag. There are no shocks that are common to the two types of factors. If there were a common shock, then the two types of variables would both load on one common factor, which would contain a common contemporaneous shock. However, as noted above, our results show that there is no common factor across the macro and financial blocks - so, empirically, there is no common shock.

A key assumption of the model is that spillovers occur with a one period lag. In the context of macroeconomic variables, the assumption implies that these variables are "sluggish" in their response to financial shocks. That sluggishness can arise from real or nominal rigidities, or, in the international context, from trade frictions. ${ }^{12}$ Since macroeconomic data are released in the quarter after the data are realized, financial markets would react with a one quarter lag, justifying our assumption in the context of the model that captures spillovers from the macroeconomy to the financial sector.

We concentrate on spillovers from the macro to the financial block, and vice versa. Shocks from the financial block are interpreted as global in nature because, as documented above, there is a distinct global cycle and no country-specific financial cycle in the three financial variables we focus on. From the macro block, we have both country-specific and global macro shocks that can affect the financial cycles. ${ }^{13}$ To highlight the different types of spillovers, we

\footnotetext{
${ }^{12}$ In simple terms, our assumption is equivalent to ordering macroeconomic variables after financial variables in a Cholesky identification of a VAR. Since we are using quarterly data and assume that spillovers take place with a one period lag, our model framework is unable to capture spillovers at higher frequencies than a quarter. We also report robustness results with the monthly data later in the paper.

${ }^{13}$ We do not argue or show here that there are no cross-block spillovers within countries. Instead, we only focus on spillovers at the global level.
} 
isolate them by allowing for one type of spillover at a time. For example, our first model allows for spillovers from the financial factor (one for each of three financial variables) to the world macro factor as in equation (7). Each of our models can be described as relaxing the zero restriction on the lag polynomial in equation (6) to allow one factor to depend on lags of another. When we write that one factor spills over to another, we mean that we allow for nonzero coefficients in the relevant rows of $\Phi(\mathrm{L})$.

Our four models can be described as follows: In Model 1, the financial factor spills over to the world macro factor. In Model 2, the financial factor spills over directly to country macro factors. The difference between these two models is that the first imposes proportional responses (scaled by the factor loading) to the financial factor, meaning that the financial spillovers are symmetric across countries, while the second allows for asymmetric responses. Model 3 allows for the world macro factor to spill over to the financial factor. Model 4 allows the U.S. country factor to spill over to the financial factor. In principle, any country can be used here; we choose the United States since, in view of its being the largest economy and having a dominant role in global finance, conventional wisdom is that spillovers from its economy are most likely to affect others.

In addition, we estimate models that are combinations of these. For example, Models 1 and 2 combined would capture both channels through which the financial factor affects macro activity. We have estimated such models and they naturally lead to variance decompositions where the overall spillover effects equal the sum of the variance contributions of the spillover effects from Models 1 and 2. The same is true for Models 3 and 4.

The combination of models such as Models 1 and 2 yields the same result as estimating the two models separately because our spillover model does not deliver 'new' factors compared to a standard factor model. ${ }^{14}$ The spillover parameters do not affect the estimates of the factors themselves. We have estimated models without spillovers and found factors that are identical to those without spillovers. The value added here then is in the variance decompositions that break down the common factors into sources that are macro and financial in nature. Specifically, we know there is a global business cycle in macro aggregates (i.e., there is a significant common factor among key macroeconomic variables). We document how much of that global business cycle is due to spillovers from financial cycles - or, more precisely, how important are innovations that originate in the financial side of the economy for the macro side. Likewise, we document what proportion of financial cycles can be attributed to innovations that originate in the real side of the economy (macroeconomy).

\subsection{Model Estimation and Identification}

The estimation of the model is Bayesian, though we have strong priors only on the stationarity of the model. Since we are interested in the parameters of the model to measure spillovers, approximate solutions to the model are not appropriate. The state space approach to estimating parametric factor models is shown to yield more accurate estimates of variance decompositions than the asymptotically justified principal components methods when the model includes multiple layers of factors (Jackson et al., 2016). The size of the model allows us, with some partitioning of the model into blocks, to evaluate its exact likelihood.

\footnotetext{
${ }^{14}$ Our model does not provide a new estimate of the global common factor since our macro factor is in fact the same as in a standard model. Our model decomposes the movements in that common macro factor into shocks that are innovations to the factor itself, and shocks that originate elsewhere, such as the financial sector, and then spill over into the macro sector.
} 
It is not possible to derive analytical solutions for the posterior distribution of the model. Therefore, we use numerical methods to simulate from the posterior distribution of model parameters and factors. We use a state space approach following Kim and Nelson (1998). Their approach is based on using a Gibbs sampler to sequentially sample from the posterior of the parameters conditional on the last draw of the factors and then the factors conditional on the draw of the parameters. The estimation procedure for state-space estimation of dynamic factor models is fairly well known. The specific procedure for drawing factors and parameters is described in Jackson et al. (2016).

The number of lags that describe the evolution of the idiosyncratic shocks (q) and latent factors (p) are kept at 2 and 3, respectively. ${ }^{15}$ Our priors for the model parameters are generally weak, with the exception that we impose stationarity on the dynamic components. The prior for the autoregressive coefficients in the law of motion of each idiosyncratic shock is $\left(0, \Omega_{0}\right)$. The variance terms of the prior $\Omega_{0}$ are calculated numerically based on a prior over the roots of the polynomial. We specify a prior over each root of the polynominal that is $\mathrm{N}(0,0.5)$. We then draw the two roots and translate those roots into polynomial coefficients. If the polynomial is stationary, we retain the draw. These terms are then averaged to get the elements of $\Omega_{0}$.

The prior for the autoregressive coefficients that govern the evolution of each factor is similarly specified. When $\Phi(\mathrm{L})$ is block diagonal, the only variables that enter each factor equation are its own lags. In this case, the prior for the autoregressive coefficients corresponding to these lags is $N\left(0, \Phi_{0}\right)$. As with the idiosyncratic terms, these values come from first specifying a prior over the roots of the polynomial and then translating it into priors for the coefficients. When the block diagonality is relaxed to allow for spillovers, lags of other factors also appear in the law of motion of one or more factors, depending on the exact specification of $\Phi(\mathrm{L})$. Accordingly, in these specifications the variance covariance matrix $\Phi_{0}$ is augmented to include priors for the coefficients of those lags as well. ${ }^{16}$ The prior on all factor loading coefficients is $\mathrm{N}(0,1)$. The prior for the innovation variances in the observable equation is Inverted Gamma $\left(0.1^{*} \mathrm{~T}, 0.25^{2}\right)$. These priors are fairly diffuse and none of the results we report below are sensitive to changes in them.

The model faces standard identification issues that permeate this literature. Following the previous literature, we require that one factor loading for each factor be positive. Second, we normalize the innovation variances of the factors to unity as the scale of the factors is not identified. The additional parameters we estimate in the model cause no new problems for identification. To see this, consider the main blocks that we draw from in the Gibbs sampler. Drawing from the factors conditional on the parameters is a standard use of the Carter-Kohn version of the Kalman filter. The fact that there are fewer zero restrictions than usual has no effect on this step, as the filter itself is derived under the assumption that all elements are nonzero. Conditional on the factors, the parameters are drawn equation by equation. For example, drawing the $\phi^{W, U S}$ term just requires that an additional regressor (the U.S. factor) appears in the regression. There is no concern about the factors being misidentified-say, as the world rather than U.S. factor - as the factors are identified through the zero restrictions on the factor loading equations.

\footnotetext{
${ }^{15}$ That $q=p-1$ is a matter of convenience as this allows us to perform quasi-differencing of the observables in a straightforward manner. We estimated some of the models with longer lags but the lags beyond 3 were not statistically significant in nearly all cases.

${ }^{16}$ For example, the prior for the autoregressive coefficients in the law of motion of the world factor with spillovers from the financial factor (Model 1) is then given by $N\left(0, \Phi_{00}\right)$ where $\Phi_{00}=\left[\begin{array}{cc}\Phi_{0} & 0 \\ 0 & \Phi_{1}\end{array}\right]$.
} 


\subsection{Variance Decompositions}

We quantify the relative importance of various factors by calculating how much of the unconditional variance of each observable variable can be attributed to which factor. In the benchmark case, the factors are assumed to be orthogonal so one can simply apply the variance operator to the left and right hand sides of equation (1) and calculate the variance shares. However, in the model presented above, the factors are not orthogonal by assumption of the spillovers. Hence, we need an alternative method for quantifying the relative importance of different factors.

Our approach is to use a forecast error variance decomposition and let the horizon go to infinity. In a stationary system, the unconditional variance is the limit of the forecast error variance as the horizon goes to infinity, so this procedure still yields a decomposition of the unconditional variance of each series. This indicates how much of the variance in each observable variable is attributed to the innovations to each factor and is equivalent to writing out the $\mathrm{MA}(\infty)$ representation of the model and then applying the variance operator. If a factor is relatively more important for a variable, then its share of the explained variance will be large.

In practice, we apply standard VAR forecasting formulas (with many zeros imposed on the VAR coefficients) to calculate the variance decompositions. These formulas trace the impact of an innovation to factor $\mathrm{A}$ on factor $\mathrm{B}$ at horizon $h$. The variance decompositions for observable variable $\mathrm{Y}$ then rescales the factor decomposition based on the factor loadings of $\mathrm{Y}$ on each factor. For example, denote the variance of the world macro factor explained by the financial factor at horizon $\mathrm{H}$ as $\operatorname{Var}_{\mathrm{H}}\left(\mathrm{F}^{\mathrm{W}} \mid \mathrm{F}^{\mathrm{F}}\right)$. The variance of U.S. output at horizon $\mathrm{H}$ due to the financial factor is then given by:

$$
\operatorname{Var}_{H}\left(Y_{U S} \mid F^{F}\right)=\frac{\left[b_{U S, Y}^{W}\right]^{2} \operatorname{Var}_{H}\left(F^{W} \mid F^{F}\right)}{\operatorname{var}_{H}\left(Y_{U S}\right)}
$$

In this case, U.S. output does not load on the financial factor. Yet, the formula reveals that U.S. output does depend on the financial factor, due to the impact of the financial factor on the world macro factor. This is the spillover we attempt to measure.

We examine the variance decompositions at a horizon of 30 periods (quarters) in order to abstract from short-term fluctuations. In practice, the variance decompositions generally settle down after about 8 quarters, so our approach essentially focuses on a medium- to long-term forecasting horizon. The relative share of each factor's contribution to the forecasting error of each variable does not change substantially from short- to long-term forecasting horizons. The spillover effects, however, do increase over the first few quarters since these effects are generated from lags of the macro or financial factor.

An interesting ancillary question is whether the contributions of different factors have changed over time. In particular, a question is whether the financial crisis that hit the world economy in 2008-09 has a major bearing on the results. To address this issue, we consider two exercises. First, we estimate the models over the full sample (1985-2019) and then separately over two partially overlapping periods: 1985-2007 and 1998-2019. The first period excludes the financial crisis while the second one includes part of the period of the Great Moderation and the subsequent crisis. Second, we consider an exercise that involves the estimation of our combined Models 1 and 2 over 15 year rolling sub-periods with one year increments. This provides a better characterization of the evolution of the importance of common factors and spillovers in 
explaining variation in macroeconomic and financial variables, especially during the global financial crisis.

To avoid cluttering the tables in the main text, we mostly report variance decomposition results averaged across the G-7 economies. We do not report posterior coverage intervals for the variance decompositions (which, in turn, are posterior medians of the variance decompositions based on 10,000 draws). In the main text, we emphasize those results where the one standard deviation bands of the coverage intervals around the estimated medians do not include zero.

\subsection{Global and Country-Specific Factors}

Before getting into the details of results from variance decompositions, we briefly discuss the estimated factors and their properties. Figure 2 plots the global macro factor, the U.S. country factor, and global factors of the three financial variables. The figure presents the posterior median for each factor, along with the 16 and 84 percent posterior quantile bands. The factors are estimated reasonably precisely as the quantile bands are generally quite tight. ${ }^{17}$

The estimated global factor tracks global output growth well and picks up the major peaks and troughs: the recession of the early 1990s; the 2001 recession and the subsequent recovery; and the global financial crisis. The U.S. country factor also picks up the main cyclical episodes. The correlation between the U.S. country factor and global factor is about 0.16 . We also check the cross-correlations among the country factors. These correlations are often quite low, implying that most of the business cycle comovement among G-7 countries is captured by the global macro factor, with little residual correlation among the country-specific cycles.

The estimated financial factors are also consistent with major developments in financial markets. The equity price factor is substantially more volatile than the common factors for each of the other financial variables. The posterior quantile bands for the house price factor are larger than those for the other financial variables, reflecting more variability across G-7 countries in the time series behavior of house prices. The volatility of the house price factor is high in the late 1980s-early 1990s and mid to late 2000s, reflecting boom-bust cycles in G-7 housing markets during these periods. Between these two periods, the house price factor has substantially lower volatility.

\section{Spillovers from the Financial Sector to the Macroeconomy}

\subsection{Global Spillovers}

In this section, we explore the importance of spillovers from the financial sector in explaining fluctuations in macroeconomic aggregates of the G-7 countries. We estimate Models 1 and 2 for this purpose. In the former model, the global financial factor spills over to the global macro factor whereas, in the latter one, it spills over directly to country-specific macro factors. We also estimate the combination of these two models in which financial market spillovers operate through both the global and country-specific macro factors. Table 2 reports the averages of variance decompositions based on these three models for each financial variable.

\footnotetext{
${ }^{17}$ In Appendix Tables A2 and A3, we report posterior medians of factor loadings and factor vector-autoregressive coefficients.
} 
Equity Prices. We first consider equity prices as the main measure of global financial market activity. The comparison of results from Models 1 and 2 indicate that spillovers from the equity markets to output and investment take place mostly through the global macro factor (rather than country-specific factors). For instance, the spillovers from the global equity price factor through the global macro factor in Model 1 account for 7 percent of output fluctuations for the full sample (see Table 2, Panel A, third column marked SF). The spillovers through the country-specific macro factor (Model 2) account for a much smaller share of output fluctuations - just 1.3 percent. The global equity price factor is responsible for 5 percent of the variation in investment in Model 1 but only a negligible fraction of consumption fluctuations. The results from the combination of Models 1 and 2 indicate that the spillovers through the global macro factor and country-specific factors are together responsible for 17 percent of output fluctuations, 6 percent of consumption fluctuations, and 11 percent of investment fluctuations in 1998-2019. These results collectively suggest that spillovers originating in equity markets play a significant, although not large, role in explaining macroeconomic fluctuations.

The potency of spillovers from equity markets has increased over time for all macroeconomic variables (Figure 3). For example, the average variance of output due to spillovers from the global equity price factor in Model 1 increases from 4 percent in 1985-2007 to 15 percent in 1998-2019. ${ }^{18}$ This increase is mainly driven by the larger role of spillovers from the global macro factor as the importance of spillovers through the country-specific macro factors has not changed much over time. Contributions of spillovers from equity markets to fluctuations in output and investment have become larger in 1998-2019 than those in the case of consumption. Interestingly, the comovement of equity prices, captured by the fraction of variance of equity prices accounted for by the global equity price factor (Table 2, column marked F), increases only slightly in 1998-2019 relative to 1985-2007 (from 50 to 59 percent in the combined model). Thus, it is not the greater integration of equity markets across the G-7 countries but the size of their spillover effects on to macro cycles that distinguishes the latter period from the former one.

How important are financial market spillovers relative to the global macro factor in driving macroeconomic fluctuations? Among the G-7 countries, the role of spillovers from the global equity markets is on average smaller but, relative to that of the global macro factors, it remains sizeable (Figures 4 and 5). Specifically, over the period 1998-2019, the global macro factor (comparable numbers for spillovers from the global equity price factor are in parentheses) on average accounts for about 34 (17) percent of output fluctuations, 8 (6) percent of consumption fluctuations, and 22 (11) percent of investment fluctuations. While the average variance of output and investment explained by the global macro factor is higher in this period compared to 1985-2007, the corresponding increase in the relative importance of spillovers from the global equity price factor between the two periods is slightly larger.

The global macro factor explains a much larger fraction of output variance than it does for consumption. This result is consistent with other evidence that, contrary to the predictions of standard international risk sharing models, output fluctuations are more correlated across countries than consumption fluctuations (Backus, Kehoe, and Kydland 1992). Country-specific factors account for about one-quarter to one-third of fluctuations in output and investment, and an even higher share of consumption fluctuations, in the 1998-2019 period (Table 2, columns marked C).

${ }^{18}$ We check the robustness of these findings by studying the posterior coverage intervals around the posterior medians of the estimated variance contributions (Appendix Figure A5). Nonoverlapping posterior coverage intervals indicate "statistically significant" changes between the two periods. Our results indicate that the averages presented here are representative of patterns at the country level. 
Given that the combined model captures both the global and country-specific channels of spillovers and the degree of comovement is higher in the period 1998-2019, in the rest of this sub-section we focus our discussion on the results from the combined model over the second period - the table does report results for the full sample and the earlier period.

House Prices. In Panel B of Table 2, we present results using house prices as the financial market variable. This is of particular interest as developments in housing markets in the United States and certain other G-7 countries seem to have played a significant role in precipitating the 2009 global recession and amplifying the recession's macroeconomic effects. The crosscountry comovement of house prices, as captured by the share of fluctuations in this variable accounted for by the estimated global house price factor, is much smaller than that of equity prices. For the combined model, this share is only about 12 percent for the full sample and 20 percent for 1998-2019 (column marked F, last row of panel B).

Although it is smaller than that of the global equity price factor, the role of the global house price factor in driving macroeconomic fluctuations is significant and increases over time. The results from the combined model for the period 1998-2019 indicate that the global house price factor on average accounts for about 16 percent of output fluctuations, 11 percent of investment fluctuations, and 6 percent of consumption fluctuations (column marked SF). Similar to the results with equity prices, the spillover effects on to the macroeconomy operate mainly through the global macro factor rather than the country-specific factor-in the case of output, the corresponding variance contributions are 15 percent and 2 percent, respectively.

The global macro factor plays an increasingly more important role in explaining fluctuations in output and investment (Table 2 and Figure 5). Similar to the results with equity prices, although the role of the global macro factor has become more pronounced in the second period, the relative importance of spillovers from the global house price factor nearly doubles between the two periods (the absolute increase in the variance contribution of the global macro factor is greater). Over the period 1998-2019, the average variance of output explained by the global macro factor is about two to three times larger than that of spillovers from the global house price factor (40 percent versus 16 percent), compared to a ratio of roughly four over the full sample (33 percent versus 8 percent).

Interest Rates. Panel C of Table 2 shows the results when we use short-term interest rates as the financial market variable. During 1998-2019, the variance contributions of the global interest-rate factor through the spillover effects on the global macro factor amount to 7 percent for output, 4 percent for consumption, and 5 percent for investment fluctuations (see column marked SF, bottom row of the panel). As in the case of the equity and house prices, a substantial portion of these spillovers takes place through the global macro factor. The average variance explained by spillovers through the country-specific factors are in the range of only about 1-2 percent. Although the importance of the global macro factor increases by more than twofold in the second period (48 percent versus 21 percent), the change in the variance of output due to the spillovers from the global interest rate factor registers only a marginal increase. The average variance of interest rates due to the global interest rate factor rose from 25 percent in 1985-2007 to 31 percent in 1998-2019. The degree of comovement of interest rates across G-7 countries is much higher than that of house prices, although lower than that of equity prices, especially in the aftermath of the global financial crisis. Our headline results did not change when we used long-term interest rates (10-year bond yields) (These robustness exercises are discussed in more detail in Section 6). 
Evolution of Spillovers. Splitting the full sample into two overlapping periods has provided a coarse view of how the relative importance of different factors has shifted over time. To explore this dimension of the analysis further, we now briefly discuss results from the estimation of our combined Models 1 and 2 over 15 year rolling sub-periods with one year increments. In Figure 6 , we present the average variance of output explained by the global macro factor and spillovers stemming from the financial sector over the rolling sub-periods. The results indicate a sharp increase in the importance of the global macro factor especially after the 2007-08 global financial crisis. Specifically, the average variance due to the global macro factor (over the 15year rolling sub-periods) increases from about 20-30 percent from the early 2000s to roughly 35-55 percent after 2007, depending on which financial variable we use in estimating the model. ${ }^{19}$

While spillovers from the global equity and house price factors to output fluctuations have become larger after the global financial crisis, those associated with the global interest rate factor have not changed much. For example, prior to the 2007-08 crisis, spillovers from the global equity and house price factors on average account for 7 percent and 8 percent, respectively, of output variation over the 15 year rolling sub-periods. With the unfolding of the crisis, spillovers from these two factors on average account for 15-25 percent of output variance. These results are broadly consistent with our earlier findings from the two specific sub-samples (1985-2007 and 1998-2019). However, the results with the rolling windows also highlight significant changes in the nature of cross-border spillovers and the extent of comovement between the financial sector and the macroeconomy during periods of financial stress. There was naturally a steep increase in the importance of the global macro factor because of the global financial crisis. In addition, spillovers from some financial market segments onto the macroeconomy have become more pronounced after the onset of the crisis.

Summary. The main results to this point can be summarized as follows. First, among the G-7 countries, there are sizeable spillovers from the global equity and house price factors onto macroeconomic fluctuations. These spillovers are responsible for a larger share of variation of output and investment than of consumption. There are also some spillovers from the global interest rate factor but their contributions to macroeconomic fluctuations are relatively modest compared with those of equity and house prices.

Second, the global macro factor plays a more important role than the financial factor in explaining macroeconomic fluctuations but the relative importance of spillovers stemming from the financial sector is sizeable, especially in the case of equity and housing markets. ${ }^{20}$ Third, spillovers from the global equity and house price factors operate mainly through the global macro factor rather than through the country-specific macro factors.

Fourth, the importance of spillovers from the equity price and house price global factors has risen over time. Specifically, it increased by more than twofold in the case of equity prices and by more than threefold in the case of house prices in 1998-2019. The importance of spillovers from equity and housing markets has increased over time, especially after the global financial

\footnotetext{
${ }^{19}$ These findings are consistent with others in the literature that also report an increase in the extent of business cycle synchronization during periods of financial stress (Helbling et al., 2011; Imbs ,2010; and Kalemli-Ozcan, Papaioannou, and Peydro, 2013).

${ }^{20}$ This result is broadly in line with the findings with those in Huo, Levchenko, and Pandalai-Nayar (2019) and Di Giovanni, Levchenko, and Mejean (2018) in the sense that most of the business cycle synchronization among G-7 countries is accounted for by common or correlated shocks, and that the cross-border transmission of shocks has an economically meaningful, but smaller, role in comovement.
} 
crisis. Given the global nature of the crisis, there has also been a substantial increase in the importance of the global macro factor in explaining macroeconomic fluctuations after 2007. Finally, both equity prices and interest rates display a high degree of cross-country comovement among G-7 countries. The degree of cross-country comovement of equity prices and interest rates has intensified in the period 1998-2019 relative to 1985-2007. Comovement of house prices is modest, even during the latter period.

These results emphasize the importance of spillovers from the financial sector to the macroeconomy. ${ }^{21}$ We document that spillovers from cross-country comovements in global equity and housing markets play a substantial role in driving national business cycle fluctuations even after accounting for the roles played by the global and country-specific macro factors. These results lend support to the findings in theoretical studies linking developments in equity and housing markets to macroeconomic fluctuations. For example, some studies examine how fluctuations in equity prices can be associated with leverage cycles that can then translate into fluctuations in the real economy (Adrian, Colla, and Shin, 2013; Geanakoplos, 2010; Mendoza, 2010; Jermann and Quadrini, 2012). Other studies analyze how shocks originating in housing markets can be a source of macroeconomic fluctuations in the context of general equilibrium models (Iacoviello, 2005; Liu, Wang and Zha, 2015).

Our results indicate that spillovers from the global interest rate factor also contribute to macroeconomic fluctuations but their roles tend to be smaller than those of the global equity and house price factors. The small role of the interest rate factor in driving macroeconomic fluctuations in the period 1998-2019 may reflect the weak role of monetary policy in influencing economic activity once policy rates in the G-7 economies approached the zero lower bound.

\subsection{Country-Specific Spillovers}

In the discussion above, we have focused on averages for the G-7 countries. We now present results at the level of individual countries. The composite spillovers from financial variables to output growth fluctuations, operating through both the global factor and the country-specific factors (combination of Models 1 and 2), are shown for each country and macroeconomic variable in Tables 3-4. Table 3 shows the combined spillovers over different periods. For all financial variables, these spillovers are usually much higher - or at least as high - during the period 1998-2019 relative to estimates based on the period 1985-2007 or the full sample. Hence, to conserve space, we mainly emphasize the results for $1998-2019 .{ }^{22}$ Table 4 shows the breakdown of the variance contributions of different factors over the period 1998-2019.

Table 3 shows that there are significant spillovers from the global equity price factor to output in all G-7 countries. The average variance of output due to spillovers associated with the global equity price factor is about 17 percent, ranging from 10 percent in the United States to 24 percent in France. The spillover effects from the global house price factor are also quite large: it on average accounts for 16 percent of output fluctuations (ranging from 10-13 percent in

\footnotetext{
${ }^{21}$ The variance decompositions we discuss here are a product of the factor loadings and the variances of the factors. We present some of the key parameter estimates - the factor loadings and the vector-autoregressive coefficients on the factors - in Appendix Tables A2 and A3. In most cases, the loadings of the macroeconomic factors on the global macro factor are larger than the loadings on the country macro factors. The loadings of equity prices on the global financial factor are much greater than the loadings of other financial variables on their corresponding financial factors, confirming the evidence we presented earlier in the paper on the substantial comovement of equity prices among G-7 countries.

${ }^{22}$ We present a selection of the key results for output fluctuations over the period 1998-2019 in Appendix Figure A1 and detailed country-level results from the combined models in Appendix Table A4.
} 
Japan and the United States to 20-21 percent in France and Germany). The comparison of the contributions of spillovers from the global equity and house price factors with that of the global macro factor indicate that spillovers from the financial sector play a relatively important role in driving macroeconomic fluctuations in some countries. For example, in the United Kingdom, the share of variance due to spillovers from the global equity price or the global house price factor is around one-half of the variation that is explained by the global macro factor. The importance of spillovers from the global interest rate factor is on average relatively smaller than that of other financial variables but still sizeable in the three Euro zone countries (France, Germany, and Italy).

For the United States, the global equity and house price factors play significant roles in driving output, consumption, and investment fluctuations. The global interest rate factor plays a smaller role in driving macroeconomic cycles in the United States. The global macro factor accounts for 17 percent of the variance of U.S. output while the country factor accounts for about 39 percent. The results are roughly similar for U.S. investment fluctuations while the variance contribution of the global factor is much smaller for U.S. consumption fluctuations. The results are qualitatively similar independent of which financial indicator we use. In the case of output, the share of variance due to the spillovers from the global equity price factor is about two-thirds that of the global macro factor (10.4 percent versus 16.5 percent), confirming that financial market spillovers are important but less so than the global macro factor. In the case of the house price factor, this ratio is about one-half (10.6 percent versus 22.1 percent).

We turn next to a relatively smaller but more open economy, Canada, where one would a priori expect financial market spillovers to be larger than in the case of the United States. We indeed find larger spillover effects from the financial cycle in Canada, especially when we use equity prices as the financial indicator. The global equity price factor accounts for the following variance shares: 13 percent of output fluctuations, 11 percent of consumption fluctuations, and 19 percent of investment fluctuations. The variance contributions are similar for each of the macro variables when we use house prices as the financial indicator, and 5-7 percent in the case of the global interest rate factor. When we look at the breakdown of variance contributions, it appears that the global macro factor accounts for more of the fluctuations in all three Canadian macroeconomic aggregates than in the case of the United States.

We also find sizeable financial market spillovers for other G-7 countries. For instance, in the case of France, over the period 1998-2019, 24 percent of output fluctuations, 7 percent of consumption fluctuations, and 18 percent of investment fluctuations are accounted for by the spillovers from the global equity price factor. The corresponding numbers based on the house price variable are 21 percent, 5 percent, and 17 percent, respectively. For Japan and the United Kingdom, the contributions to the variance of output fluctuations from spillovers of the global equity and house prices are around 13-16 percent.

These country-level results largely confirm the major conclusions that we summarized at the end of the previous sub-section.

\section{Spillovers from the Macroeconomy to the Financial Sector}

\subsection{Global Spillovers}

We now explore a different channel for spillovers - from the global macro factor and the U.S. country-specific macro factor to the financial sector. That is, we seek to understand the role of 
macroeconomic cycles in driving fluctuations in G-7 countries' financial markets. And it is clearly of interest to examine if the U.S. business cycle affects global activity through its effects on world financial markets. As noted in Section 3, we estimate Models 3 and 4 to study spillovers from the macroeconomy to the financial sector. Model 3 captures spillovers from the global macro factor to the global financial factor while model 4 captures spillovers from the U.S. country-specific macro factor. In addition, we estimate a combination of these two models in which spillovers from the macroeconomy to financial markets are transmitted through both the global and U.S. country-specific macro factors. Table 5 presents the averages of variance decompositions based on these three models for each financial variable. ${ }^{23}$

Our main finding is that there is little evidence of spillovers from macroeconomic cycles to financial cycles. Spillovers from the macro factors to financial variables are smaller than those from the financial sector to the macroeconomy. Specifically, the spillovers from the macroeconomy account for just 1-2 percent of the variance of equity prices and house prices even if one takes into account spillovers from both the global and U.S. country-specific macro factors (the relevant results are under the column heading SR). By contrast, the spillovers from the global and U.S. country-specific macro factors to interest rates are greater, amounting to 5 percent of the variance contribution to fluctuations in interest rates during the period 19982019. Assuming that short-term interest rates are largely reflective of policy interest rates, this result implies that any commonality in the policy actions of G-7 central banks is influenced to a significant extent by common fluctuations in key macroeconomic variables in these countries. The contribution of the U.S. country-specific macro factor to the variance of fluctuations in interest rates is slightly larger than that of the global macro factor in the second sub-sample. This is consistent with the observation that the Great Recession that initially hit the U.S. rapidly induced monetary policy responses from other G-7 economies.

The relative roles of spillovers from the macroeconomy to the financial sector across the two models and over time are quite different than those of spillovers from the financial sector to the macroeconomy (Figure 7). For example, the comparison of results from Models 3 and 4 suggest that spillovers from either the global macro factor or the U.S. factor on to global financial factors are quite muted. Moreover, the variance of financial variables accounted for by spillovers from the macro factors does not change much over time except in the case of interest rates. In light of these observations, we again focus on the results from the combined model in the 1998-2019 period.

Comparing Tables 2 and 5 reveals the importance of separating out the spillover effects of financial factors from global business cycles that reflect macroeconomic phenomena. For the period 1998-2019, the variance contribution of the global macro factor to output fluctuations in each country is on average about 49 percent when we allow for spillovers from the macroeconomy to equity prices (Table 5, Panel A, last row, column heading W). When we allow for spillovers from equity prices to the global macro and country-specific factors, the variance contributions of the macro factors drop to an average of 34 percent (Table 2, Panel A, last row, column heading W). The difference is accounted for by the spillovers from the global financial factor on to the global and country-specific macro factors.

Returning to the results in Table 5, over the second sub-sample the global macro factor accounts for about 48-50 percent of output fluctuations, 13 percent of consumption fluctuations, and 31-33 percent of investment fluctuations (depending on which financial variable we use).

\footnotetext{
${ }^{23}$ Some of the results discussed below are summarized in Appendix Figure A1.
} 
The global financial factor, which essentially measures the extent of cross-country comovement of the relevant financial variable, on average accounts for about 58 percent of equity price fluctuations and 30 percent of interest rate fluctuations (see column marked F). All of these shares are higher when the model is estimated over the period 1998-2019 compared to the period 1985-2007. The global financial factor plays a less important role in explaining house price comovement.

We also examined the results from the estimation of our combined Models 3 and 4 over 15 year rolling sub-periods with one-year increments. ${ }^{24}$ Similar to the findings in the previous section, there is a significant increase over time in the importance of the global financial factor in explaining fluctuations in equity prices and interest rates (but not house prices), especially after the 2007-08 global financial crisis. Specifically, over the 15-year rolling sub-periods, the average variance of equity prices in G-7 countries due to the global financial factor increased from about 47 percent from the early 2000s to roughly 60 percent after 2007 in the case of equity prices.

Spillovers from the macroeconomy to house prices have become larger after the global financial crisis. Prior to the 2008-09 crisis, spillovers from the macro factors on average accounted for 1 percent of the variation in house prices over the 15 year rolling sub-periods. With the onset of the crisis, this share rose to 4 percent. Spillovers from the macro factors to interest rates have not changed much over time, explaining around 4-6 percent of total variation in interest rates. These results are broadly consistent with our findings from the two sub-samples (1985-2007 and 1998-2019) documented above. Spillovers from the macro factors on to global equity have not changed much over time.

The conclusion from this set of results is that the global and the U.S. macro factors have a relatively modest impact on global financial cycles. One exception is that of G-7 short-term interest rates, which seem to experience significant spillovers from the global and U.S. countryspecific macro factors. As we summarize in the next sub-section, there are also differences across countries in terms of the strength of macro spillovers since spillovers from the macroeconomy to the financial sector tend to be more pronounced in some countries. ${ }^{25}$

These results are generally supportive of some of the earlier findings in the literature. Some of these studies consider the predictive ability of macroeconomic variables for financial aggregates while others examine the explanatory power of the second moments of macro variables for the second moments of financial aggregates. In the context of interest rates, both theory and evidence point to the presence of an interest rate channel through which movements in policy rates have implications for macroeconomic outcomes (Woodford, 2003). Some empirical studies document that interest rates react to changes in macroeconomic variables (Gurkaynak and Wright, 2012; Koijen, Lustig, and Van Nieuwerburgh, 2017; Bauer and Hamilton, 2018). However, the existing literature presents a mixed verdict about the role of macroeconomic fluctuations in explaining cycles in asset prices, including equity prices. ${ }^{26}$ Some of these studies consider macro-financial interactions at lower frequencies (rather than the quarterly data we employ here) and examine the impact of surprise macroeconomic announcements (rather than the realized data as we do here).

\footnotetext{
${ }^{24}$ Appendix Figure A2 presents the average variance of each financial variable explained by the global financial factor and spillovers from the global and U.S. country macro factors over the rolling sub-periods.

${ }^{25}$ The posterior coverage intervals around the posterior medians of the estimated variance contributions are provided in the Appendix Table A6.

${ }^{26}$ On the importance of macroeconomic variables for financial markets, see Stock and Watson (2003), Christiansen, Schmeling, and Schrimpf (2012), Diebold and Yilmaz (2010, 2015), and Engle, Ghysels, and Sohn (2013).
} 


\subsection{Country-Specific Spillovers}

Next, we briefly examine country-level results on the importance of spillovers from macroeconomic aggregates to financial variables. The composite spillovers to financial variables from macroeconomic fluctuations, operating through both the global and U.S. country-specific macro factors (combination of Models 3 and 4), are shown for each country and each macroeconomic variable in Tables 6 and 7 (Appendix Figure A3 highlights key results). We again focus on the results for 1998-2019.

Table 6 shows that the spillovers from the global and U.S. country-specific macro factors to financial variables are smaller than those from the financial sector to the macroeconomy across countries. The largest spillover effects of macroeconomic cycles are on interest rates, with the spillovers being largest in the cases of France, Canada, and the United States.

Among the financial variables that we consider, global comovement is clearly most pronounced for equity prices. The contribution of the estimated global factor for equity prices accounts for at least one-third of the fluctuations in domestic equity prices for all countries. The global comovement in interest rates is also pronounced, with the global factor accounting for more than half of the total variance in interest rates in the United States and Canada, and around one-quarter in France and Germany. For house prices, the contribution of the global financial factor is typically smaller. These results are consistent with those in section 2.2 (those results were based on single or multiple factor models estimated on financial variables alone) and the literature discussed in that section.

The importance of spillovers from the global and U.S. country-specific macro factors to the global interest rate factor rises over time (Table 7). The average variance of short-term interest rates ascribed to spillovers from the macro factors increases moderately from 4 percent in 19852007 to 5 percent in 1998-2019. For three countries - France, Germany, and Italy - the share of the variance in interest rates due to macro spillovers registers a substantial increase. For house prices, the share of spillovers from macro factors increases substantially in Canada, France, Italy, and the United Kingdom. The spillovers from macro factors onto equity prices are quite muted for all countries, even in the second sub-sample (although in most cases the variance contributions do increase marginally relative to those for the first sub-sample).

\section{Robustness Tests: Alternative Specifications and Variables}

In this section, we report results from a broad array of extensions to the baseline specifications as well as additional robustness exercises that incorporate different variables.

\subsection{Alternative Specifications and Factors}

We first consider alternative specifications that allow for other combinations of factors. The aim is to address potential concerns about whether the factors we have estimated could be capturing other driving forces that do not enter into our baseline model.

We estimate a standard dynamic factor model for the three macroeconomic variables that, in addition to a global factor, allows for variable-specific macroeconomic factors instead of country-specific factors. Over the full sample, the global factor on average accounts for onethird of the variation in output in G-7 countries while the variable-specific factor accounts for nine percent (see Appendix Table A8). The global factor accounts for a substantially greater 
share of output variation than the variable-specific factor in all countries except Canada. The same pattern holds for investment fluctuations, except in the case of the United States (where the contribution of the variable-specific factor is greater), and for consumption fluctuations. The relative importance of the global factor rises and that of the variable-specific factors falls when we estimate the model over the period 1998-2019 relative to 1985-2007. In short, estimating the model using this combination of factors confirms the importance of the global factor and suggests that leaving out the variable-specific factors is unlikely to have influenced our main results.

Next, we check if there is a global factor that is important for fluctuations in all three macroeconomic variables and, in turn, each of the three financial variables (the results are in Appendix Table A9). That is, we now allow for a common factor across four variables - the three macro variables and the relevant financial variable. We find that there is no common factor that significantly explains fluctuations in the macroeconomic variables and equity prices. The common factor in this model explains about half of the total variance in equity prices but, on average, less than 8 percent of the variance in any of the macro variables. When other financial variables are included in the model, the common factor accounts for a sizable fraction of the variance in the macroeconomic variables but less than 11 percent and 3 percent, respectively, of the variance in house prices and interest rates. These results confirm the validity of our modeling assumption that there is no single common factor that drives both the macro and financial variables.

Finally, we estimate a standard factor model that includes all three financial variables and allows for global and country-specific financial factors. In other words, we also allow for country-specific financial cycles that encompass equity prices, house prices, and interest rates. The results (see Appendix Table A10) indicate that the global financial factor is significant only for equity prices, which is consistent with the baseline results shown in Section 2. Countryspecific financial factors on average explain only a small fraction of the variance in equity prices and interest rates, although they do seem to matter more for house prices. Overall, the results validate our modeling choice of including one financial variable in the baseline model at a time, rather than incorporating all three financial variables and additional factors (which would, moreover, complicate interpretation of the results).

\subsection{Implied Contemporaneous Correlation Between Macroeconomic and Financial Variables}

A simple way to check the validity of our factor model specification is to compare the contemporaneous actual correlations between macro and financial variables in our dataset with the implied correlations of the corresponding pairs of variables based on our dynamic factor models. ${ }^{27}$ In the data, the average correlation (G-7 average) of macro variables with equity and house prices is 0.15 and 0.18 , respectively, over the period 1985-2019. Interest rates are not correlated with macroeconomic variables (average correlation coefficient: 0.04). The implied contemporaneous correlations from our estimated models are quite close to the actual correlations in the case of equity prices (0.11) and interest rates (0.02). The implied correlation between macro variables and house prices (0.04) is lower than the actual correlation, which may partly reflect our results on the weaker role of the global factor for G-7 house prices

\footnotetext{
${ }^{27}$ Due to the lack of common shocks between macro and financial variables and the orthogonality of the idiosyncratic terms, the implied correlation between any pair of macro and financial variables is given by: $\beta^{M} \beta^{F} \operatorname{corr}\left(F^{R}, F^{F}\right)$, where $\beta^{M}$ and $\beta^{F}$ are factor loadings of the macro and financial variable, respectively, and $\operatorname{corr}\left(F^{R}, F^{F}\right)$ is $\operatorname{the}$ correlation coefficient between the estimated global macro and financial factors.
} 
compared to other financial variables. Overall, the dynamic factor estimation results capture the correlations between macro and financial variables well.

\subsection{Credit Growth as an Alternative Financial Variable}

We have focused on three key financial variables that represent major financial markets with potential macro implications. In this sub-section, we consider an additional quantity variable that is relevant for macro outcomes - growth in real credit to the nonfinancial sector. Detailed results, which we only briefly summarize here, are in Appendix Figure A4 and Appendix Table A11.

Consistent with other financial factors as well as macroeconomic factors, the global credit factor tracks global recessions and subsequent recoveries. The magnitude of spillovers originating from the global credit factor is, however, smaller than that of other financial variables: the global credit factor (models 1 and 2 combined) on average accounts for only 4-6 percent of the variance of output, consumption, and investment in G-7 economies during 1998-2019. We find negligible spillovers from the global macroeconomic factor and U.S. macro factor (models 3 and 4 ) to the global credit factor. The average variance of credit accounted for by spillovers from these two macro factors is less than 1 percent.

Our findings are broadly consistent with those in Helbling et al. (2011), who document that shocks originating in credit markets appear to play a smaller role during "normal" business cycles and a larger one during periods of financial stress. Other studies argue for a more prominent role for credit shocks in explaining the global dimension of the Great Recession (Perri and Quadrini, 2018) and in accounting for macro fluctuations at the country level (e.g., Gilchrist and Zakrajsek, 2012). ${ }^{28}$

\subsection{Long-term versus Short-term Interest Rates}

Next, we replace the short-term interest rates used in our baseline models (yields on 3-month government paper), which can be regarded as a close to approximation to policy rates, with long-term interest rates (ten-year government bond yields). Variance decomposition results for spillovers between macro factors and the long-term interest rate factor are reported in Table A12. The results are in general similar to those using short-term interest rates (see panel $\mathrm{C}$ in Tables 2 and 5). However, there are some noteworthy differences. First, the spillovers from the global long-term interest rate factor to macro variables (combination of models 1 and 2) are slightly greater (about 2-3 percentage points more) than was the case with short-term interest rates. Second, the spillovers from macro factors to long-term interest rates are also greater than was the case for short-term rates. Third, comovement among G-7 long-term interest rates, as measured by the average variance contributions of the common interest rate factor to interest rate fluctuations in each country, is higher than for short-term government bond yields. One interpretation of these findings is that global macro fluctuations are associated not only with cross-country comovement of short-term interest rates (via coordinated monetary policies) but also comovement of inflation expectations and risk premia, which are additional determinants of long-term bond yields. We leave a more careful examination of this issue for future work.

\footnotetext{
${ }^{28}$ Some authors contend that indicators of credit standards applied by lenders and credit spreads are better indicators than credit growth to assess the strength of linkages between credit markets and the macroeconomy (Lown and Morgan, 2006; Meeks, 2012; Gilchrist and Zakrajsek, 2012; Faust et al., 2013).
} 


\subsection{Alternative House Price Series}

Obtaining consistent cross-country data on house prices is a challenge. We use data from Haver Analytics for our benchmark results. In this sub-section, we examine whether the results would be affected if we use BIS real house price indexes instead. The results (see Appendix Table A13) were quite similar even in terms of magnitudes. For instance, the spillover effects of the house price factor on average account for 17 percent of the variance of output during 1998-2019 (16 percent in the baseline, Panel B of Table 2). The spillover effects from macro factors to house prices remain small and the average share of the global house price factor in accounting for the variance of house prices in each country is similar for both house price variables.

\subsection{Does the United States Drive the Main Results?}

The U.S. remains the dominant economy in the world, especially in terms of international finance. To test whether our results, including the estimates of various global factors, could simply be proxying for the influence of the U.S, we now re-estimate models 1 and 3 excluding the U.S. from the dataset. ${ }^{29}$ Comparing the results regarding spillovers in Table A14 to the corresponding ones in Tables 2 and 5, most of the main results (in terms of average variance contributions) look similar. One exception is that the spillover effects from the global house price factor and the global interest rate factor to macroeconomic variables are much smaller when the U.S. is left out. Moreover, the degree of co-movement among equity prices and house prices decreases substantially when the U.S. is excluded. Clearly, the U.S. is an important driver of global cycles in those two financial markets, but the nature of financial-macroeconomic spillovers that are our main focus is not just an artifact of U.S. economic dominance.

\subsection{Alternative Sub-samples}

The two overlapping sub-samples we have used so far represent the pre-global financial crisis (1985-2007) and post-Asian crisis (1998-2019) periods. We now check the sensitivity of the subsample results when we split the sample into two nonoverlapping periods of roughly equal length: 1985-2000 and 2001-2019. The detailed results from this exercise are reported in Appendix Table A15. The variance shares (for all three macro variables) of the global macroeconomic factor and spillovers from the equity and house price factors double between the two periods, while the shares of the country-specific macro factors are halved. These results, which indicate rising comovement and increasing spillovers over time, are consistent with those reported in Section 3 based on the original sub-samples and also those based on the 15-year rolling windows (Figures 5 and 6). Variance decompositions based on the combined models 3 and 4, which capture macro to financial spillovers, estimated over the two new sub-samples are again consistent with those based on the baseline sub-samples and the rolling-window estimations. For instance, the spillover effects from macro to financial variables are sizeable only in the case of interest rates.

\footnotetext{
${ }^{29}$ We have already quantified the direct impact of the U.S. on global macro-financial linkages via models 2 and 4 . Model 2 quantifies the spillover effects from financial variables to the U.S. country factor. Model 4 quantifies the spillovers effects from the U.S. country factor onto each financial variable. The latter results show that the U.S. has a sizeable impact on the dynamics in G7 short-term interest rates. The remaining question then is the sensitivity of estimates of the global macroeconomic and financial factors, and their spillover effects, to the exclusion of U.S. data.
} 


\subsection{Higher-Frequency (Monthly) Data}

An important issue is whether our use of quarterly data drives the key results, for instance by conflating common shocks and spillovers. If shocks are transmitted rapidly from financial to real variables and vice versa, our estimates would underestimate actual spillovers. As discussed earlier, while asset prices move quickly in response to news and other shocks, macro variables tend to be more sluggish in general and the economy-wide aggregates we study are available only at a quarterly frequency and are reported with a lag. Nevertheless, in order to investigate this issue further, we use monthly industrial production as an indicator of macroeconomic cycles. In this part of the analysis, we focus on the period 1998-2019 and, since we use just one macroeconomic variable, only models 1 and 3 are applicable in analyzing spillovers. ${ }^{30}$

Appendix Table A16 (Panel A) presents variance decompositions from a single factor model applied to each of the financial variables. The global financial factor accounts for a large fraction of the variance of equity prices but this is not the case for the other two financial variables. In Panel B of Table A16, we present results from models that include industrial production and each of the financial variables in turn, allowing for one common global factor. The global factor has a significant explanatory role only for the variance of equity prices and there is little evidence of strong comovement between industrial production and any of the financial variables. These results are broadly consistent with our benchmark results based on quarterly data.

When we allow for spillovers from financial variables to the macroeconomy (Model 1), we find significant spillovers only from equity prices (Appendix Table A17). ${ }^{31}$ Moreover, the shares of variance in industrial production accounted for by the global macro factor are much larger than the shares accounted for by spillover effects. Appendix Table A18 shows that the spillover effects from industrial production to the financial variables (Model 3) are small. Reflecting the cross-country comovement of financial variables that we found even in the quarterly data, the global financial factor accounts for a substantial fraction of the variance of each of the financial variables. The degree of comovement of financial variables is higher in the monthly data than in the quarterly data. Other than that, our main results on the relative importance of different spillovers are preserved when we use monthly data. ${ }^{32}$

\section{Conclusions}

Our objective in this paper was to provide a joint empirical characterization of macroeconomic and financial cycles, and the linkages between these cycles. We developed a new dynamic factor model that allows us to study business cycle comovement, evaluate the magnitude of financial market spillovers onto real macroeconomic aggregates (and vice versa), and differentiate between global shocks and spillovers. We applied the model to quarterly macroeconomic and financial market data for the G-7 economies over the period 1985-2019.

\footnotetext{
${ }^{30}$ Monthly data on house prices was available for only four of the G-7 countries: Canada, Japan, U.K., and U.S. We use monthly growth rates of all variables except interest rates, for which we use the change in levels. As in the previous exercises, the Stock and Watson (2012) local mean approach is used to eliminate long-term trends in the data.

31 The global house price factor exhibits smaller spillover effects onto the macroeconomic factor than in the benchmark results. However, since the monthly global house price factor is extracted from data for only four countries, this direct comparison might not be appropriate.

${ }^{32}$ In the benchmark results, one interesting finding was a sizable spillover effect from the U.S. country factor to interest rates. Replicating that result is not feasible here since we do not have country-specific macro factors based on multiple macro variables.
} 
The major novelty of our factor model is that, unlike existing models, it enables us to distinguish between common shocks and spillovers from one sector to another. For instance, we are able to capture the extent to which spillovers from financial markets affect global business cycles. This provides an economically valuable decomposition of why there is comovement of some key macroeconomic and financial variables across the world. The model is general enough that we can also model spillovers from one country to others. This adds a second layer to our understanding of the nature of comovement. The model allows us to analyze if it is the transmission of country-specific shocks or the prevalence of common shocks that drives global business cycle comovement.

Our main findings are as follows. Over the period 1985-2019, there is evidence of common business cycles, as reflected in the comovement of macroeconomic aggregates, among the G-7 economies. There are also common cycles in certain financial variables, especially equity prices and interest rates.

Our analysis documents that the global macro factor plays an important role in explaining fluctuations in macroeconomic variables but there are also quantitatively significant spillovers from shocks to specific financial variables - equity prices and house prices, in particular - on to macroeconomic variables. Interest rates (and credit) do matter as well but they are quantitatively less important as sources of such spillover effects. Common cycles among real and financial variables, respectively, and also the spillovers from financial to real variables are stronger in the period leading up to and following the financial crisis.

While the global financial crisis is a special case, a broader understanding of the nature and sources of comovement of business and financial cycles and the propagation mechanisms for global, country or variable-specific shocks is important for designing effective stabilization policies at the national level and for coordination of policies at the global level. It is also an essential step to guide the development of theoretical models that could help explain changes in global business and financial cycles and transmission mechanisms between them. A better understanding of global macro-financial cycles and spillovers is an important building block for the design of dynamic models that can replicate the changing nature of these linkages. Such models could be helpful in analyzing alternative policy responses to different shocks.

There are a number of directions in which this work could be extended. The first would be to integrate a broader group of countries, including emerging markets, into the analysis to examine the shifting dynamics of macro-financial cycles across advanced and emerging market economies. Second, it would be useful to investigate how business cycle dynamics play out at the sectoral level and, in turn, how aggregate business and financial cycles are affected by sectoral dynamics. Third, in light of our findings, it would be beneficial to explore the two-way spillovers between domestic and global macro-financial cycles in the context of specific asset prices. Finally, it would be worth considering how policy responses, including monetary, fiscal, and financial sector policies, shape the transmission channels and feedback effects between different groups of countries. This may require a different class of models, however. 


\section{References}

Adrian, Tobias, Paolo Colla, and Hyun Song Shin, 2013, "Which Financial Frictions? Parsing the Evidence from the Financial Crisis of 2007 to 2009," NBER Macroeconomics Annual 2012, Vol. 27, eds. Jonathan A. Parker and Michael Woodford, pp. 159-214, Chicago: University of Chicago Press.

Avdjiev, Stefan, Leonardo Gambacorta, Linda S. Goldberg, and Stefano Schiaffi, 2017, "The Shifting Drivers of Global Liquidity, " NBER Working Papers No. 23565, National Bureau of Economic Research, Cambridge.

Backus, David K., Patrick J. Kehoe, and Finn E. Kydland, 1992, "International Real Business Cycles," Journal of Political Economy, Vol. 100:4, pp. 745-775.

Bauer, Michael D., and James D. Hamilton, 2018, "Robust Bond Risk Premia," Review of Financial Studies, Vol. 31:2, pp. 399-488..

Bernanke, Ben S., Mark Gertler, and Simon Gilchrist, 1999, "The Financial Accelerator in a Quantitative Business Cycle Framework," in Handbook of Macroeconomics, Vol. 1, eds. John B. Taylor and Michael Woodford, pp. 1341-1393, Amsterdam: North-Holland.

Borio, Claudio, 2014, "The Financial Cycle and Macroeconomics: What Have We Learnt?" Journal of Banking \& Finance, Vol. 45, pp. 182-198.

Breitung, Jörg, and Sandra Eickmeier, 2016, "Analyzing International Business and Financial Cycles Using Multi-Level Factor Models: A Comparison of Alternative Approaches," in Dynamic Factor Models, Advances in Econometrics, Vol. 35, eds. Eric Hillebrand and Siem Jan Koopman, pp. 177-214, Bradford: Emerald Group Publishing.

Brunnermeier, Markus K., Thomas Eisenbach, and Yuliy Sannikov, 2013, "Macroeconomics with Financial Frictions: A Survey," in Advances in Economics and Econometrics, Tenth World Congress of the Econometric Society, Volume II, D. Acemoglu, M. Arellano and E. Dekel (eds), pp. 4-94. New York: Cambridge University Press.

Buch, Claudia M., Matthieu Bussiere, Linda S. Goldberg, and Robert Hills, 2019. "The International Transmission of Monetary Policy, " Journal of International Money and Finance, Vol. 91, pp. 29-48.

Carlstrom, Charles T., and Timothy S. Fuerst, 1997, "Agency Costs, Net Worth, and Business Fluctuations: A Computable General Equilibrium Analysis," American Economic Review, Vol. 87:5, pp. 893-910.

Cerutti, Eugenio, Stijn Claessens, and Andrew K. Rose, 2017, "How Important is the Global Financial Cycle? Evidence from Capital Flows," IMF Working Paper No. 17/193, International Monetary Fund, Washington, DC.

Cesa-Bianchi, Ambrogio, 2013, "Housing Cycles and Macroeconomic Fluctuations: A Global Perspective," Journal of International Money and Finance, Vol. 37, pp. 215-238. 
Cesa-Bianchi, Ambrogio, Luis Felipe Cespedes, and Alessandro Rebucci, 2015, "Global Liquidity, House Prices, and the Macroeconomy: Evidence from Advanced and Emerging Economies," Journal of Money, Credit and Banking, Vol. 47:S1, pp. 301-335.

Christiansen, Charlotte, Maik Schmeling, and Andreas Schrimpf, 2012, "A Comprehensive Look at Financial Volatility Prediction by Economic Variables," Journal of Applied Economics, Vol. 27:6, pp. 956-977.

Ciccarelli, Matteo, Eva Ortega, and Maria T. Valderrama, 2016, "Commonalities and CrossCountry Spillovers in Macroeconomic-Financial Linkages." B.E. Journal of Macroeconomics, Vol. 16:1, pp. 231-275.

Claessens, Stijn, and M. Ayhan Kose, 2018, "Frontiers of Macrofinancial Linkages" BIS Papers No. 95, Bank for International Settlement, Basel, Switzerland.

Claessens, Stijn, M. Ayhan Kose, Luc Laeven, and Fabián Valencia, 2014, Financial Crises: Causes, Consequences, and Policy Reponses, Washington, DC: International Monetary Fund.

Claessens, Stijn, M. Ayhan Kose, and Marco E. Terrones, 2009, "What Happens During Recessions, Crunches and Busts?" Economic Policy, Vol. 24:60, pp. 653-700.

— 2011, "Financial Cycles: What? How? When?" NBER International Seminar on Macroeconomics 2010, eds. Richard Clarida and Francesco Giavazzi, pp. 303-343, Chicago: University of Chicago Press.

— 2012, "How Do Business and Financial Cycles Interact?" Journal of International Economics, Vol. 87:1, pp. 178-190.

Cochrane, John H., 2017, "Macro-Finance," Review of Finance, Vol. 21:3, pp. 945-985.

Dedola, Luca, and Giovanni Lombardo, 2012, "Financial Frictions, Financial Integration and the International Propagation of Shocks," Economic Policy, Vol. 27:70, pp. 319-359.

Devereux, Michael B., and Alan Sutherland, 2011, "Evaluating International Financial Integration under Leverage Constraints," European Economic Review, Vol. 55:3, pp. 427-442.

Diebold, Francis X., and Kamil Yilmaz, 2010, "Macroeconomic Volatility and Stock Market Volatility, Worldwide," in Volatility and Time Series Econometrics: Essays in Honor of Robert F. Engle, eds. Tim Bollerslev, Jeffrey R. Russell, and Mark W. Watson, pp. 97-116, Oxford: Oxford University Press.

Diebold, F. X., and K. Yilmaz, 2015, Financial and Macroeconomic Connectedness: A Network Approach to Measurement and Monitoring. New York: Oxford University Press.

di Giovanni, Julian, Andrei A. Levchenko, and Isabelle Mejean, 2018, "The Micro Origins of International Business Cycle Comovement," American Economic Review, Vol. 108:1, pp. 82108.

Eickmeier, Sandra, and Tim Ng, 2015, "How Do US Credit Supply Shocks Propagate Internationally? A GVAR Approach," European Economic Review, Vol. 74, pp. 128-145. 
Engle, Robert F., Eric Ghysels, and Bumjean Sohn, 2013, "Stock Market Volatility and Macroeconomic Fundamentals," Review of Economics and Statistics, Vol. 95:3, pp. 776-797.

Faust, Jon, Simon Gilchrisst, Jonathan H. Wright, and Egon Zakrajšek, 2013, "Credit Spreads as Predictors of Real-Time Economic Activity: A Bayesian Model-Averaging Approach," Review of Economics and Statistics, Vol. 95:5, pp. 1501-1519.

Forbes, Kristin, 2013, "The 'Big C': Identifying Contagion," The Changing Policy Landscape, Jackson Hole Symposium, Federal Reserve Bank of Kansas City, pp. 23-87.

Geanakoplos, John, 2010, "The Leverage Cycle," in NBER Macroeconomics Annual 2009, Vol. 24, eds. Daron Acemoglu, Kenneth Rogoff, and Michael Woodford, pp. 1-65, Chicago: University of Chicago Press.

Gilchrist, Simon, and Egon Zakrajšek, 2012, "Credit Spreads and Business Cycle Fluctuations," American Economic Review, Vol. 102:4, pp. 1692-1720.

Gürkaynak, Refet S., and Jonathan H. Wright, 2012, "Macroeconomics and the Term Structure," Journal of Economic Literature, Vol. 50:2, pp. 331-367.

Helbling, Thomas, Raju Huidrom, M. Ayhan Kose, and Christopher Otrok, 2011, "Do Credit Shocks Matter? A Global Perspective," European Economic Review, Vol. 55:3, pp. 340-353.

Hirata, Hideaki, M. Ayhan Kose, Christopher Otrok, and Marco E. Terrones, 2012, "Global House Price Fluctuations: Synchronization and Determinants," NBER International Seminar on Macroeconomics 2012, eds. Francesco Giavazzi and Kenneth D. West, pp. 119-166, Chicago: University of Chicago Press.

Huo, Zhen, Andrei A. Levchenko, and Nitya Pandalai-Nayar, 2019, "The Global Business Cycle: Measurement and Transmission," NBER Working Paper No. 25978.

Iacoviello, Matteo, 2005, "House Prices, Borrowing Constraints, and Monetary Policy in the Business Cycle," American Economic Review, Vol. 95:3, pp. 739-764.

Imbs, Jean, 2010, "The First Global Recession in Decades," IMF Economic Review, Vol. 58:2, pp. 327-354.

Jackson, Laura E., M. Ayhan Kose, Christopher Otrok, and Michael T. Owyang, 2016, "Specification and Estimation of Bayesian Dynamic Factor Models: A draw Carlo Analysis," in Dynamic Factor Models, Advances in Econometrics, Vol. 35, eds. Eric Hillebrand and Siem Jan Koopman, pp. 361-400, Bradford: Emerald Group Publishing.

Jermann, Urban, and Vincenzo Quadrini, 2012, "Macroeconomic Effects of Financial Shocks," American Economic Review, Vol. 102:1, pp. 238-271.

Jordà, Òscar, Moritz Schularick, and Alan M. Taylor, 2017, "Macrofinancial History and the New Business Cycle Facts," in NBER Macroeconomics Annual 2016, Vol. 31, eds. Martin Eichenbaum and Jonathan A. Parker, pp. 213-263, Chicago: University of Chicago Press. 
Kalemli-Ozcan, Sebnem, Elias Papaioannou, and José-Luis Peydró, 2013, "Financial Regulation, Financial Globalization, and the Synchronization of Economic Activity," Journal of Finance, Vol. 68:3, pp. 1179-1228.

Koijen, Ralph S.J., Hanno Lustig, and Stijin Van Nieuwerburgh, 2017. "The Cross-section and Time Series of Stock and Bond Returns," Journal of Monetary Economics, Vol. 88:C, pp. 5069.

Kim, Chang-Jin, and Charles R. Nelson, 1998, "Business Cycle Turning Points, A New Coincident Index, and Tests of Duration Dependence Based on a Dynamic Factor Model with Regime Switching," Review of Economics and Statistics, Vol. 80:2, pp. 188-201.

Kiyotaki, Nobuhiro, and John Moore, 1997, "Credit Cycles," Journal of Political Economy, Vol. 105:2, pp. 211-248.

Kollmann, Robert, 2013, "Global Banks, Financial Shocks, and International Business Cycles: Evidence from an Estimated Model," Journal of Money, Credit and Banking, Vol. 45:S2, pp. 159-195.

Kose, M. Ayhan, Christopher Otrok, and Eswar S. Prasad, 2012, "Global Business Cycles: Convergence or Decoupling?" International Economic Review, Vol. 53:2, pp. 511-538.

Kose, M. Ayhan, Christopher Otrok, and Charles Whiteman, 2003, "International Business Cycles: World, Region, and Country Specific Factors," American Economic Review, Vol. 93:4, pp. 1216-1239.

—, 2008, "Understanding the Evolution of World Business Cycles," Journal of International Economics, Vol. 75:1, pp. 110-130.

Kose, M. Ayhan, and Marco E. Terrones, 2015, Collapse and Revival: Understanding Global Recessions and Recoveries, Washington, DC: International Monetary Fund.

Liu, Zheng, Pengfei Wang, and Tao Zha, 2013, "Land-Price Dynamics and Macroeconomic Fluctuations," Econometrica, Vol. 81:3, pp. 1147-1184.

Lown, Cara, and Donald P. Morgan, 2006, "The Credit Cycle and the Business Cycle: New Findings Using the Loan Officer Opinion Survey," Journal of Money, Credit and Banking, Vol. 38:6, pp. 1575-1597.

Meeks, Roland, 2012, "Do Credit Market Shocks Drive Output Fluctuations? Evidence from Corporate Spreads and Defaults," Journal of Economic Dynamics \& Control, Vol. 36:4, pp. 568-584.

Mendoza, Enrique G., 2010, "Sudden Stops, Financial Crises, and Leverage," American Economic Review, Vol. 100:5, pp. 1941-1966.

Mian, Atif, Amir Sufi, and Francesco Trebbi, 2015, "Foreclosures, House Prices, and the Real Economy," Journal of Finance, Vol. 70:6, 2587-2634. 
Miranda-Agrippino, Silvia, and Hélène Rey, 2015, "World Asset Markets and the Global Financial Cycle," NBER Working Paper No. 21722, National Bureau of Economic Research, Cambridge.

Perri, Fabrizio, and Vincenzo Quadrini, 2018, "International Recessions," American Economic Review, Vol. 108:4-5, pp. 935-984.

Prieto, Esteban, Sandra Eickmeier, and Massimiliano Marcellino, 2016, "Time Variation in Macro-Financial Linkages," Journal of Applied Econometrics, Vol. 31:1, pp. 1215-1233.

Quadrini, Vincenzo, 2014, "Macroeconomic Effects of Asset-Price Shocks in a Globalized Financial Market," Scandinavian Journal of Economics, Vol. 116:1, pp. 190-217.

Reinhart, Carmen M., and Kenneth S. Rogoff, 2009, This Time IS Different: Eight Centuries of Financial Folly, Princeton: Princeton University Press.

Rey, Hélène, 2015, "Dilemma not Trilemma: The Global Financial Cycle and Monetary Policy Independence," NBER Working Paper No. 21162, National Bureau of Economic Research, Cambridge.

Stock, James H., and Mark W. Watson, 2003, "Forecasting Output and Inflation: The Role of Asset Prices," Journal of Economic Literature, Vol. 41:3, pp. 788-829.

- 2005, "Understanding Changes in International Business Cycles," Journal of the European Economic Association, Vol. 3:5, pp. 968-1006.

— 2011, "Dynamic Factor Models," in The Oxford Handbook of Economic Forecasting, eds. Michael P. Clements and David F. Hendry, Oxford: Oxford University Press.

— 2012, "Disentangling the Channels of the 2007-09 Recession," Brookings Papers on Economic Activity, Spring, pp. 81-156.

—, 2016, "Dynamic Factor Models, Factor-Augmented Vector Autoregressions, and Structural Vector Autoregressions in Macroeconomics," in Handbook of Macroeconomics, Vol. 2, eds. John B. Taylor and Harald Uhlig, pp. 415-525, Amsterdam: Elsevier.

Woodford, Michael, 2003, Interest and Prices: Foundations of a Theory of Monetary Policy, Princeton: Princeton University Press. 
Table 1. Variance Decompositions

(Models with Only Financial Variables; 1998-2019)

\section{A. Equity Prices}

\begin{tabular}{|c|c|c|c|c|c|c|c|c|c|}
\hline & \multicolumn{2}{|c|}{ One Factor Model } & \multicolumn{3}{|c|}{ Two Factor Model } & \multicolumn{4}{|c|}{ Three Factor Model } \\
\hline & Global & Idiosyncratic & Global & Variable & Idiosyncratic & Global & Variable & Country & Idiosyncratic \\
\hline Canada & 64.4 & 35.6 & 1.9 & 67.3 & 30.8 & 0.7 & 67.8 & 0.2 & 30.7 \\
\hline France & 63.1 & 36.9 & 20.9 & 68.8 & 10.4 & 35.9 & 55.7 & 0.2 & 7.0 \\
\hline Germany & 64.7 & 35.3 & 14.5 & 67.1 & 18.4 & 25.9 & 55.4 & 0.8 & 16.2 \\
\hline Italy & 45.4 & 54.6 & 19.4 & 53.1 & 27.4 & 33.7 & 41.7 & 0.3 & 24.8 \\
\hline Japan & 45.8 & 54.2 & 5.3 & 46.6 & 48.1 & 2.6 & 49.5 & 32.6 & 14.7 \\
\hline United Kingdom & 78.7 & 21.3 & 1.5 & 79.0 & 19.5 & 0.7 & 79.4 & 0.8 & 18.1 \\
\hline United States & 74.3 & 25.7 & 3.0 & 79.6 & 17.4 & 0.7 & 81.8 & 2.0 & 14.5 \\
\hline Average & 62.3 & 37.7 & 9.5 & 65.9 & 24.6 & 14.3 & 61.6 & 5.3 & 18.0 \\
\hline
\end{tabular}

\section{B. House Prices}

\begin{tabular}{|c|c|c|c|c|c|c|c|c|c|}
\hline & \multicolumn{2}{|c|}{ One Factor Model } & \multicolumn{3}{|c|}{ Two Factor Model } & \multicolumn{4}{|c|}{ Three Factor Model } \\
\hline & Global & Idiosyncratic & Global & Variable & Idiosyncratic & Global & Variable & Country & Idiosyncratic \\
\hline Canada & 8.7 & 91.3 & 1.1 & 8.2 & 90.7 & 0.5 & 28.6 & 44.3 & 26.2 \\
\hline France & 6.9 & 93.1 & 0.7 & 16.8 & 82.5 & 0.2 & 14.3 & 2.9 & 82.5 \\
\hline Germany & 0.0 & 100.0 & 1.5 & 0.7 & 97.8 & 0.8 & 0.6 & 8.0 & 90.3 \\
\hline Italy & 8.2 & 91.8 & 0.9 & 5.6 & 93.5 & 0.1 & 29.0 & 0.4 & 70.0 \\
\hline Japan & 0.0 & 100.0 & 0.1 & 11.3 & 88.6 & 0.1 & 0.3 & 7.7 & 91.7 \\
\hline United Kingdom & 6.7 & 93.3 & 1.6 & 76.2 & 22.1 & 0.6 & 82.1 & 1.6 & 14.9 \\
\hline United States & 0.6 & 99.4 & 2.1 & 15.0 & 82.8 & 0.2 & 0.4 & 29.3 & 69.6 \\
\hline Average & 4.4 & 95.6 & 1.2 & 19.1 & 79.7 & 0.4 & 22.2 & 13.4 & 63.6 \\
\hline
\end{tabular}




\section{Interest Rates}

\begin{tabular}{|c|c|c|c|c|c|c|c|c|c|}
\hline & \multicolumn{2}{|c|}{ One Factor Model } & \multicolumn{3}{|c|}{ Two Factor Model } & \multicolumn{4}{|c|}{ Three Factor Model } \\
\hline & Global & Idiosyncratic & Global & Variable & Idiosyncratic & Global & Variable & Country & Idiosyncratic \\
\hline Canada & 1.3 & 98.7 & 0.9 & 0.6 & 98.6 & 0.2 & 65.7 & 5.6 & 24.5 \\
\hline France & 0.6 & 99.4 & 0.7 & 61.2 & 38.2 & 0.5 & 40.5 & 2.2 & 55.3 \\
\hline Germany & 1.3 & 98.7 & 3.3 & 33.5 & 63.2 & 2.7 & 27.5 & 1.3 & 67.5 \\
\hline Italy & 0.3 & 99.7 & 0.6 & 19.1 & 80.4 & 0.4 & 9.0 & 1.0 & 88.9 \\
\hline Japan & 0.6 & 99.4 & 2.7 & 1.5 & 95.9 & 0.6 & 5.2 & 10.0 & 83.3 \\
\hline United Kingdom & 4.1 & 95.9 & 0.3 & 14.6 & 85.0 & 0.7 & 17.2 & 1.2 & 80.3 \\
\hline United States & 0.1 & 99.9 & 6.4 & 27.0 & 66.6 & 0.8 & 44.8 & 40.6 & 13.7 \\
\hline Average & 1.2 & 98.8 & 2.1 & 22.5 & 75.4 & 0.8 & 30.0 & 8.9 & 59.1 \\
\hline
\end{tabular}

Notes: In each cell, the variance share attributable to the relevant factor is reported. The variance contributions are attributed to: Global (global factor), Variable (variable-specific factor), Country (country-specific factor), and Idiosyncratic (idiosyncratic factor). One factor model refers to the dynamic factor model that includes only a global factor common to all variables and countries. Two factor model includes: (i) a global factor common to all variables and countries; and (ii) variable-specific factors that capture common cross-country fluctuations specific to each financial variable. Three factor model includes (i) a global factor common to all variables and countries; (ii) variablespecific factors that capture common cross-country fluctuations specific to each financial variable; and (iii) countryspecific factors that capture the comovement of all financial variables within a particular country. The last row in each panel shows the unweighted average of variance contributions in the respective columns. 
Table 2. Variance Decompositions: Spillovers From Financial Sector to Macroeconomy (Models 1, 2, and 1\&2; G-7 Averages)

\section{A. Model with Equity Prices}

\begin{tabular}{|c|c|c|c|c|c|c|c|c|c|c|c|c|c|c|}
\hline & \multicolumn{4}{|c|}{ Output } & \multicolumn{4}{|c|}{ Consumption } & \multicolumn{4}{|c|}{ Investment } & \multicolumn{2}{|c|}{ Equity prices } \\
\hline & $\mathbf{W}$ & C & SF & I & $\mathbf{W}$ & C & SF & I & $\mathbf{W}$ & C & SF & I & $\mathbf{F}$ & I \\
\hline & \multicolumn{14}{|c|}{ Model 1} \\
\hline $1985-2019$ & 31.4 & 33.1 & 7.4 & 28.2 & 7.1 & 29.2 & 1.7 & 62.0 & 20.1 & 24.4 & 4.7 & 50.8 & 56.0 & 44.0 \\
\hline $1985-2007$ & 23.5 & 39.7 & 3.6 & 33.2 & 7.7 & 29.7 & 1.2 & 61.5 & 18.8 & 23.2 & 2.8 & 55.2 & 42.7 & 57.3 \\
\hline \multirow[t]{2}{*}{$1998-2019$} & 34.6 & 24.7 & 15.4 & 25.3 & 8.6 & 31.3 & 3.9 & 56.3 & 22.3 & 17.0 & 10.0 & 50.6 & 59.6 & 40.4 \\
\hline & \multicolumn{14}{|c|}{ Model 2} \\
\hline 1985-2019 & 40.0 & 32.6 & 1.3 & 26.1 & 10.2 & 28.0 & 1.1 & 60.7 & 26.2 & 23.1 & 1.0 & 49.8 & 55.9 & 44.1 \\
\hline $1985-2007$ & 30.3 & 36.5 & 2.1 & 31.1 & 10.8 & 29.1 & 1.6 & 58.5 & 24.3 & 21.6 & 1.3 & 52.8 & 50.6 & 49.4 \\
\hline \multirow[t]{2}{*}{$1998-2019$} & 47.0 & 25.6 & 1.9 & 25.5 & 12.3 & 28.6 & 2.1 & 57.0 & 31.0 & 16.7 & 1.2 & 51.1 & 59.2 & 40.8 \\
\hline & \multicolumn{14}{|c|}{ Model 1\&2 } \\
\hline 1985-2019 & 31.7 & 33.6 & 8.7 & 26.0 & 7.3 & 29.6 & 2.9 & 60.3 & 20.6 & 22.5 & 5.7 & 51.2 & 55.9 & 44.1 \\
\hline $1985-2007$ & 21.5 & 39.0 & 6.5 & 33.0 & 6.8 & 29.5 & 3.0 & 60.6 & 17.0 & 23.0 & 4.8 & 55.2 & 50.4 & 49.6 \\
\hline $1998-2019$ & 33.6 & 24.4 & 17.3 & 24.7 & 8.3 & 30.7 & 6.2 & 54.8 & 22.1 & 16.1 & 11.4 & 50.4 & 59.3 & 40.7 \\
\hline
\end{tabular}

\section{B. Model with House Prices}

\begin{tabular}{|c|c|c|c|c|c|c|c|c|c|c|c|c|c|c|}
\hline & \multicolumn{4}{|c|}{ Output } & \multicolumn{4}{|c|}{ Consumption } & \multicolumn{4}{|c|}{ Investment } & \multicolumn{2}{|c|}{ House prices } \\
\hline & $\mathbf{W}$ & $\mathbf{C}$ & SF & I & $\mathbf{W}$ & $\mathbf{C}$ & SF & I & $\mathbf{W}$ & $\mathbf{C}$ & SF & $\mathbf{I}$ & $\mathbf{F}$ & I \\
\hline & \multicolumn{14}{|c|}{ Model 1} \\
\hline $1985-2019$ & 33.7 & 33.0 & 6.2 & 27.2 & 8.1 & 28.1 & 1.5 & 62.3 & 21.4 & 25.0 & 3.9 & 49.6 & 12.4 & 87.6 \\
\hline $1985-2007$ & 25.7 & 38.6 & 3.6 & 32.2 & 8.9 & 29.7 & 1.3 & 60.0 & 20.0 & 22.7 & 2.8 & 54.4 & 10.7 & 89.3 \\
\hline \multirow[t]{2}{*}{$1998-2019$} & 38.8 & 23.1 & 14.7 & 23.4 & 10.5 & 31.0 & 3.9 & 54.6 & 26.3 & 16.0 & 9.9 & 47.9 & 19.8 & 80.2 \\
\hline & \multicolumn{14}{|c|}{ Model 2} \\
\hline $1985-2019$ & 37.0 & 33.3 & 2.0 & 27.7 & 8.1 & 28.4 & 1.5 & 62.0 & 23.6 & 23.8 & 1.3 & 51.3 & 10.5 & 89.5 \\
\hline $1985-2007$ & 27.6 & 37.8 & 3.2 & 31.4 & 9.0 & 29.8 & 2.3 & 58.8 & 21.7 & 21.6 & 2.0 & 54.7 & 10.6 & 89.4 \\
\hline \multirow[t]{2}{*}{ 1998-2019 } & 50.0 & 23.7 & 1.9 & 24.4 & 13.8 & 28.1 & 2.2 & 55.9 & 33.9 & 16.8 & 1.3 & 48.0 & 20.4 & 79.6 \\
\hline & \multicolumn{14}{|c|}{ Model 1\&2 } \\
\hline $1985-2019$ & 33.0 & 33.7 & 8.2 & 25.2 & 7.8 & 29.0 & 3.1 & 60.1 & 21.4 & 22.1 & 5.4 & 51.2 & 12.4 & 87.6 \\
\hline $1985-2007$ & 19.2 & 41.8 & 5.9 & 33.2 & 5.5 & 30.2 & 3.2 & 61.0 & 16.3 & 25.2 & 4.2 & 54.3 & 9.6 & 90.4 \\
\hline $1998-2019$ & 39.8 & 21.9 & 16.1 & 22.3 & 11.2 & 28.9 & 6.3 & 53.6 & 27.7 & 15.4 & 11.1 & 45.8 & 20.0 & 80.0 \\
\hline
\end{tabular}




\section{Model with Interest Rates}

\begin{tabular}{|c|c|c|c|c|c|c|c|c|c|c|c|c|c|c|}
\hline & \multicolumn{4}{|c|}{ Output } & \multicolumn{4}{|c|}{ Consumption } & \multicolumn{4}{|c|}{ Investment } & \multicolumn{2}{|c|}{ Interest rates } \\
\hline & $\mathbf{W}$ & $\mathbf{C}$ & SF & $\mathbf{I}$ & $\mathbf{W}$ & C & SF & $\mathbf{I}$ & $\mathbf{W}$ & $\mathbf{C}$ & SF & $\mathbf{I}$ & $\mathbf{F}$ & $\mathbf{I}$ \\
\hline & \multicolumn{14}{|c|}{ Model 1} \\
\hline $1985-2019$ & 38.5 & 34.4 & 1.3 & 25.9 & 9.6 & 28.0 & 0.3 & 62.1 & 25.0 & 23.2 & 0.8 & 50.9 & 24.5 & 75.5 \\
\hline $1985-2007$ & 26.4 & 38.1 & 3.0 & 32.5 & 9.2 & 29.1 & 1.1 & 60.5 & 20.4 & 23.6 & 2.4 & 53.7 & 24.3 & 75.7 \\
\hline \multirow[t]{2}{*}{ 1998-2019 } & 48.8 & 23.2 & 4.4 & 23.6 & 14.0 & 28.9 & 1.3 & 55.8 & 32.7 & 16.5 & 3.0 & 47.8 & 30.5 & 69.5 \\
\hline & \multicolumn{14}{|c|}{ Model 2} \\
\hline 1985-2019 & 39.6 & 33.5 & 1.4 & 25.6 & 10.0 & 27.6 & 1.1 & 61.2 & 25.9 & 22.8 & 1.0 & 50.4 & 24.7 & 75.3 \\
\hline $1985-2007$ & 27.2 & 38.6 & 2.2 & 31.9 & 9.1 & 29.7 & 1.7 & 59.5 & 21.7 & 22.2 & 1.4 & 54.8 & 23.9 & 76.1 \\
\hline \multirow[t]{2}{*}{$1998-2019$} & 48.8 & 24.6 & 1.6 & 25.1 & 12.9 & 29.0 & 2.0 & 56.1 & 32.7 & 17.6 & 1.1 & 48.6 & 31.2 & 68.8 \\
\hline & \multicolumn{14}{|c|}{ Model 1\&2 } \\
\hline $1985-2019$ & 38.9 & 32.6 & 3.0 & 25.5 & 9.9 & 27.6 & 1.6 & 61.0 & 25.6 & 22.9 & 2.1 & 49.5 & 24.6 & 75.4 \\
\hline $1985-2007$ & 20.6 & 41.4 & 5.9 & 32.1 & 6.4 & 33.0 & 3.6 & 57.0 & 18.4 & 26.4 & 4.5 & 50.7 & 24.9 & 75.1 \\
\hline 1998-2019 & 48.0 & 22.2 & 7.1 & 22.7 & 13.8 & 28.6 & 3.5 & 54.1 & 33.3 & 16.0 & 5.0 & 45.7 & 30.9 & 69.1 \\
\hline
\end{tabular}

Notes: In each cell, the variance share attributable to the relevant factor is reported. The share is averaged across the G-7 countries at a horizon of 30 quarters. The variance contributions are attributed to: W (global macro factor), C (country-specific macro factor), F (global financial factor), SF (spillovers from financial to macro factors), and I (idiosyncratic factor). In Model 1, the financial factor spills over to the global macro factor. In Model 2, the financial factor spills over directly to the country-specific macro factor. Models 1 and 2 combined captures both channels through which the financial factor affects macro fluctuations. 
Table 3. Country-Specific Variance Decompositions:

Spillovers from Financial Sector to Macroeconomy (Models 1\&2)

\begin{tabular}{|c|c|c|c|c|c|c|c|c|c|c|}
\hline & & \multicolumn{3}{|c|}{ Equity prices } & \multicolumn{3}{|c|}{ House prices } & \multicolumn{3}{|c|}{ Interest rates } \\
\hline & & $\mathbf{Y}$ & C & I & $\mathbf{Y}$ & C & I & $\mathbf{Y}$ & $\mathbf{C}$ & I \\
\hline \multirow[t]{3}{*}{ Canada } & 1985-2019 & 6.6 & 3.9 & 7.7 & 6.5 & 3.9 & 6.9 & 2.5 & 1.2 & 2.7 \\
\hline & 1985-2007 & 4.4 & 1.7 & 2.8 & 5.4 & 2.4 & 3.2 & 5.5 & 2.7 & 3.5 \\
\hline & 1998-2019 & 13.1 & 11.2 & 18.7 & 12.5 & 10.6 & 17.1 & 5.6 & 4.7 & 7.2 \\
\hline \multirow[t]{3}{*}{ France } & 1985-2019 & 13.4 & 2.6 & 11.0 & 11.3 & 2.3 & 9.4 & 4.0 & 1.9 & 2.9 \\
\hline & 1985-2007 & 12.8 & 4.0 & 11.3 & 8.0 & 3.3 & 6.8 & 7.8 & 4.7 & 7.0 \\
\hline & 1998-2019 & 24.1 & 6.7 & 17.5 & 20.6 & 5.2 & 17.4 & 8.9 & 3.3 & 7.3 \\
\hline \multirow[t]{3}{*}{ Germany } & 1985-2019 & 9.5 & 1.2 & 5.0 & 8.5 & 1.4 & 4.6 & 3.1 & 0.9 & 1.9 \\
\hline & 1985-2007 & 5.8 & 2.0 & 4.3 & 5.1 & 2.2 & 3.4 & 4.3 & 1.8 & 3.6 \\
\hline & 1998-2019 & 22.3 & 2.0 & 12.2 & 19.6 & 1.6 & 11.3 & 8.2 & 1.1 & 5.2 \\
\hline \multirow{3}{*}{ Italy } & 1985-2019 & 11.5 & 3.5 & 4.5 & 10.1 & 3.9 & 4.6 & 3.1 & 1.9 & 2.0 \\
\hline & 1985-2007 & 8.7 & 5.7 & 5.6 & 6.0 & 3.9 & 4.6 & 5.9 & 4.0 & 4.7 \\
\hline & 1998-2019 & 22.4 & 6.8 & 8.3 & 20.1 & 8.2 & 8.5 & 8.9 & 6.1 & 4.3 \\
\hline \multirow[t]{3}{*}{ Japan } & 1985-2019 & 6.9 & 2.4 & 3.0 & 6.4 & 2.3 & 2.8 & 2.7 & 1.5 & 1.2 \\
\hline & 1985-2007 & 5.0 & 2.7 & 2.9 & 4.8 & 3.2 & 2.8 & 4.8 & 2.5 & 2.6 \\
\hline & 1998-2019 & 13.4 & 3.8 & 5.8 & 12.9 & 4.5 & 6.0 & 5.9 & 2.5 & 2.8 \\
\hline \multirow{3}{*}{$\begin{array}{l}\text { United } \\
\text { Kingdom }\end{array}$} & 1985-2019 & 6.3 & 2.6 & 1.6 & 7.5 & 3.5 & 1.9 & 2.4 & 1.3 & 0.7 \\
\hline & 1985-2007 & 2.9 & 1.6 & 1.2 & 5.6 & 3.4 & 2.0 & 4.5 & 3.6 & 1.6 \\
\hline & 1998-2019 & 15.4 & 5.5 & 3.3 & 16.2 & 6.1 & 3.6 & 6.9 & 2.6 & 1.6 \\
\hline \multirow{3}{*}{$\begin{array}{l}\text { United } \\
\text { States }\end{array}$} & 1985-2019 & 6.6 & 4.0 & 7.1 & 7.1 & 4.6 & 7.5 & 3.1 & 2.2 & 3.2 \\
\hline & 1985-2007 & 5.9 & 3.7 & 5.4 & 6.5 & 4.3 & 6.8 & 8.3 & 5.8 & 8.8 \\
\hline & 1998-2019 & 10.4 & 7.1 & 14.0 & 10.6 & 7.8 & 13.8 & 5.5 & 4.3 & 6.7 \\
\hline \multirow[t]{3}{*}{ Average } & 1985-2019 & 8.7 & 2.9 & 5.7 & 8.2 & 3.1 & 5.4 & 3.0 & 1.6 & 2.1 \\
\hline & 1985-2007 & 6.5 & 3.0 & 4.8 & 5.9 & 3.2 & 4.2 & 5.9 & 3.6 & 4.5 \\
\hline & 1998-2019 & 17.3 & 6.2 & 11.4 & 16.1 & 6.3 & 11.1 & 7.1 & 3.5 & 5.0 \\
\hline
\end{tabular}

Notes: This table shows the variance shares attributable to spillovers from the financial sector to the macroeconomy. The relevant spillovers are from the global financial factors (equity prices, house prices, and interest rates) to fluctuations in macro variables through the global macro factor and the country-specific macro factor. The results are based on the combined Model 1 and 2, which captures spillovers to the global macro factor (Model 1) and to the country-specific macro factor (Model 2) through which the financial factor affects macro activity. Y, C, and I refer to output, consumption, and investment, respectively. 
Table 4. Country-Specific Variance Decompositions: Spillovers From Financial Sector to Macroeconomy

(Models 1\&2; 1998-2019)

\begin{tabular}{|c|c|c|c|c|c|c|c|c|c|c|}
\hline & & \multicolumn{3}{|c|}{ Equity prices } & \multicolumn{3}{|c|}{ House prices } & \multicolumn{3}{|c|}{ Interest rates } \\
\hline & & $\mathbf{Y}$ & $\mathbf{C}$ & $\mathbf{I}$ & $\mathbf{Y}$ & $\mathbf{C}$ & $\mathbf{I}$ & $\mathbf{Y}$ & $\mathbf{C}$ & $\mathbf{I}$ \\
\hline \multirow[t]{4}{*}{ Canada } & Global Macro Factor & 26.2 & 22.9 & 40.1 & 32.5 & 28.2 & 46.4 & 40.8 & 34.6 & 55.8 \\
\hline & Country-Specific Factor & 12.7 & 9.6 & 3.7 & 11.4 & 6.4 & 6.5 & 9.5 & 7.8 & 5.9 \\
\hline & Idiosyncratic Factor & 48.1 & 56.3 & 37.5 & 43.5 & 54.8 & 29.9 & 44.1 & 52.9 & 31.2 \\
\hline & Financial Spillovers & 13.1 & 11.2 & 18.7 & 12.5 & 10.6 & 17.1 & 5.6 & 4.7 & 7.2 \\
\hline \multirow[t]{4}{*}{ France } & Global Macro Factor & 48.3 & 6.8 & 36.4 & 55.3 & 8.9 & 47.9 & 66.2 & 10.9 & 57.7 \\
\hline & Country-Specific Factor & 15.5 & 30.5 & 5.5 & 13.3 & 33.2 & 4.4 & 14.0 & 30.8 & 4.8 \\
\hline & Idiosyncratic Factor & 12.1 & 56.0 & 40.6 & 10.8 & 52.7 & 30.3 & 10.9 & 55.0 & 30.1 \\
\hline & Financial Spillovers & 24.1 & 6.7 & 17.5 & 20.6 & 5.2 & 17.4 & 8.9 & 3.3 & 7.3 \\
\hline \multirow[t]{4}{*}{ Germany } & Global Macro Factor & 46.4 & 0.6 & 22.5 & 52.5 & 0.8 & 27.7 & 62.2 & 1.1 & 32.5 \\
\hline & Country-Specific Factor & 15.4 & 25.1 & 25.1 & 14.6 & 22.7 & 24.2 & 15.9 & 21.7 & 26.8 \\
\hline & Idiosyncratic Factor & 15.9 & 72.2 & 40.3 & 13.4 & 74.8 & 36.7 & 13.7 & 76.2 & 35.5 \\
\hline & Financial Spillovers & 22.3 & 2.0 & 12.2 & 19.6 & 1.6 & 11.3 & 8.2 & 1.1 & 5.2 \\
\hline \multirow[t]{4}{*}{ Italy } & Global Macro Factor & 46.0 & 5.8 & 15.4 & 52.2 & 8.7 & 19.5 & 62.4 & 11.3 & 23.7 \\
\hline & Country-Specific Factor & 16.2 & 53.2 & 14.5 & 14.2 & 50.2 & 14.2 & 14.5 & 49.9 & 14.3 \\
\hline & Idiosyncratic Factor & 15.4 & 34.3 & 61.8 & 13.5 & 32.8 & 57.8 & 14.2 & 32.7 & 57.7 \\
\hline & Financial Spillovers & 22.4 & 6.8 & 8.3 & 20.1 & 8.2 & 8.5 & 8.9 & 6.1 & 4.3 \\
\hline \multirow[t]{4}{*}{ Japan } & Global Macro Factor & 24.0 & 2.2 & 9.7 & 28.5 & 3.0 & 12.4 & 34.6 & 3.8 & 15.1 \\
\hline & Country-Specific Factor & 39.8 & 50.6 & 21.9 & 38.2 & 49.9 & 21.8 & 38.6 & 50.2 & 22.1 \\
\hline & Idiosyncratic Factor & 22.8 & 43.4 & 62.6 & 20.4 & 42.7 & 59.9 & 20.9 & 43.4 & 59.9 \\
\hline & Financial Spillovers & 13.4 & 3.8 & 5.8 & 12.9 & 4.5 & 6.0 & 5.9 & 2.5 & 2.8 \\
\hline \multirow{4}{*}{$\begin{array}{l}\text { United } \\
\text { Kingdom }\end{array}$} & Global Macro Factor & 27.8 & 10.3 & 6.4 & 35.5 & 14.3 & 8.8 & 43.5 & 17.2 & 11.2 \\
\hline & Country-Specific Factor & 32.8 & 9.5 & 3.3 & 27.7 & 7.7 & 3.2 & 28.4 & 7.8 & 3.4 \\
\hline & Idiosyncratic Factor & 24.0 & 74.7 & 87.0 & 20.5 & 72.0 & 84.4 & 21.2 & 72.4 & 83.8 \\
\hline & Financial Spillovers & 15.4 & 5.5 & 3.3 & 16.2 & 6.1 & 3.6 & 6.9 & 2.6 & 1.6 \\
\hline \multirow{4}{*}{$\begin{array}{l}\text { United } \\
\text { States }\end{array}$} & Global Macro Factor & 16.5 & 9.8 & 24.3 & 22.1 & 14.5 & 31.1 & 26.6 & 17.7 & 37.0 \\
\hline & Country-Specific Factor & 38.6 & 36.4 & 38.7 & 33.6 & 32.2 & 33.6 & 34.1 & 31.9 & 34.6 \\
\hline & Idiosyncratic Factor & 34.5 & 46.7 & 23.0 & 33.8 & 45.5 & 21.5 & 33.8 & 46.2 & 21.6 \\
\hline & Financial Spillovers & 10.4 & 7.1 & 14.0 & 10.6 & 7.8 & 13.8 & 5.5 & 4.3 & 6.7 \\
\hline \multirow[t]{4}{*}{ Average } & Global Macro Factor & 33.6 & 8.3 & 22.1 & 39.8 & 11.2 & 27.7 & 48.0 & 13.8 & 33.3 \\
\hline & Country-Specific Factor & 24.4 & 30.7 & 16.1 & 21.9 & 28.9 & 15.4 & 22.2 & 28.6 & 16.0 \\
\hline & Idiosyncratic Factor & 24.7 & 54.8 & 50.4 & 22.3 & 53.6 & 45.8 & 22.7 & 54.1 & 45.7 \\
\hline & Financial Spillovers & 17.3 & 6.2 & 11.4 & 16.1 & 6.3 & 11.1 & 7.1 & 3.5 & 5.0 \\
\hline
\end{tabular}

Notes: In each cell, the variance share attributable to the relevant factor is reported. The results are based on the combined Models 1 and 2, which capture spillovers of the global financial factor to the global macro factor (Model 1) and to the country-specific macro factor (Model 2). Y, C, and I refer to output, consumption, and investment, respectively. 
Table 5. Variance Decompositions: Spillovers From Macroeconomy to Financial Markets (Models 3, 4 and 3\&4; G-7 Averages)

A. Model with Equity Prices

\begin{tabular}{|c|c|c|c|c|c|c|c|c|c|c|c|c|}
\hline & \multicolumn{3}{|c|}{ Output } & \multicolumn{3}{|c|}{ Consumption } & \multicolumn{3}{|c|}{ Investment } & \multicolumn{3}{|c|}{ Equity prices } \\
\hline & $\mathbf{W}$ & $\mathbf{C}$ & I & $\mathbf{W}$ & C & I & $\mathbf{W}$ & $\mathbf{C}$ & I & SR & $\mathbf{F}$ & I \\
\hline & \multicolumn{12}{|c|}{ Model 3} \\
\hline $1985-2019$ & 39.6 & 34.8 & 25.6 & 9.8 & 28.5 & 61.7 & 25.7 & 24.2 & 50.0 & 0.7 & 55.6 & 43.7 \\
\hline $1985-2007$ & 22.7 & 43.0 & 34.3 & 6.7 & 30.9 & 62.4 & 17.6 & 25.3 & 57.1 & 0.5 & 50.5 & 49.0 \\
\hline \multirow[t]{2}{*}{$1998-2019$} & 49.5 & 26.2 & 24.3 & 13.4 & 30.3 & 56.3 & 33.4 & 17.8 & 48.8 & 1.0 & 58.9 & 40.1 \\
\hline & \multicolumn{12}{|c|}{ Model 4} \\
\hline $1985-2019$ & 40.8 & 32.2 & 27.0 & 10.2 & 28.3 & 61.5 & 26.6 & 23.9 & 49.5 & 0.3 & 55.4 & 44.3 \\
\hline $1985-2007$ & 29.9 & 37.7 & 32.4 & 10.5 & 29.6 & 59.8 & 23.7 & 22.8 & 53.6 & 0.3 & 50.4 & 49.3 \\
\hline \multirow[t]{2}{*}{$1998-2019$} & 49.7 & 25.4 & 24.9 & 13.4 & 28.9 & 57.7 & 33.0 & 17.2 & 49.7 & 0.4 & 58.9 & 40.7 \\
\hline & \multicolumn{12}{|c|}{ Model 3\&4 } \\
\hline $1985-2019$ & 39.2 & 34.4 & 26.4 & 9.6 & 29.0 & 61.4 & 25.3 & 24.5 & 50.1 & 1.0 & 55.1 & 43.9 \\
\hline $1985-2007$ & 25.3 & 41.1 & 33.6 & 8.0 & 30.4 & 61.6 & 19.0 & 25.5 & 55.4 & 0.8 & 50.4 & 48.8 \\
\hline $1998-2019$ & 49.0 & 26.4 & 24.6 & 12.9 & 30.0 & 57.0 & 31.7 & 18.3 & 50.1 & 1.3 & 58.3 & 40.4 \\
\hline
\end{tabular}

B. Model with House Prices

\begin{tabular}{|c|c|c|c|c|c|c|c|c|c|c|c|c|}
\hline & \multicolumn{3}{|c|}{ Output } & \multicolumn{3}{|c|}{ Consumption } & \multicolumn{3}{|c|}{ Investment } & \multicolumn{3}{|c|}{ House prices } \\
\hline & $\mathbf{W}$ & $\mathbf{C}$ & I & $\mathbf{W}$ & $\mathbf{C}$ & I & $\mathbf{W}$ & $\mathbf{C}$ & I & SR & $\mathbf{F}$ & $\mathbf{I}$ \\
\hline & \multicolumn{12}{|c|}{ Model 3} \\
\hline $1985-2019$ & 40.7 & 33.7 & 25.6 & 10.3 & 28.5 & 61.2 & 26.6 & 23.9 & 49.4 & 0.9 & 11.6 & 87.5 \\
\hline $1985-2007$ & 23.9 & 42.0 & 34.1 & 7.3 & 31.1 & 61.7 & 18.2 & 24.9 & 56.9 & 0.5 & 8.4 & 91.1 \\
\hline \multirow[t]{2}{*}{$1998-2019$} & 48.9 & 26.5 & 24.5 & 12.8 & 30.2 & 57.0 & 31.8 & 18.0 & 50.2 & 2.8 & 17.5 & 79.8 \\
\hline & \multicolumn{12}{|c|}{ Model 4} \\
\hline $1985-2019$ & 39.3 & 33.5 & 27.2 & 9.7 & 27.8 & 62.4 & 25.2 & 24.4 & 50.4 & 0.5 & 11.4 & 88.1 \\
\hline $1985-2007$ & 29.2 & 38.4 & 32.3 & 9.9 & 29.6 & 60.5 & 22.7 & 23.0 & 54.2 & 0.5 & 7.8 & 91.7 \\
\hline \multirow[t]{2}{*}{$1998-2019$} & 48.4 & 26.4 & 25.2 & 13.0 & 28.8 & 58.2 & 30.8 & 17.8 & 51.4 & 1.1 & 18.0 & 80.9 \\
\hline & \multicolumn{12}{|c|}{ Model 3\&4 } \\
\hline 1985-2019 & 39.8 & 34.2 & 26.0 & 9.8 & 28.8 & 61.5 & 25.8 & 24.3 & 50.0 & 1.2 & 11.0 & 87.8 \\
\hline $1985-2007$ & 23.2 & 42.2 & 34.7 & 7.0 & 30.3 & 62.7 & 17.7 & 25.6 & 56.6 & 0.9 & 8.5 & 90.7 \\
\hline 1998-2019 & 49.5 & 26.0 & 24.5 & 13.0 & 30.3 & 56.7 & 33.0 & 18.2 & 48.9 & 3.9 & 17.9 & 78.2 \\
\hline
\end{tabular}




\section{Model with Interest Rates}

\begin{tabular}{|c|c|c|c|c|c|c|c|c|c|c|c|c|}
\hline & \multicolumn{3}{|c|}{ Output } & \multicolumn{3}{|c|}{ Consumption } & \multicolumn{3}{|c|}{ Investment } & \multicolumn{3}{|c|}{ Interest rates } \\
\hline & W & C & I & $\mathbf{W}$ & C & I & W & C & I & SR & $\mathbf{F}$ & I \\
\hline & \multicolumn{12}{|c|}{ Model 3} \\
\hline $1985-2019$ & 40.0 & 33.9 & 26.1 & 9.7 & 29.0 & 61.2 & 25.7 & 24.3 & 50.0 & 1.0 & 24.9 & 74.1 \\
\hline $1985-2007$ & 24.0 & 41.6 & 34.4 & 7.3 & 31.1 & 61.6 & 18.0 & 25.4 & 56.7 & 3.0 & 24.2 & 72.8 \\
\hline \multirow[t]{2}{*}{ 1998-2019 } & 48.6 & 26.2 & 25.3 & 12.8 & 30.3 & 57.0 & 31.4 & 18.6 & 50.0 & 2.1 & 30.8 & 67.1 \\
\hline & \multicolumn{12}{|c|}{ Model 4} \\
\hline $1985-2019$ & 40.5 & 33.4 & 26.1 & 10.3 & 28.7 & 61.0 & 26.4 & 23.0 & 50.6 & 1.1 & 23.9 & 75.0 \\
\hline 1985-2007 & 29.4 & 38.1 & 32.5 & 10.2 & 29.8 & 60.0 & 23.2 & 22.8 & 54.0 & 1.4 & 23.4 & 75.2 \\
\hline \multirow[t]{2}{*}{ 1998-2019 } & 47.8 & 26.8 & 25.5 & 12.4 & 29.6 & 58.0 & 30.4 & 18.3 & 51.3 & 2.2 & 29.6 & 68.2 \\
\hline & \multicolumn{12}{|c|}{ Model 3\&4 } \\
\hline $1985-2019$ & 39.1 & 34.6 & 26.3 & 9.5 & 28.7 & 61.7 & 25.2 & 24.6 & 50.2 & 2.5 & 24.3 & 73.2 \\
\hline $1985-2007$ & 24.2 & 41.7 & 34.1 & 7.3 & 31.7 & 61.0 & 18.1 & 24.7 & 57.2 & 4.3 & 23.4 & 72.3 \\
\hline 1998-2019 & 48.3 & 27.2 & 24.4 & 12.7 & 29.7 & 57.6 & 31.0 & 18.4 & 50.6 & 4.9 & 29.6 & 65.4 \\
\hline
\end{tabular}

Notes: In each cell, the variance share attributable to the relevant factor is reported. The share is averaged across the G-7 countries at a horizon of 30 quarters. The variance contributions are attributed to: W (global macro factor), C (country-specific macro factor), F (global financial factor), SR (spillovers from macro to financial factor), and I (idiosyncratic factor). In Model 3, the global macro factor spills over to the financial factor. In Model 4, the U.S. country factor spills over to the financial factor. Model 3 and 4 combined capture both channels through which the macro factors affect fluctuations in financial markets. 
Table 6. Country-Specific Variance Decompositions: Spillovers From Macroeconomy to Financial Markets (Model 3\&4; 1998-2019)

\begin{tabular}{|c|c|c|c|c|}
\hline & & $\begin{array}{c}\text { Equity } \\
\text { prices }\end{array}$ & $\begin{array}{r}\text { House } \\
\text { prices }\end{array}$ & $\begin{array}{r}\text { Interest } \\
\text { rates }\end{array}$ \\
\hline \multirow[t]{3}{*}{ Canada } & Global Financial Factor & 56.5 & 24.1 & 54.9 \\
\hline & Idiosyncratic Factor & 42.2 & 70.6 & 35.9 \\
\hline & Macroeconomic Spillovers & 1.3 & 5.3 & 9.2 \\
\hline \multirow[t]{3}{*}{ France } & Global Financial Factor & 59.4 & 15.8 & 33.7 \\
\hline & Idios yncratic Factor & 39.3 & 80.5 & 60.8 \\
\hline & Macroeconomic Spillovers & 1.4 & 3.7 & 5.6 \\
\hline \multirow[t]{3}{*}{ Ge rmany } & Global Financial Factor & 61.4 & 4.5 & 24.4 \\
\hline & Idiosyncratic Factor & 37.2 & 94.6 & 71.6 \\
\hline & Macroeconomic Spillovers & 1.4 & 1.0 & 4.0 \\
\hline \multirow[t]{3}{*}{ Italy } & Global Financial Factor & 44.6 & 39.7 & 14.3 \\
\hline & Idiosyncratic Factor & 54.3 & 52.1 & 83.3 \\
\hline & Macroeconomic Spillovers & 1.0 & 8.2 & 2.4 \\
\hline \multirow[t]{3}{*}{ Japan } & Global Financial Factor & 33.5 & 11.0 & 11.1 \\
\hline & Idiosyncratic Factor & 65.7 & 86.6 & 87.0 \\
\hline & Macroeconomic Spillovers & 0.8 & 2.4 & 1.9 \\
\hline \multirow[t]{3}{*}{ United Kingdom } & Global Financial Factor & 78.0 & 25.4 & 17.7 \\
\hline & Idiosyncratic Factor & 20.2 & 69.1 & 79.2 \\
\hline & Macroeconomic Spillovers & 1.8 & 5.5 & 3.0 \\
\hline \multirow[t]{3}{*}{ United States } & Global Financial Factor & 74.6 & 5.1 & 51.1 \\
\hline & Idios yncratic Factor & 23.7 & 93.8 & 40.3 \\
\hline & Macroeconomic Spillovers & 1.7 & 1.1 & 8.6 \\
\hline \multirow[t]{3}{*}{ Average } & Global Financial Factor & 58.3 & 17.9 & 29.6 \\
\hline & Idios yncratic Factor & 40.4 & 78.2 & 65.4 \\
\hline & Macroeconomic Spillovers & 1.3 & 3.9 & 4.9 \\
\hline
\end{tabular}

Notes: In each cell, the variance share attributable to the relevant factor is reported. The results are based on the combined Models 3 and 4, which capture spillovers from the global macro factor (Model 3) and from the U.S. country factor (Model 4) to financial markets. 
Table 7. Country-Specific Variance Decompositions:

Spillovers from Macroeconomy to Financial Markets

(Model 3\&4)

\begin{tabular}{|c|c|c|c|c|}
\hline & & $\begin{array}{l}\text { Equity } \\
\text { prices }\end{array}$ & $\begin{array}{c}\text { House } \\
\text { prices }\end{array}$ & $\begin{array}{r}\text { Interest } \\
\text { rates }\end{array}$ \\
\hline \multirow[t]{3}{*}{ Canada } & 1985-2019 & 1.1 & 1.3 & 3.7 \\
\hline & 1985-2007 & 0.9 & 0.5 & 5.2 \\
\hline & 1998-2019 & 1.3 & 5.3 & 9.2 \\
\hline \multirow[t]{3}{*}{ France } & 1985-2019 & 1.0 & 0.9 & 2.2 \\
\hline & 1985-2007 & 1.0 & 1.7 & 3.9 \\
\hline & 1998-2019 & 1.4 & 3.7 & 5.6 \\
\hline \multirow[t]{3}{*}{ Germany } & 1985-2019 & 1.0 & 0.2 & 3.1 \\
\hline & 1985-2007 & 0.9 & 0.6 & 6.9 \\
\hline & 1998-2019 & 1.4 & 1.0 & 4.0 \\
\hline \multirow[t]{3}{*}{ Italy } & 1985-2019 & 0.7 & 0.8 & 2.0 \\
\hline & 1985-2007 & 0.6 & 0.5 & 4.5 \\
\hline & 1998-2019 & 1.0 & 8.2 & 2.4 \\
\hline \multirow[t]{3}{*}{ Japan } & 1985-2019 & 0.4 & 1.0 & 1.0 \\
\hline & 1985-2007 & 0.1 & 1.5 & 1.5 \\
\hline & 1998-2019 & 0.8 & 2.4 & 1.9 \\
\hline \multirow[t]{3}{*}{ United Kingdom } & 1985-2019 & 1.3 & 3.9 & 1.5 \\
\hline & 1985-2007 & 1.0 & 0.7 & 2.5 \\
\hline & 1998-2019 & 1.8 & 5.5 & 3.0 \\
\hline \multirow[t]{3}{*}{ United States } & 1985-2019 & 1.3 & 0.3 & 3.9 \\
\hline & 1985-2007 & 1.1 & 0.8 & 5.4 \\
\hline & 1998-2019 & 1.7 & 1.1 & 8.6 \\
\hline \multirow[t]{3}{*}{ Average } & 1985-2019 & 1.0 & 1.2 & 2.5 \\
\hline & 1985-2007 & 0.8 & 0.9 & 4.3 \\
\hline & 1998-2019 & 1.3 & 3.9 & 4.9 \\
\hline
\end{tabular}

Notes: This table shows the variance shares attributable to spillovers from the macroeconomy to financial markets. The relevant spillovers are from macroeconomic agregates to the global financial factors (equity prices, house prices, and interest rates) through the global macro factor and the U.S. country factor. The results are based on the combined Models 3 and 4, which capture spillovers from the global macro factor (Model 3) and from the U.S. country factor (Model 4) to the financial sector. 


\title{
Figure 1. Variance Contributions of the Global Factor: Models With Only Financial Variables
}

\author{
A. One Factor Model
}

80

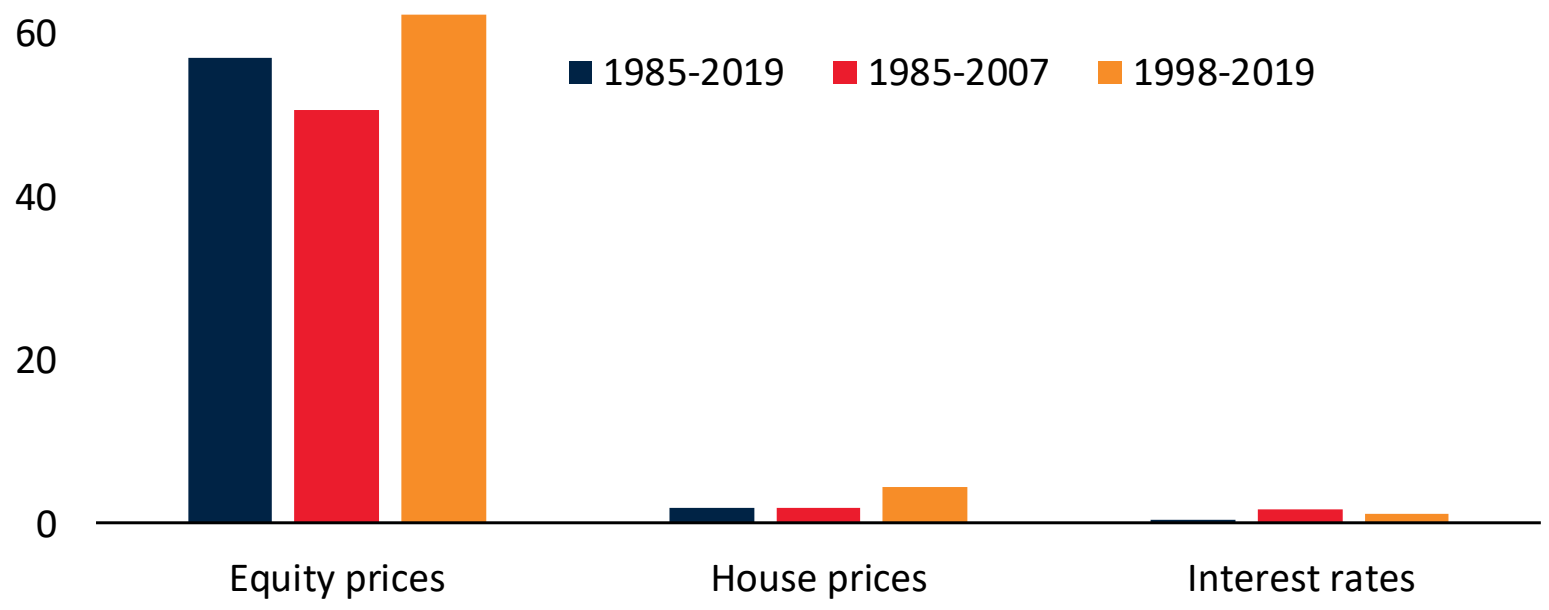

B. Models with Multiple Factors: 1998-2019

80

One Factor Model $\quad$ Two Factor Model $\quad$ Three Factor Model

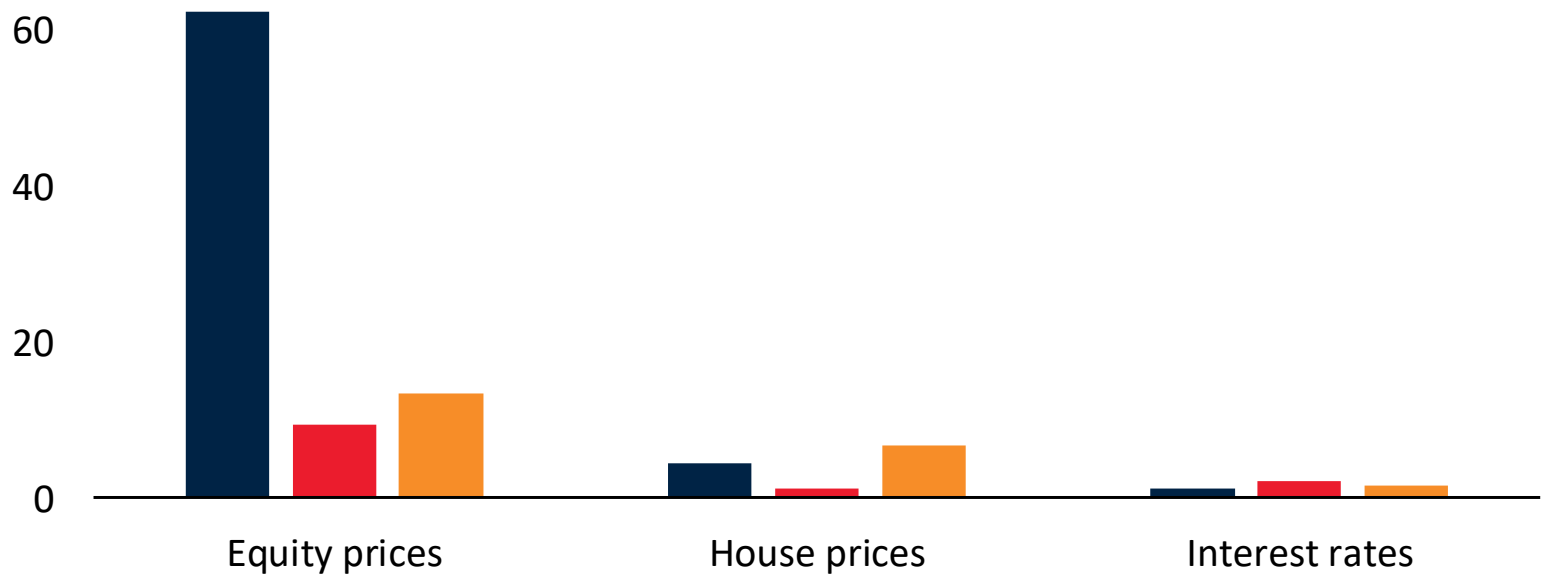

Notes: These figures show the variance contributions of the global factor based on variance decompositions from standard dynamic factor models estimated for the three financial variables (equity prices, house prices, and interest rates). The one factor model refers to the dynamic factor model that includes only a global factor common to all variables and countries. The two factor model includes: (i) a global factor common to all variables and countries; and (ii) variable-specific factors that capture common cross-country fluctuations specific to each financial variable. The three factor model includes (i) a global factor common to all variables and countries; (ii) variable-specific factors that capture common cross-country fluctuations specific to each financial variable; and (iii) country-specific factors that capture the comovement of all financial variables within a particular country. 


\section{Figure 2. Estimates of Macroeconomic and Financial Factors}

(1985-2019)

A. Global Macro Factor

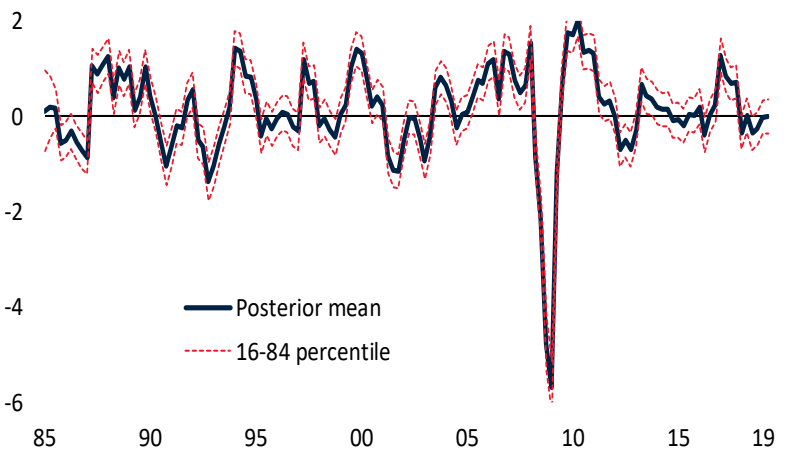

C. Global Equity Price Factor

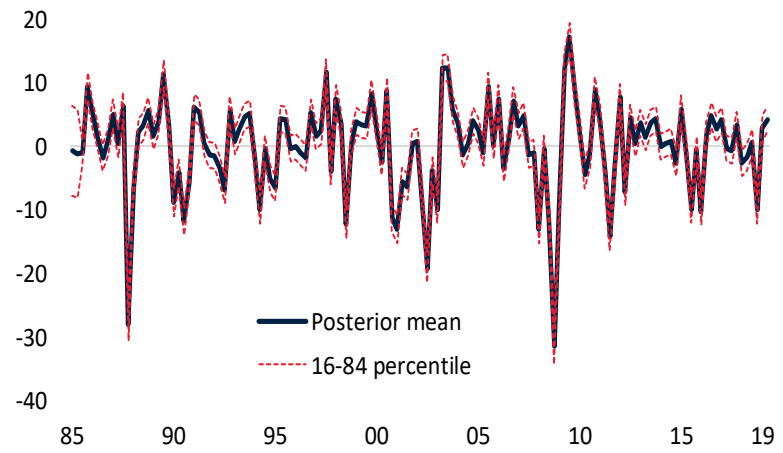

B. U.S. Country Factor

2

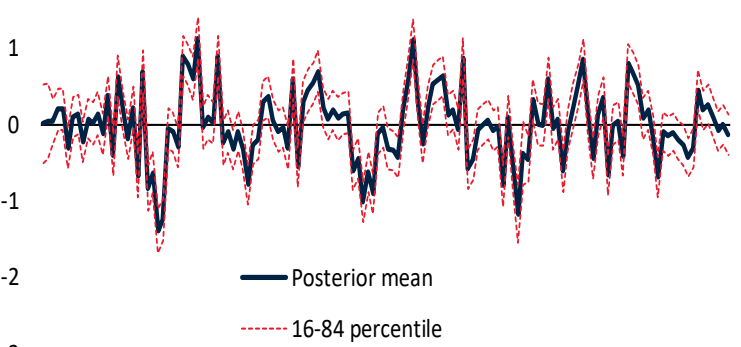

$-3$

10

D. Global House Price Factor

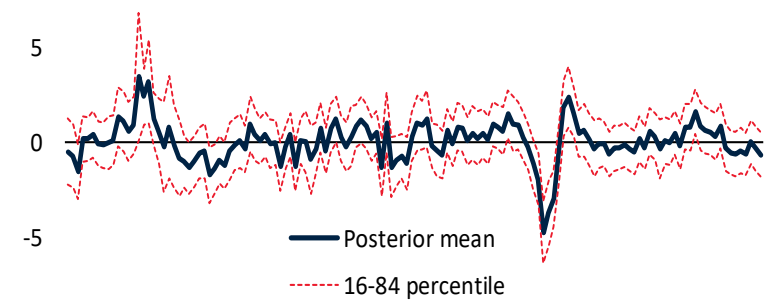

$-10$

$\begin{array}{llllllll}85 & 90 & 95 & 00 & 05 & 10 & 15 & 19\end{array}$

E. Global Interest Rate Factor

2
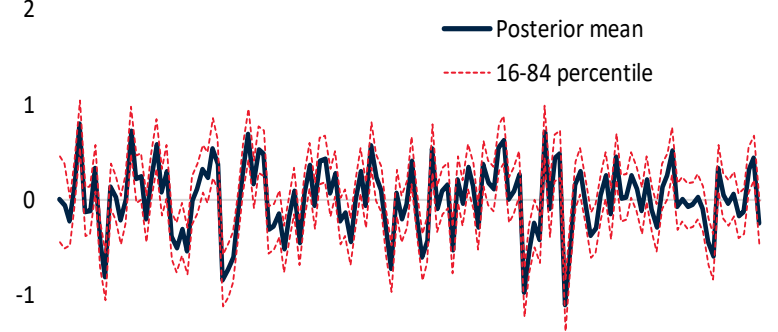

$-2$

$\begin{array}{llllllll}85 & 90 & 95 & 00 & 05 & 10 & 15 & 19\end{array}$

Notes: The factors shown as solid lines are posterior medians. The dashed lines represent the 16 and 84 percent posterior quantile bands. Panels $\mathrm{A}$ and $\mathrm{B}$ are based on the combined Model $1 \& 2$ and Panels $\mathrm{C}$ to E are based on the combined Model 3\&4 estimated over the full sample (1985-2019). In Model 1, the financial factor spills over to the global macro factor. In Model 2, the financial factor spills over directly onto the country-specific macro factor. Models 1 and 2 combined capture both channels through which the financial factor affects macro fluctuations. In Model 3, the global macro factor spills over to the financial factor. In Model 4, the U.S. country factor spills over to the financial factor. Models 3 and 4 combined capture both channels through which the macro factors affect financial markets. 
Figure 3. Variance Decompositions:

Spillovers From Financial Sector to Macroeconomy

(Models 1 and 2; G-7 Averages)
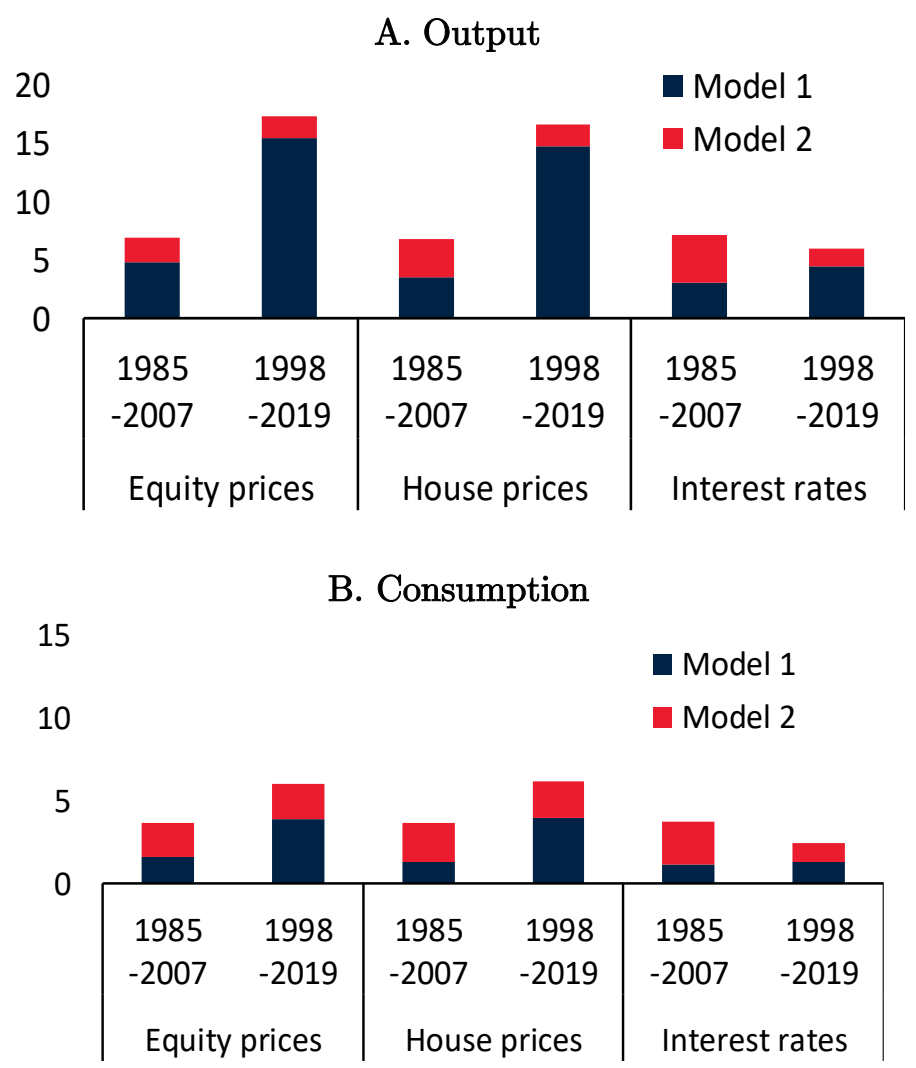

\section{Investment}

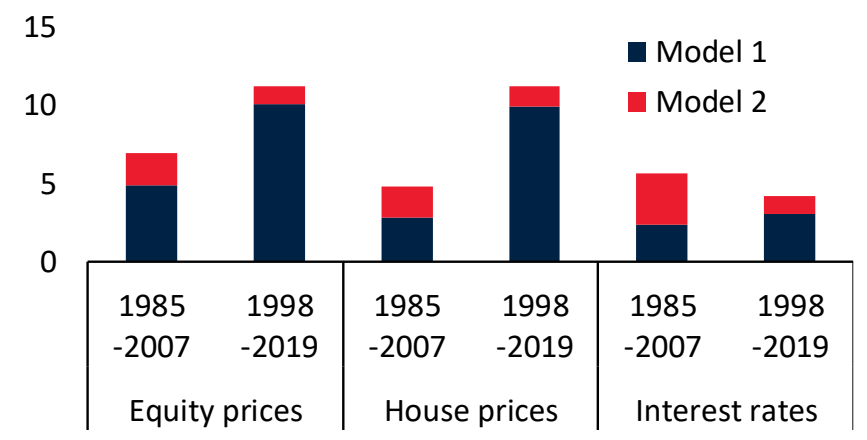

Notes: These figures show spillovers from the global financial factors (equity prices, house prices, and interest rates) to fluctuations in macro variables through the global macro factor and the countryspecific macro factor. In Model 1, the financial factor spills over to the global macro factor. In Model 2, the financial factor spills over directly to country-specific macro factor. 
Figure 4. Variance Decompositions:

Spillovers From Financial Sector to Macroeconomy (Model 1\&2; G-7 Averages)

\section{A. Output}

20

15

10

5

0

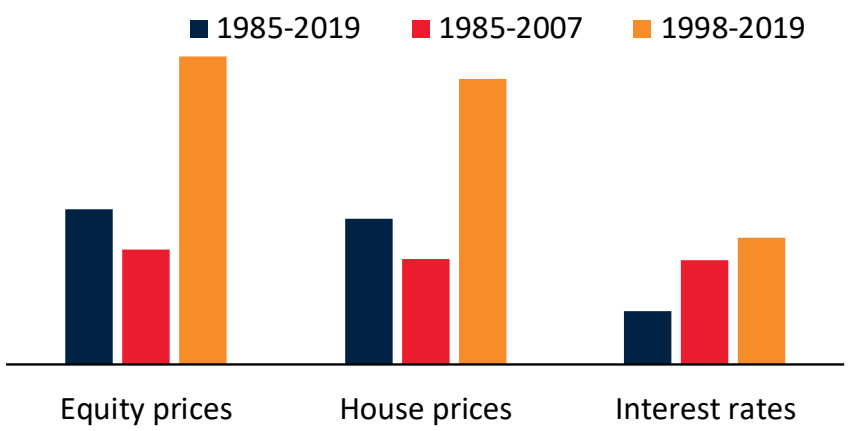

B. Consumption

16

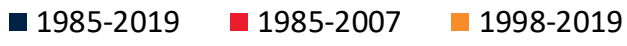

12

8

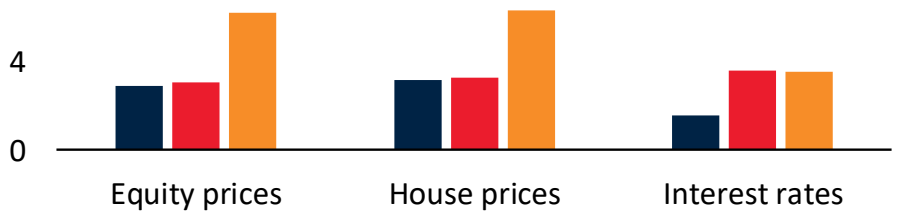

C. Investment

16

—1985-2019 —1985-2007 —1998-2019

12

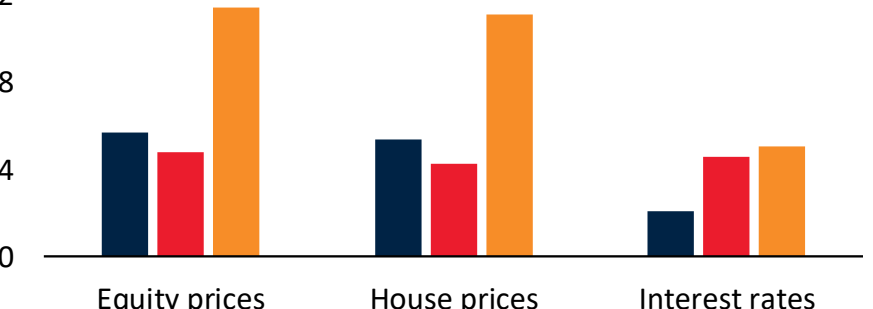

Equity prices House prices Interest rates

Notes: These figures show spillovers from the global financial factors (equity prices, house prices, and interest rates) to fluctuations in macro variables, based on the combined Model 1 and 2, which captures spillovers to the global macro factor (Model 1) and to country-specific macro factor (Model 2) through which the financial factor affects macro activity. 
Figure 5. Variance Decompositions:

Spillovers From Financial Sector to Macroeconomy

(Model 1\&2; G-7 Averages)

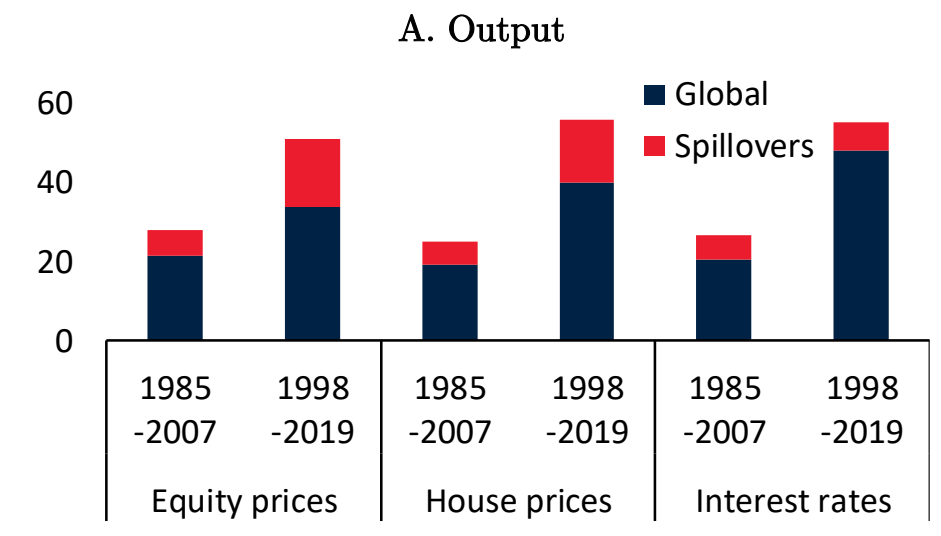

B. Consumption

60

- Global

40

Spillovers

20

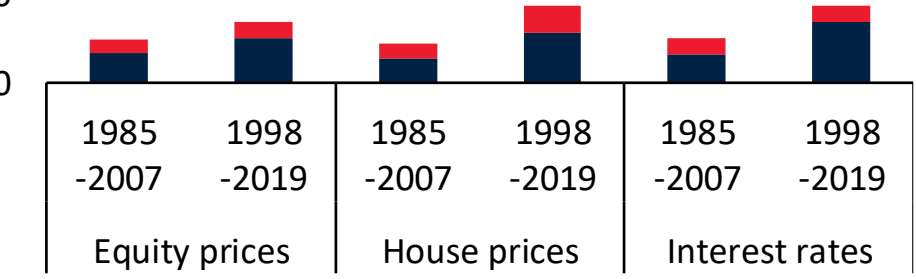

C. Investment

60

Global

40

20

0

\begin{tabular}{|cc|cc|cc|}
\hline 1985 & 1998 & 1985 & 1998 & 1985 & 1998 \\
-2007 & -2019 & -2007 & -2019 & -2007 & -2019 \\
Equity prices & House prices & Interest rates
\end{tabular}

Notes: These figures show the variance decompositions for the global macro factor ("global") and spillovers from financial factors (equity prices, house prices, and interest rates) to fluctuations in macro variables ("spillovers"). The results are based on the combined Model 1 and 2, which captures spillovers to the global macro factor (Model 1) and to countryspecific macro factor (Model 2) through which the financial factor affects macro activity. 
Figure 6. Variance Decompositions: Spillovers From Financial Sector to Output (15-Year Rolling Windows; Model 1\&2; G-7 Averages; 1985-2019)

A. Equity Prices

100

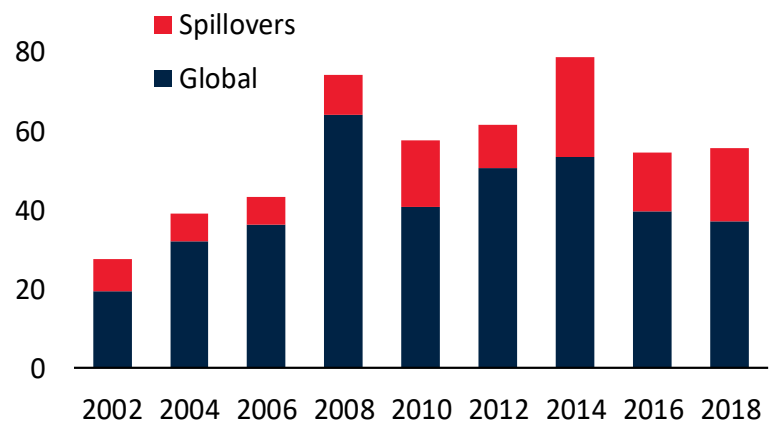

\section{B. House Prices}

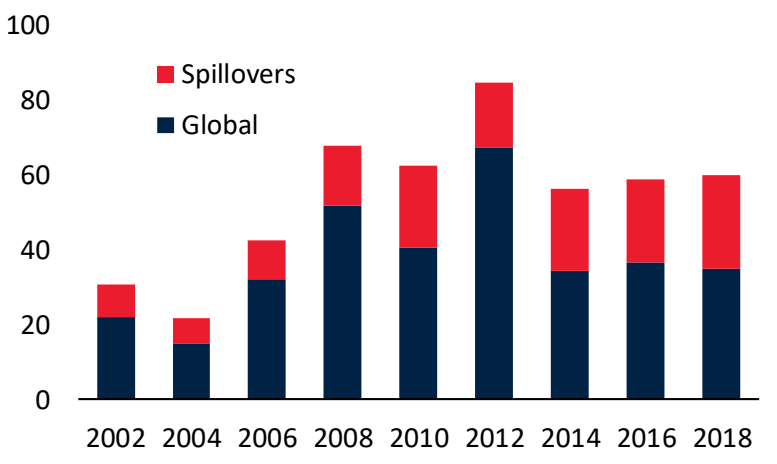

\section{Interest Rates}

100

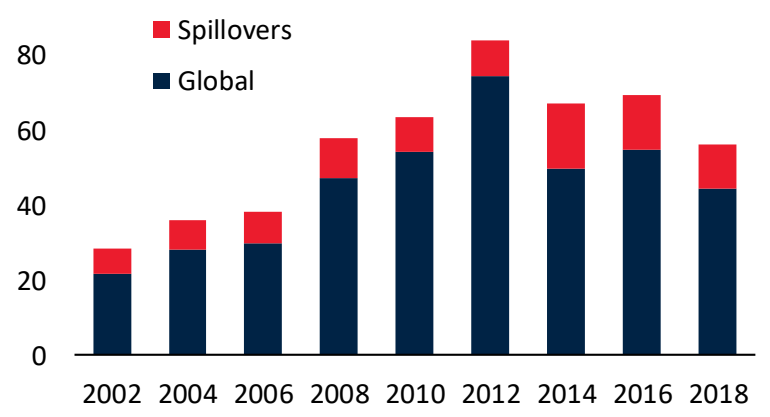

Notes: These figures are based on variance decompositions from estimates over 15-year (trailing) rolling windows. The bars show the average (for the G-7 countries) shares of output variance accounted for by the global macro factor ("global") and spillovers from financial factors ("spillovers"). The results are based on the combined Model 1 and 2, which captures spillovers of the financial factor on output fluctuations through the global macro factor (Model 1) and the country-specific macro factor (Model 2). 


\title{
APPENDIX (not intended for publication)
}

\section{Global Macro-Financial Cycles and Spillovers}

\author{
Jongrim Ha, M. Ayhan Kose, Christopher Otrok, and Eswar S. Prasad
}

February 2020

\section{This appendix contains:}

Table A1. Database

Table A2. Factor Loadings (Model 1\&2; 1998-2019)

Table A3. Factor Vector-autoregressive Coefficients (1998-2019)

Table A4. Variance Decompositions for G-7 Countries (1998-2019)

Table A5. Confidence bands for Variance decompositions (Model 1\&2)

Table A6. Confidence bands for Variance decompositions (Model 3\&4)

Table A7. Variance Decompositions for G-7 Countries (HP filtered data)

Table A8. Variance Decompositions: Models With Only Macroeconomic Variables

Table A9. Variance Decompositions: Models with Macroeconomic and Financial variables (1985-2019)

Table A10. Variance Decompositions: Models with Financial Variables

Table A11. Variance Decompositions: Credit Growth as the Financial Variable (G-7 Averages)

Table A12. Variance Decompositions: Long-term Interest Rates (G-7 Averages; Model $1 \& 2$ and Model 3\&4)

Table A13. Variance Decompositions: Alternative House Price Indicator (G-7 Averages)

Table A14. Variance Decompositions: Dataset Excluding the U.S. (G-7 Averages)

Table A15. Variance Decompositions: Alternative Sub-Samples (G-7 Averages)

Table A16. Variance Decompositions: Monthly Industrial Production and Financial Variables

Table A17. Variance Decompositions: Spillover Model 1 with Industrial Production and Financial Variables

Table A18. Variance decompositions: Spillover Model 3 with Industrial Production and Financial Variables

Figure A1. Country-Specific Variance Decompositions: Spillovers from Financial Sector to Macroeconomy (Model 1\&2; Output; 1998-2019)

Figure A2. Variance Decompositions: Spillovers From Macroeconomy to Financial Sector (15-Year Rolling Windows; Model 3\&4; G-7 Averages; 1985-2019)

Figure A3. Country-Specific Variance Decompositions: Spillovers From Macroeconomy to Financial Sector (Model 3\&4; 1998-2019)

Figure A4. Dynamic Factor Estimation Results with Credit Growth 


\section{Table A1. Database}

\begin{tabular}{|c|c|c|c|}
\hline Variable & Definition & Source & Transformation \\
\hline Output & Real GDP & Haver Analytics & Growth (in percent) \\
\hline Consumption & Real private consumption & Haver Analytics & Growth (in percent) \\
\hline Investment & $\begin{array}{l}\text { Real gross fixed capital } \\
\text { formation }\end{array}$ & Haver Analytics & Growth (in percent) \\
\hline Equity Prices & Equity price index & Haver Analytics & Growth (in percent) \\
\hline Housing Prices & Real housing price index & Haver Analytics, OECD & Growth (in percent) \\
\hline Interest Rates & $\begin{array}{l}3 \text {-month treasury bill } \\
\text { yields }\end{array}$ & $\begin{array}{l}\text { Federal Reserve Economic Data, } \\
\text { OECD }\end{array}$ & Difference (in percentage points) \\
\hline Credit & Domestic credit & $\begin{array}{l}\text { Federal Reserve Economic Data, } \\
\text { Haver Analytics }\end{array}$ & Growth (in percent) \\
\hline
\end{tabular}

Notes: Data series cover the 1985-2019 period. Macroeconomic aggregates and financial variables are all seasonally adjusted. Financial variables are deflated by the CPI of each country. We use growth rates of all variables (except interest rates) and, following Stock and Watson (2012), remove low-frequency movements using the Local Mean method. 
Table A2. Factor Loadings

(Model 1\&2; 1998-2019)

\begin{tabular}{|c|c|c|c|c|c|c|c|}
\hline & Factor & Output & Consumption & Investment & $\begin{array}{c}\text { Equity } \\
\text { Prices }\end{array}$ & $\begin{array}{l}\text { House } \\
\text { Prices }\end{array}$ & $\begin{array}{r}\text { Interes } \\
\text { Rate }\end{array}$ \\
\hline \multirow[t]{4}{*}{ Canada } & Global Macro Factor & 0.38 & 0.28 & 1.62 & & & \\
\hline & Country-Specific Factor & 0.24 & 0.11 & 0.22 & & & \\
\hline & Financial Factor & & & & 0.68 & 0.18 & 0.37 \\
\hline & Constant & -0.08 & -0.05 & -0.36 & -0.66 & 0.04 & 0.04 \\
\hline \multirow[t]{4}{*}{ France } & Global Macro Factor & 0.40 & 0.14 & 0.73 & & & \\
\hline & Country-Specific Factor & 0.36 & 0.49 & 0.41 & & & \\
\hline & Financial Factor & & & & 0.90 & 0.27 & 0.56 \\
\hline & Constant & -0.07 & -0.02 & -0.12 & -0.88 & 0.09 & 0.01 \\
\hline \multirow[t]{4}{*}{ Germany } & Global Macro Factor & 0.74 & 0.02 & 1.11 & & & \\
\hline & Country-Specific Factor & 0.35 & 0.33 & 0.97 & & & \\
\hline & Financial Factor & & & & 1.05 & 0.02 & 0.30 \\
\hline & Constant & -0.14 & -0.01 & -0.23 & -1.02 & 0.01 & 0.00 \\
\hline \multirow[t]{4}{*}{ Italy } & Global Macro Factor & 0.53 & 0.12 & 0.73 & & & \\
\hline & Country-Specific Factor & 0.35 & 0.46 & 0.81 & & & \\
\hline & Financial Factor & & & & 0.81 & 0.56 & 0.54 \\
\hline & Constant & -0.09 & -0.01 & -0.12 & -0.81 & 0.07 & 0.01 \\
\hline \multirow[t]{4}{*}{ Japan } & Global Macro Factor & 0.61 & 0.16 & 0.55 & & & \\
\hline & Country-Specific Factor & 0.58 & 0.61 & 0.62 & & & \\
\hline & Financial Factor & & & & 0.59 & -0.18 & 0.06 \\
\hline & Constant & -0.12 & -0.04 & -0.14 & -0.60 & 0.01 & 0.00 \\
\hline United & Global Macro Factor & 0.36 & 0.24 & 0.92 & & & \\
\hline \multirow[t]{3}{*}{ Kingdom } & Country-Specific Factor & 0.26 & 0.15 & 0.40 & & & \\
\hline & Financial Factor & & & & 0.58 & 0.21 & 0.60 \\
\hline & Constant & -0.07 & -0.05 & -0.21 & -0.55 & 0.17 & 0.01 \\
\hline United & Global Macro Factor & 0.29 & 0.15 & 0.81 & & & \\
\hline \multirow[t]{3}{*}{ States } & Country-Specific Factor & 0.56 & 0.38 & 1.28 & & & \\
\hline & Financial Factor & & & & 0.60 & 0.59 & 0.26 \\
\hline & Constant & 0.00 & 0.01 & -0.04 & -0.55 & 0.13 & 0.02 \\
\hline
\end{tabular}

Notes: This table shows posterior medians of factor loadings based on the combined Model 1 and 2, which captures spillovers to the global macro factor (Model 1) and to country-specific macro factor (Model 2) through which the financial factor affects macro activity. 
Table A3. Factor Vector-autoregressive Coefficients (1998-2019)

A. Global Macro and Country-Specific Factors (Model 1\&2)

\begin{tabular}{|c|c|c|c|c|c|}
\hline & \multirow[b]{2}{*}{ Lags } & \multirow[b]{2}{*}{$\begin{array}{r}\text { Own } \\
\text { Factor }\end{array}$} & \multicolumn{3}{|c|}{ Financial Factor } \\
\hline & & & $\begin{array}{l}\text { Equity } \\
\text { Prices }\end{array}$ & $\begin{array}{l}\text { House } \\
\text { Prices }\end{array}$ & $\begin{array}{r}\text { Interest } \\
\text { Rates }\end{array}$ \\
\hline \multirow{3}{*}{$\begin{array}{l}\text { Global Macro } \\
\text { Factor }\end{array}$} & 1 & 0.55 & 0.04 & 0.09 & 0.10 \\
\hline & 2 & -0.13 & 0.00 & -0.01 & 0.20 \\
\hline & 3 & -0.03 & 0.02 & -0.07 & -0.01 \\
\hline \multicolumn{6}{|c|}{ Country-Specific Factor } \\
\hline \multirow{3}{*}{ Canada } & 1 & 0.17 & 0.00 & 0.00 & -0.05 \\
\hline & 2 & -0.13 & 0.00 & 0.01 & 0.02 \\
\hline & 3 & -0.02 & 0.00 & -0.01 & -0.01 \\
\hline \multirow[t]{3}{*}{ France } & 1 & -0.28 & 0.01 & 0.00 & 0.05 \\
\hline & 2 & -0.06 & -0.01 & 0.02 & 0.07 \\
\hline & 3 & -0.01 & 0.01 & -0.02 & -0.02 \\
\hline \multirow[t]{3}{*}{ Germany } & 1 & -0.29 & 0.00 & -0.04 & -0.05 \\
\hline & 2 & -0.12 & 0.00 & 0.03 & -0.10 \\
\hline & 3 & 0.04 & 0.01 & 0.03 & -0.02 \\
\hline \multirow[t]{3}{*}{ Italy } & 1 & 0.55 & 0.01 & 0.04 & 0.15 \\
\hline & 2 & -0.07 & 0.00 & -0.04 & 0.05 \\
\hline & 3 & 0.02 & 0.00 & 0.00 & 0.00 \\
\hline \multirow[t]{3}{*}{ Japan } & 1 & 0.02 & 0.01 & 0.04 & 0.06 \\
\hline & 2 & -0.17 & -0.01 & 0.01 & 0.10 \\
\hline & 3 & -0.08 & 0.00 & -0.06 & -0.02 \\
\hline \multirow{3}{*}{$\begin{array}{l}\text { United } \\
\text { Kingdom }\end{array}$} & 1 & 1.03 & 0.00 & 0.04 & -0.01 \\
\hline & 2 & -0.53 & 0.01 & 0.00 & -0.05 \\
\hline & 3 & -0.07 & 0.00 & -0.01 & -0.05 \\
\hline \multirow{3}{*}{$\begin{array}{l}\text { United } \\
\text { States }\end{array}$} & 1 & 0.24 & 0.01 & 0.01 & 0.08 \\
\hline & 2 & 0.09 & 0.00 & 0.01 & -0.14 \\
\hline & 3 & 0.03 & 0.00 & -0.02 & 0.00 \\
\hline
\end{tabular}


C. Financial Factors (Model 3\&4)

\begin{tabular}{lcrrr}
\hline & Lags & $\begin{array}{r}\text { Own } \\
\text { Factor }\end{array}$ & $\begin{array}{r}\text { Global } \\
\text { Macro } \\
\text { Factor }\end{array}$ & $\begin{array}{r}\text { U.S. } \\
\text { Country } \\
\text { Factor }\end{array}$ \\
\hline \hline Financial Factor & & & & \\
Equity Prices & $\mathbf{1}$ & 0.36 & -0.09 & 0.42 \\
& $\mathbf{2}$ & -0.07 & -0.23 & 0.08 \\
House Prices & $\mathbf{3}$ & -0.03 & -0.02 & 0.00 \\
& $\mathbf{1}$ & 0.65 & 0.21 & 0.24 \\
& $\mathbf{2}$ & 0.07 & -0.43 & -0.01 \\
Interest Rates & $\mathbf{3}$ & -0.05 & -0.03 & 0.01 \\
& $\mathbf{1}$ & 0.19 & 0.02 & 0.13 \\
& $\mathbf{2}$ & -0.12 & -0.04 & -0.02 \\
& $\mathbf{3}$ & 0.02 & 0.07 & -0.01 \\
\hline
\end{tabular}

Notes: This table shows factor VAR coefficients (posterior medians) for the global macro factor and country-specific factors, based on the results of the combined Models 1 and 2 (in Panel A). The corresponding coefficients for financial factors are based on the results of the combined Model 3 and 4 (in Panel B). Combined Model 1 and 2 captures spillovers to the global macro factor (Model 1) and to country-specific macro factor (Model 2) through which the financial factor affects macro activity. Combined Model 3 and 4, which captures spillovers from the global macro factor (Model 3) and from the U.S. country factor (Model 4) through which the financial sector is affected. 
Table A4. Variance Decompositions for G-7 Countries

(Model 1\&2 and Model 3\&4; Country-Specific; 1998-2019)

\section{A. Canada}

\begin{tabular}{|c|c|c|c|c|c|c|c|c|c|c|c|c|c|c|c|}
\hline & \multicolumn{4}{|c|}{ Output } & \multicolumn{4}{|c|}{ Consumption } & \multicolumn{4}{|c|}{ Investment } & \multicolumn{3}{|c|}{ Financial } \\
\hline & $\mathbf{W}$ & C & SF & $\mathbf{I}$ & $\mathbf{W}$ & $\mathbf{C}$ & SF & I & $\mathbf{W}$ & $\mathbf{C}$ & SF & I & SR & $\mathbf{F}$ & I \\
\hline & \multicolumn{15}{|c|}{ Model 1\&2 } \\
\hline Equity prices & 26.2 & 12.7 & 13.1 & 48.1 & 22.9 & 9.6 & 11.2 & 56.3 & 40.1 & 3.7 & 37.5 & 18.7 & & 57.7 & 42.3 \\
\hline House prices & 32.5 & 11.4 & 12.5 & 43.5 & 28.2 & 6.4 & 10.6 & 54.8 & 46.4 & 6.5 & 29.9 & 17.1 & & 29.5 & 70.5 \\
\hline \multirow[t]{2}{*}{ Interest rates } & 40.8 & 9.5 & 5.6 & 44.1 & 34.6 & 7.8 & 4.7 & 52.9 & 55.8 & 5.9 & 31.2 & 7.2 & & 60.6 & 39.4 \\
\hline & \multicolumn{15}{|c|}{ Model 3\&4 } \\
\hline Equity prices & 38.4 & 16.6 & & 45.0 & 34.0 & 6.3 & & 59.7 & 56.4 & 6.8 & & 36.7 & 1.3 & 56.5 & 42.2 \\
\hline House prices & 39.4 & 14.7 & & 45.9 & 33.4 & 6.6 & & 60.0 & 56.8 & 9.6 & & 33.6 & 5.3 & 24.1 & 70.6 \\
\hline Interest rates & 38.1 & 19.2 & & 42.7 & 33.3 & 6.4 & & 60.3 & 56.0 & 6.6 & & 37.4 & 9.2 & 54.9 & 35.9 \\
\hline
\end{tabular}

\section{B. France}

\begin{tabular}{|c|c|c|c|c|c|c|c|c|c|c|c|c|c|c|c|}
\hline & \multicolumn{4}{|c|}{ Output } & \multicolumn{4}{|c|}{ Consumption } & \multicolumn{4}{|c|}{ Investment } & \multicolumn{3}{|c|}{ Financial } \\
\hline & $\mathbf{W}$ & C & SF & I & $\mathbf{W}$ & C & SF & I & $\mathbf{W}$ & C & SF & I & SR & $\mathbf{F}$ & I \\
\hline & \multicolumn{15}{|c|}{ Model 1\&2 } \\
\hline Equity prices & 48.3 & 15.5 & 24.1 & 12.1 & 6.8 & 30.5 & 6.7 & 56.0 & 36.4 & 5.5 & 40.6 & 17.5 & & 60.6 & 39.4 \\
\hline House prices & 55.3 & 13.3 & 20.6 & 10.8 & 8.9 & 33.2 & 5.2 & 52.7 & 47.9 & 4.4 & 30.3 & 17.4 & & 17.3 & 82.7 \\
\hline \multirow[t]{2}{*}{ Interest rates } & 66.2 & 14.0 & 8.9 & 10.9 & 10.9 & 30.8 & 3.3 & 55.0 & 57.7 & 4.8 & 30.1 & 7.3 & & 32.4 & 67.6 \\
\hline & \multicolumn{15}{|c|}{ Model 3\&4 } \\
\hline Equity prices & 69.0 & 17.7 & & 13.3 & 9.5 & 29.5 & & 61.0 & 52.1 & 6.5 & & 41.4 & 1.4 & 59.4 & 39.3 \\
\hline House prices & 69.5 & 17.8 & & 12.7 & 9.4 & 33.2 & & 57.3 & 58.5 & 6.2 & & 35.4 & 3.7 & 15.8 & 80.5 \\
\hline Interest rates & 67.9 & 18.7 & & 13.4 & 9.3 & 27.5 & & 63.3 & 50.5 & 7.4 & & 42.1 & 5.6 & 33.7 & 60.8 \\
\hline
\end{tabular}

\section{Germany}

\begin{tabular}{|c|c|c|c|c|c|c|c|c|c|c|c|c|c|c|c|}
\hline & \multicolumn{4}{|c|}{ Output } & \multicolumn{4}{|c|}{ Consumption } & \multicolumn{4}{|c|}{ Investment } & \multicolumn{3}{|c|}{ Financial } \\
\hline & $\mathbf{W}$ & $\mathbf{C}$ & SF & I & $\mathbf{W}$ & $\mathbf{C}$ & SF & I & $\mathbf{W}$ & $\mathbf{C}$ & SF & I & SR & $\mathbf{F}$ & I \\
\hline & \multicolumn{15}{|c|}{ Model 1\&2 } \\
\hline Equity prices & 46.4 & 15.4 & 22.3 & 15.9 & 0.6 & 25.1 & 2.0 & 72.2 & 22.5 & 25.1 & 40.3 & 12.2 & & 62.3 & 37.7 \\
\hline House prices & 52.5 & 14.6 & 19.6 & 13.4 & 0.8 & 22.7 & 1.6 & 74.8 & 27.7 & 24.2 & 36.7 & 11.3 & & 3.9 & 96.1 \\
\hline \multirow[t]{2}{*}{ Interest rates } & 62.2 & 15.9 & 8.2 & 13.7 & 1.1 & 21.7 & 1.1 & 76.2 & 32.5 & 26.8 & 35.5 & 5.2 & & 17.8 & 82.2 \\
\hline & \multicolumn{15}{|c|}{ Model 3\&4 } \\
\hline Equity prices & 64.7 & 18.5 & & 16.9 & 0.8 & 22.7 & & 76.5 & 30.0 & 31.7 & & 38.3 & 1.4 & 59.4 & 39.3 \\
\hline House prices & 65.0 & 19.3 & & 15.7 & 0.9 & 22.2 & & 77.0 & 30.5 & 30.3 & & 39.2 & 1.0 & 4.5 & 94.6 \\
\hline Interest rates & 63.3 & 19.5 & & 17.2 & 0.8 & 24.4 & & 74.8 & 28.4 & 31.8 & & 39.8 & 4.0 & 24.4 & 71.6 \\
\hline
\end{tabular}




\section{Italy}

\begin{tabular}{|c|c|c|c|c|c|c|c|c|c|c|c|c|c|c|c|}
\hline & \multicolumn{4}{|c|}{ Output } & \multicolumn{4}{|c|}{ Consumption } & \multicolumn{4}{|c|}{ Investment } & \multicolumn{3}{|c|}{ Financial } \\
\hline & $\mathbf{W}$ & $\mathbf{C}$ & SF & $\mathbf{I}$ & $\mathbf{W}$ & C & SF & $\mathbf{I}$ & $\mathbf{W}$ & $\mathbf{C}$ & SF & $\mathbf{I}$ & SR & $\mathbf{F}$ & I \\
\hline & \multicolumn{15}{|c|}{ Model 1\&2 } \\
\hline Equity prices & 46.0 & 16.2 & 22.4 & 15.4 & 5.8 & 53.2 & 6.8 & 34.3 & 15.4 & 14.5 & 61.8 & 8.3 & & 45.5 & 54.5 \\
\hline House prices & 52.2 & 14.2 & 20.1 & 13.5 & 8.7 & 50.2 & 8.2 & 32.8 & 19.5 & 14.2 & 57.8 & 8.5 & & 42.1 & 57.9 \\
\hline \multirow[t]{2}{*}{ Interest rates } & 62.4 & 14.5 & 8.9 & 14.2 & 11.3 & 49.9 & 6.1 & 32.7 & 23.7 & 14.3 & 57.7 & 4.3 & & 13.7 & 86.3 \\
\hline & \multicolumn{15}{|c|}{ Model 3\&4 } \\
\hline Equity prices & 66.4 & 17.2 & & 16.4 & 10.0 & 54.5 & & 35.5 & 22.1 & 15.4 & & 62.5 & 1.0 & 44.6 & 54.3 \\
\hline House prices & 65.5 & 17.8 & & 16.7 & 9.4 & 55.9 & & 34.6 & 21.5 & 15.9 & & 62.6 & 8.2 & 39.7 & 52.1 \\
\hline Interest rates & 64.4 & 19.0 & & 16.6 & 9.5 & 54.3 & & 36.2 & 21.0 & 16.9 & & 62.0 & 2.4 & 14.3 & 83.3 \\
\hline
\end{tabular}

\section{E. Japan}

\begin{tabular}{|c|c|c|c|c|c|c|c|c|c|c|c|c|c|c|c|}
\hline & \multicolumn{4}{|c|}{ Output } & \multicolumn{4}{|c|}{ Consumption } & \multicolumn{4}{|c|}{ Investment } & \multicolumn{3}{|c|}{ Financial } \\
\hline & $\mathbf{W}$ & $\mathbf{C}$ & SF & I & $\mathbf{W}$ & $\mathbf{C}$ & SF & I & $\mathbf{W}$ & $\mathbf{C}$ & SF & I & SR & $\mathbf{F}$ & I \\
\hline & \multicolumn{15}{|c|}{ Model 1\&2 } \\
\hline Equity prices & 24.0 & 39.8 & 13.4 & 22.8 & 2.2 & 50.6 & 3.8 & 43.4 & 9.7 & 21.9 & 62.6 & 5.8 & & 34.0 & 66.0 \\
\hline House prices & 28.5 & 38.2 & 12.9 & 20.4 & 3.0 & 49.9 & 4.5 & 42.7 & 12.4 & 21.8 & 59.9 & 6.0 & & 10.1 & 89.9 \\
\hline \multirow[t]{2}{*}{ Interest rates } & 34.6 & 38.6 & 5.9 & 20.9 & 3.8 & 50.2 & 2.5 & 43.4 & 15.1 & 22.1 & 59.9 & 2.8 & & 13.6 & 86.4 \\
\hline & \multicolumn{15}{|c|}{ Model 3\&4 } \\
\hline Equity prices & 33.9 & 42.8 & & 23.3 & 3.5 & 53.1 & & 43.4 & 13.4 & 24.6 & & 62.0 & 0.8 & 33.5 & 65.7 \\
\hline House prices & 34.1 & 43.0 & & 22.9 & 3.5 & 53.3 & & 43.2 & 13.6 & 24.3 & & 62.2 & 2.4 & 11.0 & 86.6 \\
\hline Interest rates & 33.9 & 42.5 & & 23.6 & 3.7 & 52.0 & & 44.3 & 13.6 & 23.9 & & 62.6 & 1.9 & 11.1 & 87.0 \\
\hline
\end{tabular}

\section{F. United Kingdom}

\begin{tabular}{|c|c|c|c|c|c|c|c|c|c|c|c|c|c|c|c|}
\hline & \multicolumn{4}{|c|}{ Output } & \multicolumn{4}{|c|}{ Consumption } & \multicolumn{4}{|c|}{ Investment } & \multicolumn{3}{|c|}{ Financial } \\
\hline & $\mathbf{W}$ & $\mathbf{C}$ & SF & I & $\mathbf{W}$ & C & SF & I & $\mathbf{W}$ & $\mathbf{C}$ & SF & I & SR & $\mathbf{F}$ & I \\
\hline & \multicolumn{15}{|c|}{ Model 1\&2 } \\
\hline Equity prices & 27.8 & 32.8 & 15.4 & 24.0 & 10.3 & 9.5 & 5.5 & 74.7 & 6.4 & 3.3 & 87.0 & 3.3 & & 79.2 & 20.8 \\
\hline House prices & 35.5 & 27.7 & 16.2 & 20.5 & 14.3 & 7.7 & 6.1 & 72.0 & 8.8 & 3.2 & 84.4 & 3.6 & & 32.3 & 67.7 \\
\hline \multirow[t]{2}{*}{ Interest rates } & 43.5 & 28.4 & 6.9 & 21.2 & 17.2 & 7.8 & 2.6 & 72.4 & 11.2 & 3.4 & 83.8 & 1.6 & & 13.8 & 86.2 \\
\hline & \multicolumn{15}{|c|}{ Model 3\&4 } \\
\hline Equity prices & 43.5 & 32.6 & & 24.0 & 15.9 & 8.4 & & 75.7 & 9.7 & 3.5 & & 86.8 & 1.8 & 78.0 & 20.2 \\
\hline House prices & 43.9 & 32.3 & & 23.7 & 15.9 & 8.1 & & 76.0 & 9.9 & 3.5 & & 86.6 & 5.5 & 25.4 & 69.1 \\
\hline Interest rates & 42.9 & 32.8 & & 24.4 & 15.2 & 8.3 & & 76.4 & 9.3 & 3.6 & & 87.1 & 3.0 & 17.7 & 79.2 \\
\hline
\end{tabular}




\section{G. United States}

\begin{tabular}{|c|c|c|c|c|c|c|c|c|c|c|c|c|c|c|c|}
\hline & \multicolumn{4}{|c|}{ Output } & \multicolumn{4}{|c|}{ Consumption } & \multicolumn{4}{|c|}{ Investment } & \multicolumn{3}{|c|}{ Financial } \\
\hline & $\mathbf{W}$ & $\mathbf{C}$ & SF & $\mathbf{I}$ & $\mathbf{W}$ & $\mathbf{C}$ & SF & I & $\mathbf{W}$ & $\mathbf{C}$ & SF & $\mathbf{I}$ & SR & $\mathbf{F}$ & I \\
\hline & \multicolumn{15}{|c|}{ Model 1\&2 } \\
\hline Equity prices & 16.5 & 38.6 & 10.4 & 34.5 & 9.8 & 36.4 & 7.1 & 46.7 & 24.3 & 38.7 & 23.0 & 14.0 & & 75.6 & 24.4 \\
\hline House prices & 22.1 & 33.6 & 10.6 & 33.8 & 14.5 & 32.2 & 7.8 & 45.5 & 31.1 & 33.6 & 21.5 & 13.8 & & 4.6 & 95.4 \\
\hline \multirow[t]{2}{*}{ Interest rates } & 26.6 & 34.1 & 5.5 & 33.8 & 17.7 & 31.9 & 4.3 & 46.2 & 37.0 & 34.6 & 21.6 & 6.7 & & 64.4 & 35.6 \\
\hline & \multicolumn{15}{|c|}{ Model 3\&4 } \\
\hline Equity prices & 27.1 & 39.8 & & 33.1 & 16.9 & 35.8 & & 47.3 & 37.8 & 39.3 & & 22.9 & 1.7 & 74.6 & 23.7 \\
\hline House prices & 29.0 & 37.2 & & 33.8 & 18.8 & 32.7 & & 48.5 & 39.9 & 37.5 & & 22.6 & 1.1 & 5.1 & 93.8 \\
\hline Interest rates & 27.6 & 39.2 & & 33.3 & 17.3 & 35.1 & & 47.7 & 38.3 & 38.7 & & 23.0 & 8.6 & 51.1 & 40.3 \\
\hline
\end{tabular}

Notes: This table shows the country-specific variance shares attributable to spillovers from the financial (equity prices, house prices, and interest rates) to macroeconomic aggregates (model 1\&2) and from the macroeconomy to financial sector (model 3\&4). The variance contributions are attributed to: W (global macro factor), C (countryspecific macro factor), SF (spillovers from financial to macro factors), F (global financial factor), and I (idiosyncratic factor) in the case of the combined Model $1 \& 2$, and $\mathrm{W}$ (global macro factor), $\mathrm{C}$ (country-specific macro factor), SR (spillovers from macro to financial factors), F (global financial factor), and I (idiosyncratic factor) in the case of the Model $3 \& 4$. 
Table A5. Confidence bands for Variance decompositions (Average across G-7 countries; Model 1\&2)

\section{A. Equity Prices}

\begin{tabular}{|c|c|c|c|c|c|c|c|c|c|c|c|c|c|c|}
\hline & \multicolumn{4}{|c|}{ Output } & \multicolumn{4}{|c|}{ Consumption } & \multicolumn{4}{|c|}{ Investment } & \multicolumn{2}{|c|}{ Equity prices } \\
\hline & W & $\mathbf{C}$ & SF & I & $\mathbf{W}$ & $\mathbf{C}$ & SF & I & W & C & SF & I & $\mathbf{F}$ & $\mathbf{I}$ \\
\hline & \multicolumn{14}{|c|}{ 1985-2019 } \\
\hline Mean & 31.7 & 33.6 & 8.7 & 26.0 & 7.3 & 29.6 & 2.9 & 60.3 & 20.6 & 22.5 & 5.7 & 51.2 & 55.9 & 44.1 \\
\hline $33 \%$ & 27.9 & 29.5 & 6.4 & 23.1 & 5.4 & 24.9 & 1.9 & 56.5 & 17.4 & 17.9 & 4.0 & 49.0 & 53.4 & 41.3 \\
\hline \multirow[t]{2}{*}{$66 \%$} & 33.8 & 37.1 & 9.8 & 29.3 & 8.2 & 32.9 & 3.2 & 64.5 & 22.3 & 24.1 & 6.4 & 55.3 & 58.5 & 46.4 \\
\hline & \multicolumn{14}{|c|}{ 1985-2007 } \\
\hline Mean & 21.5 & 39.0 & 6.5 & 33.0 & 6.8 & 29.5 & 3.0 & 60.6 & 17.0 & 23.0 & 4.8 & 55.2 & 50.4 & 49.6 \\
\hline $33 \%$ & 18.5 & 32.6 & 4.7 & 27.2 & 4.8 & 24.1 & 2.0 & 55.0 & 14.0 & 17.5 & 3.2 & 49.8 & 47.2 & 45.7 \\
\hline \multirow[t]{2}{*}{$66 \%$} & 26.2 & 42.1 & 8.3 & 34.8 & 8.9 & 32.8 & 3.8 & 64.1 & 20.7 & 24.6 & 6.1 & 58.5 & 54.1 & 52.5 \\
\hline & \multicolumn{14}{|c|}{ 1998-2019 } \\
\hline Mean & 33.6 & 24.4 & 17.3 & 24.7 & 8.3 & 30.7 & 6.2 & 54.8 & 22.1 & 16.1 & 11.4 & 50.4 & 59.3 & 40.7 \\
\hline $33 \%$ & 29.7 & 19.6 & 13.7 & 21.2 & 6.0 & 24.7 & 4.2 & 49.9 & 18.8 & 12.3 & 8.6 & 46.6 & 56.0 & 36.8 \\
\hline $66 \%$ & 36.5 & 27.1 & 19.7 & 27.4 & 9.5 & 34.3 & 7.0 & 60.1 & 24.5 & 18.0 & 12.9 & 53.7 & 63.0 & 43.7 \\
\hline
\end{tabular}

\section{B. House Price}

\begin{tabular}{|c|c|c|c|c|c|c|c|c|c|c|c|c|c|c|}
\hline & \multicolumn{4}{|c|}{ Output } & \multicolumn{4}{|c|}{ Consumption } & \multicolumn{4}{|c|}{ Investment } & \multicolumn{2}{|c|}{ House prices } \\
\hline & $\mathbf{W}$ & C & SF & I & $\mathbf{W}$ & $\mathbf{C}$ & SF & I & $\mathbf{W}$ & C & SF & I & $\mathbf{F}$ & $\mathbf{I}$ \\
\hline & \multicolumn{14}{|c|}{ 1985-2019 } \\
\hline Mean & 33.0 & 33.7 & 8.2 & 25.2 & 7.8 & 29.0 & 3.1 & 60.1 & 21.4 & 22.1 & 5.4 & 51.2 & 12.4 & 87.6 \\
\hline $33 \%$ & 29.3 & 29.4 & 5.0 & 21.5 & 5.8 & 24.5 & 1.8 & 56.9 & 18.2 & 18.0 & 3.1 & 48.0 & 2.6 & 85.6 \\
\hline \multirow[t]{2}{*}{$66 \%$} & 35.9 & 37.2 & 9.5 & 28.0 & 8.9 & 31.6 & 3.5 & 64.4 & 23.7 & 24.4 & 6.2 & 54.3 & 13.8 & 97.2 \\
\hline & \multicolumn{14}{|c|}{ 1985-2007 } \\
\hline Mean & 19.2 & 41.8 & 5.9 & 33.2 & 5.5 & 30.2 & 3.2 & 61.0 & 16.3 & 25.2 & 4.2 & 54.3 & 9.6 & 90.4 \\
\hline $33 \%$ & 15.4 & 36.1 & 2.9 & 28.4 & 3.4 & 24.9 & 1.4 & 56.4 & 12.1 & 19.5 & 2.0 & 49.9 & 2.1 & 90.2 \\
\hline \multirow[t]{2}{*}{$66 \%$} & 22.1 & 46.0 & 6.2 & 36.7 & 6.3 & 34.0 & 3.3 & 66.1 & 19.0 & 28.1 & 4.4 & 58.8 & 9.4 & 97.7 \\
\hline & \multicolumn{14}{|c|}{ 1998-2019 } \\
\hline Mean & 39.8 & 21.9 & 16.1 & 22.3 & 11.2 & 28.9 & 6.3 & 53.6 & 27.7 & 15.4 & 11.1 & 45.8 & 20.0 & 80.0 \\
\hline $33 \%$ & 50.1 & 8.1 & 8.0 & 8.9 & 14.8 & 18.5 & 3.9 & 36.3 & 36.8 & 6.9 & 6.1 & 23.7 & 14.2 & 76.3 \\
\hline $66 \%$ & 69.4 & 15.5 & 15.7 & 16.0 & 30.6 & 27.9 & 7.4 & 49.8 & 56.4 & 12.6 & 11.8 & 36.7 & 23.4 & 85.5 \\
\hline
\end{tabular}




\section{Interest Rates}

\begin{tabular}{|c|c|c|c|c|c|c|c|c|c|c|c|c|c|c|}
\hline & \multicolumn{4}{|c|}{ Output } & \multicolumn{4}{|c|}{ Consumption } & \multicolumn{4}{|c|}{ Investment } & \multicolumn{2}{|c|}{ Interest rates } \\
\hline & $\mathbf{W}$ & C & SF & I & $\mathbf{W}$ & C & SF & I & $\mathbf{W}$ & C & SF & I & $\mathbf{F}$ & I \\
\hline & \multicolumn{14}{|c|}{ 1985-2019 } \\
\hline Mean & 38.9 & 32.6 & 3.0 & 25.5 & 9.9 & 27.6 & 1.6 & 61.0 & 25.6 & 22.9 & 2.1 & 49.5 & 24.6 & 75.4 \\
\hline $33 \%$ & 35.3 & 28.2 & 1.7 & 22.3 & 7.5 & 23.5 & 0.9 & 57.5 & 22.2 & 18.8 & 1.1 & 46.4 & 20.3 & 71.7 \\
\hline \multirow[t]{2}{*}{$66 \%$} & 42.0 & 35.9 & 3.2 & 28.3 & 11.3 & 30.5 & 1.7 & 64.6 & 28.1 & 25.4 & 2.2 & 53.2 & 28.0 & 79.4 \\
\hline & \multicolumn{14}{|c|}{ 1985-2007 } \\
\hline Mean & 20.6 & 41.4 & 5.9 & 32.1 & 6.4 & 33.0 & 3.6 & 57.0 & 18.4 & 26.4 & 4.5 & 50.7 & 24.9 & 75.1 \\
\hline $33 \%$ & 16.9 & 35.7 & 3.0 & 26.6 & 4.2 & 27.1 & 1.7 & 51.1 & 14.7 & 20.8 & 2.4 & 45.8 & 19.3 & 70.8 \\
\hline \multirow[t]{2}{*}{$66 \%$} & 22.7 & 46.4 & 6.2 & 36.2 & 7.2 & 37.7 & 3.7 & 62.7 & 20.5 & 29.6 & 4.8 & 55.9 & 28.9 & 80.4 \\
\hline & \multicolumn{14}{|c|}{ 1998-2019 } \\
\hline Mean & 48.0 & 22.2 & 7.1 & 22.7 & 13.8 & 28.6 & 3.5 & 54.1 & 33.3 & 16.0 & 5.0 & 45.7 & 30.9 & 69.1 \\
\hline $33 \%$ & 43.0 & 17.4 & 3.9 & 19.0 & 9.7 & 22.7 & 1.8 & 49.3 & 28.2 & 11.9 & 2.7 & 41.6 & 26.6 & 65.4 \\
\hline $66 \%$ & 51.9 & 24.8 & 8.0 & 25.5 & 15.5 & 31.8 & 3.8 & 59.7 & 36.5 & 17.9 & 5.5 & 49.8 & 34.3 & 73.2 \\
\hline
\end{tabular}

Notes: In each cell, posterior median and 16 and 84 percentiles of the variance share attributable to the relevant factor at a horizon of 30th quarter is reported. The variance contributions are attributed to: $\mathrm{W}$ (global macro factor), $\mathrm{C}$ (country-specific macro factor), SF (spillovers from financial to macro factors), $\mathrm{F}$ (global financial factor), and I (idiosyncratic factor). Combined Model 1 and 2 captures spillovers to the global macro factor and to country-specific macro factor through which the financial factor affects macro activity. 
Table A6. Confidence bands for Variance decompositions (Average across G-7 countries; Model 3+4)

A. Equity Prices

\begin{tabular}{|c|c|c|c|c|c|c|c|c|c|c|c|c|}
\hline & \multicolumn{3}{|c|}{ Output } & \multicolumn{3}{|c|}{ Consumption } & \multicolumn{3}{|c|}{ Investment } & \multicolumn{3}{|c|}{ Equity prices } \\
\hline & $\mathbf{W}$ & C & I & $\mathbf{W}$ & $\mathbf{C}$ & I & $\mathbf{W}$ & C & $\mathbf{I}$ & SR & $\mathbf{F}$ & I \\
\hline & \multicolumn{12}{|c|}{ 1985-2019 } \\
\hline Mean & 39.2 & 34.4 & 26.4 & 9.6 & 29.0 & 61.4 & 25.3 & 24.5 & 50.1 & 1.0 & 55.1 & 43.9 \\
\hline $33 \%$ & 35.7 & 30.1 & 23.0 & 7.2 & 24.7 & 58.1 & 21.9 & 20.4 & 46.9 & 0.4 & 52.6 & 41.1 \\
\hline \multirow[t]{2}{*}{$66 \%$} & 42.6 & 37.6 & 28.9 & 10.9 & 31.9 & 65.2 & 28.1 & 27.1 & 53.3 & 1.0 & 57.7 & 46.3 \\
\hline & \multicolumn{12}{|c|}{$1985-2007$} \\
\hline Mean & 25.3 & 41.1 & 33.6 & 8.0 & 30.4 & 61.6 & 19.0 & 25.5 & 55.4 & 0.8 & 50.4 & 48.8 \\
\hline $33 \%$ & 20.7 & 36.0 & 29.2 & 5.0 & 25.0 & 57.0 & 14.7 & 20.4 & 51.1 & 0.3 & 47.2 & 45.0 \\
\hline \multirow[t]{2}{*}{$66 \%$} & 28.2 & 45.4 & 36.9 & 9.1 & 34.4 & 66.3 & 21.6 & 28.5 & 59.7 & 0.8 & 53.9 & 51.8 \\
\hline & \multicolumn{12}{|c|}{ 1998-2019 } \\
\hline Mean & 49.0 & 26.4 & 24.6 & 12.9 & 30.0 & 57.0 & 31.7 & 18.3 & 50.1 & 1.3 & 58.3 & 40.4 \\
\hline $33 \%$ & 45.1 & 21.3 & 20.9 & 9.7 & 24.6 & 52.6 & 27.6 & 14.0 & 46.3 & 0.6 & 55.1 & 36.6 \\
\hline $66 \%$ & 52.9 & 29.5 & 27.4 & 14.8 & 33.3 & 61.8 & 35.1 & 20.4 & 53.6 & 1.4 & 61.8 & 43.4 \\
\hline
\end{tabular}

B. House Prices

\begin{tabular}{|c|c|c|c|c|c|c|c|c|c|c|c|c|}
\hline & \multicolumn{3}{|c|}{ Output } & \multicolumn{3}{|c|}{ Consumption } & \multicolumn{3}{|c|}{ Investment } & \multicolumn{3}{|c|}{ House prices } \\
\hline & $\mathbf{W}$ & $\mathbf{C}$ & I & $\mathbf{W}$ & C & $\mathbf{I}$ & $\mathbf{W}$ & $\mathbf{C}$ & $\mathbf{I}$ & SR & $\mathbf{F}$ & $\mathbf{I}$ \\
\hline & \multicolumn{12}{|c|}{ 1985-2019 } \\
\hline Mean & 39.8 & 34.2 & 26.0 & 9.8 & 28.8 & 61.5 & 25.8 & 24.3 & 50.0 & 1.2 & 11.0 & 87.8 \\
\hline $33 \%$ & 36.2 & 29.9 & 22.8 & 7.4 & 24.6 & 58.1 & 22.3 & 20.3 & 46.6 & 0.2 & 2.3 & 84.1 \\
\hline \multirow[t]{2}{*}{$66 \%$} & 43.0 & 37.6 & 28.4 & 11.2 & 31.8 & 65.2 & 28.4 & 26.9 & 53.2 & 1.2 & 13.8 & 97.3 \\
\hline & \multicolumn{12}{|c|}{ 1985-2007 } \\
\hline Mean & 23.2 & 42.2 & 34.7 & 7.0 & 30.3 & 62.7 & 17.7 & 25.6 & 56.6 & 0.9 & 8.5 & 90.7 \\
\hline $33 \%$ & 20.1 & 37.0 & 28.9 & 4.7 & 26.0 & 57.1 & 14.1 & 20.3 & 52.1 & 0.3 & 4.5 & 86.6 \\
\hline \multirow[t]{2}{*}{$66 \%$} & 27.6 & 46.5 & 36.7 & 8.6 & 34.8 & 66.1 & 20.8 & 28.4 & 60.5 & 0.9 & 11.9 & 94.7 \\
\hline & \multicolumn{12}{|c|}{ 1998-2019 } \\
\hline Mean & 49.5 & 26.0 & 24.5 & 13.0 & 30.3 & 56.7 & 33.0 & 18.2 & 48.9 & 3.9 & 17.9 & 78.2 \\
\hline $33 \%$ & 20.1 & 37.0 & 28.9 & 4.7 & 26.0 & 57.1 & 14.1 & 20.3 & 52.1 & 0.3 & 4.5 & 86.6 \\
\hline $66 \%$ & 27.6 & 46.5 & 36.7 & 8.6 & 34.8 & 66.1 & 20.8 & 28.4 & 60.5 & 3.9 & 11.9 & 94.7 \\
\hline
\end{tabular}




\section{Interest Rates}

\begin{tabular}{|c|c|c|c|c|c|c|c|c|c|c|c|c|}
\hline & \multicolumn{3}{|c|}{ Output } & \multicolumn{3}{|c|}{ Consumption } & \multicolumn{3}{|c|}{ Investment } & \multicolumn{3}{|c|}{ Interest rates } \\
\hline & $\mathbf{W}$ & C & I & W & C & I & W & C & I & SR & $\mathbf{F}$ & I \\
\hline & \multicolumn{12}{|c|}{$1985-2019$} \\
\hline Mean & 39.1 & 34.6 & 26.3 & 9.5 & 28.7 & 61.7 & 25.2 & 24.6 & 50.2 & 2.5 & 24.3 & 73.2 \\
\hline $33 \%$ & 35.7 & 30.4 & 23.0 & 7.3 & 24.5 & 58.5 & 22.0 & 20.7 & 47.0 & 1.5 & 20.2 & 69.5 \\
\hline \multirow[t]{2}{*}{$66 \%$} & 42.1 & 37.9 & 28.9 & 10.9 & 31.6 & 65.5 & 27.8 & 27.2 & 53.3 & 2.8 & 27.4 & 77.4 \\
\hline & \multicolumn{12}{|c|}{ 1985-2007 } \\
\hline Mean & 24.2 & 41.7 & 34.1 & 7.3 & 31.7 & 61.0 & 18.1 & 24.7 & 57.2 & 4.3 & 23.4 & 72.3 \\
\hline $33 \%$ & 20.0 & 36.5 & 29.6 & 4.7 & 26.4 & 56.6 & 14.1 & 19.9 & 52.9 & 2.5 & 18.6 & 67.7 \\
\hline \multirow[t]{2}{*}{$66 \%$} & 26.9 & 46.0 & 37.5 & 8.3 & 35.6 & 65.7 & 20.4 & 27.8 & 61.4 & 4.8 & 27.1 & 77.7 \\
\hline & \multicolumn{12}{|c|}{ 1998-2019 } \\
\hline Mean & 48.3 & 27.2 & 24.4 & 12.7 & 29.7 & 57.6 & 31.0 & 18.4 & 50.6 & 4.9 & 29.6 & 65.4 \\
\hline $33 \%$ & 44.8 & 21.1 & 21.7 & 9.2 & 24.9 & 51.9 & 27.4 & 14.1 & 46.5 & 3.2 & 25.1 & 61.5 \\
\hline $66 \%$ & 52.5 & 28.9 & 28.2 & 14.4 & 34.6 & 61.5 & 34.7 & 20.4 & 53.7 & 5.6 & 32.6 & 70.2 \\
\hline
\end{tabular}

Notes: In each cell, posterior median and 16 and 84 percentiles of the variance share attributable to the relevant factor at a horizon of 30th quarter is reported. The variance contributions are attributed to: $\mathrm{W}$ (global macro factor), C (country-specific macro factor), SR (spillover from macro factors to global financial factor), F (global financial factor), and I (idiosyncratic factor). Combined Model 3 and 4, which captures spillovers from the global macro factor and from the U.S. country factor through which the financial sector is affected. 
Table A7. Variance decomposition

(Average across G-7, HP filtered data)

A. Equity Price

\begin{tabular}{|c|c|c|c|c|c|c|c|c|c|c|c|c|c|c|c|}
\hline & \multicolumn{4}{|c|}{ Output } & \multicolumn{4}{|c|}{ Consumption } & \multicolumn{4}{|c|}{ Investment } & \multicolumn{3}{|c|}{ Financial } \\
\hline & $\mathbf{W}$ & C & SF & $\mathbf{I}$ & $\mathbf{W}$ & $\mathbf{C}$ & SF & I & $\mathbf{W}$ & $\mathbf{C}$ & SF & $\mathbf{I}$ & SR & $\mathbf{F}$ & $\mathbf{I}$ \\
\hline & \multicolumn{15}{|c|}{ Model 1} \\
\hline $1985-2019$ & 46.8 & 26.0 & 5.2 & 22.0 & 14.6 & 27.5 & 1.5 & 56.4 & 33.8 & 20.2 & 3.6 & 42.4 & & 55.2 & 44.8 \\
\hline $1985-2007$ & 31.6 & 34.4 & 5.0 & 29.0 & 12.2 & 27.2 & 1.9 & 58.6 & 25.9 & 22.4 & 4.1 & 47.7 & & 50.9 & 49.1 \\
\hline \multirow[t]{2}{*}{ 1998-2019 } & 34.4 & 25.4 & 15.1 & 25.2 & 8.8 & 31.3 & 3.8 & 56.1 & 22.4 & 17.5 & 9.8 & 50.2 & & 57.5 & 42.5 \\
\hline & \multicolumn{15}{|c|}{ Model 2} \\
\hline 1985-2019 & 51.2 & 26.0 & 0.9 & 21.9 & 15.8 & 29.0 & 1.1 & 54.1 & 36.7 & 19.3 & 0.7 & 43.3 & & 55.3 & 44.7 \\
\hline $1985-2007$ & 34.9 & 33.6 & 1.9 & 29.6 & 13.2 & 28.3 & 1.6 & 56.9 & 28.1 & 22.2 & 1.4 & 48.4 & & 50.7 & 49.3 \\
\hline \multirow[t]{2}{*}{ 1998-2019 } & 55.7 & 21.3 & 1.5 & 21.5 & 17.9 & 28.1 & 2.0 & 52.1 & 39.4 & 15.7 & 1.0 & 43.8 & & 57.0 & 43.0 \\
\hline & \multicolumn{15}{|c|}{ Model 3} \\
\hline $1985-2019$ & 46.2 & 30.2 & & 23.6 & 13.3 & 28.5 & & 58.3 & 32.2 & 22.1 & & 45.8 & 0.5 & 55.5 & 43.9 \\
\hline $1985-2007$ & 34.8 & 35.7 & & 29.5 & 13.0 & 29.2 & & 57.7 & 27.3 & 24.8 & & 47.9 & 0.4 & 50.6 & 48.9 \\
\hline \multirow[t]{2}{*}{ 1998-2019 } & 47.3 & 26.6 & & 26.1 & 12.7 & 31.7 & & 55.6 & 31.0 & 18.5 & & 50.5 & 0.8 & 56.2 & 43.1 \\
\hline & \multicolumn{15}{|c|}{ Model 4} \\
\hline 1985-2019 & 58.1 & 23.1 & & 18.8 & 19.9 & 26.1 & & 54.0 & 42.4 & 18.6 & & 39.0 & 0.2 & 55.2 & 44.6 \\
\hline $1985-2007$ & 39.5 & 32.3 & & 28.3 & 15.6 & 27.3 & & 57.2 & 31.8 & 22.7 & & 45.5 & 0.3 & 50.9 & 48.8 \\
\hline $1998-2019$ & 47.0 & 27.2 & & 25.7 & 12.5 & 30.0 & & 57.5 & 30.6 & 18.0 & & 51.4 & 0.4 & 56.4 & 43.2 \\
\hline
\end{tabular}

\section{B. House price}

\begin{tabular}{|c|c|c|c|c|c|c|c|c|c|c|c|c|c|c|c|}
\hline & \multicolumn{4}{|c|}{ Output } & \multicolumn{4}{|c|}{ Consumption } & \multicolumn{4}{|c|}{ Investment } & \multicolumn{3}{|c|}{ House prices } \\
\hline & $\mathbf{W}$ & C & SF & $\mathbf{I}$ & $\mathbf{W}$ & C & SF & I & $\mathbf{W}$ & C & SF & $\mathbf{I}$ & SR & $\mathbf{F}$ & $\mathbf{I}$ \\
\hline & \multicolumn{15}{|c|}{ Model 1} \\
\hline $1985-2019$ & 36.5 & 32.3 & 4.1 & 27.1 & 9.2 & 30.0 & 1.0 & 59.8 & 24.2 & 22.8 & 2.7 & 50.2 & & 9.3 & 90.7 \\
\hline $1985-2007$ & 28.4 & 36.1 & 3.9 & 31.7 & 10.4 & 28.9 & 1.4 & 59.3 & 22.2 & 23.0 & 3.0 & 51.8 & & 8.2 & 91.8 \\
\hline \multirow[t]{2}{*}{ 1998-2019 } & 52.3 & 18.3 & 10.3 & 19.1 & 18.6 & 27.8 & 3.6 & 50.0 & 38.0 & 14.1 & 7.4 & 40.5 & & 15.8 & 84.2 \\
\hline & \multicolumn{15}{|c|}{ Model 2} \\
\hline $1985-2019$ & 42.4 & 31.2 & 1.8 & 24.7 & 11.4 & 28.1 & 1.5 & 58.9 & 28.9 & 21.8 & 1.2 & 48.0 & & 11.3 & 88.7 \\
\hline $1985-2007$ & 38.6 & 31.7 & 2.4 & 27.3 & 15.9 & 26.4 & 1.9 & 55.8 & 31.0 & 21.4 & 1.6 & 46.0 & & 9.1 & 90.9 \\
\hline \multirow[t]{2}{*}{ 1998-2019 } & 51.1 & 23.4 & 1.8 & 23.7 & 15.3 & 28.7 & 2.2 & 53.8 & 34.4 & 17.1 & 1.2 & 47.3 & & 15.6 & 84.4 \\
\hline & \multicolumn{15}{|c|}{ Model 3} \\
\hline $1985-2019$ & 47.0 & 29.2 & & 23.8 & 13.4 & 28.8 & & 57.7 & 31.4 & 22.5 & & 46.1 & 1.0 & 13.3 & 85.7 \\
\hline $1985-2007$ & 32.8 & 35.5 & & 31.8 & 12.2 & 30.2 & & 57.6 & 25.6 & 24.5 & & 49.9 & 0.5 & 10.4 & 89.1 \\
\hline \multirow[t]{2}{*}{ 1998-2019 } & 48.2 & 24.8 & & 27.0 & 13.0 & 30.8 & & 56.3 & 30.6 & 23.7 & & 45.7 & 2.1 & 16.7 & 81.2 \\
\hline & \multicolumn{15}{|c|}{ Model 4} \\
\hline $1985-2019$ & 51.3 & 26.9 & & 21.8 & 16.0 & 27.4 & & 56.6 & 34.9 & 21.0 & & 44.1 & 0.5 & 11.7 & 87.7 \\
\hline $1985-2007$ & 37.2 & 31.0 & & 31.7 & 14.6 & 27.4 & & 58.0 & 30.6 & 23.3 & & 46.2 & 0.3 & 8.2 & 91.5 \\
\hline 1998-2019 & 46.9 & 23.5 & & 29.5 & 12.4 & 29.5 & & 58.1 & 28.7 & 26.4 & & 44.9 & 0.7 & 17.0 & 82.3 \\
\hline
\end{tabular}


Panel C. Interest Rates

\begin{tabular}{|c|c|c|c|c|c|c|c|c|c|c|c|c|c|c|c|}
\hline & \multicolumn{4}{|c|}{ Output } & \multicolumn{4}{|c|}{ Consumption } & \multicolumn{4}{|c|}{ Investment } & \multicolumn{3}{|c|}{ Financial } \\
\hline & $\mathbf{W}$ & C & SF & $\mathbf{I}$ & $\mathbf{W}$ & C & SF & I & $\mathbf{W}$ & C & SF & $\mathbf{I}$ & SR & $\mathbf{F}$ & $\mathbf{I}$ \\
\hline & \multicolumn{15}{|c|}{ Model 1} \\
\hline $1985-2019$ & 50.1 & 26.4 & 1.9 & 21.6 & 15.9 & 27.2 & 0.6 & 56.3 & 36.0 & 20.0 & 1.3 & 42.6 & & 24.5 & 75.5 \\
\hline $1985-2007$ & 27.6 & 37.5 & 2.7 & 32.3 & 9.5 & 29.3 & 1.0 & 60.2 & 21.8 & 24.8 & 2.1 & 51.4 & & 24.1 & 75.9 \\
\hline \multirow[t]{2}{*}{$1998-2019$} & 62.2 & 15.9 & 6.7 & 15.2 & 23.7 & 26.0 & 2.6 & 47.7 & 46.4 & 13.0 & 5.0 & 35.5 & & 30.8 & 69.2 \\
\hline & \multicolumn{15}{|c|}{ Model 2} \\
\hline $1985-2019$ & 58.9 & 22.2 & 2.3 & 16.6 & 21.3 & 25.5 & 0.8 & 52.4 & 44.1 & 17.2 & 1.7 & 37.0 & & 24.5 & 75.5 \\
\hline $1985-2007$ & 43.0 & 29.5 & 1.6 & 25.9 & 18.3 & 26.3 & 1.4 & 53.9 & 35.0 & 19.9 & 1.2 & 43.9 & & 24.2 & 75.8 \\
\hline \multirow[t]{2}{*}{$1998-2019$} & 51.7 & 22.8 & 2.0 & 23.5 & 16.0 & 29.3 & 0.6 & 54.1 & 35.4 & 16.7 & 1.3 & 46.6 & & 30.7 & 69.3 \\
\hline & \multicolumn{15}{|c|}{ Model 3} \\
\hline $1985-2019$ & 38.2 & 34.7 & & 27.1 & 9.5 & 29.5 & & 61.1 & 25.2 & 24.4 & & 50.4 & 0.9 & 25.1 & 74.0 \\
\hline $1985-2007$ & 27.4 & 40.2 & & 32.4 & 9.1 & 29.6 & & 61.3 & 21.2 & 25.2 & & 53.6 & 2.4 & 24.4 & 73.2 \\
\hline \multirow[t]{2}{*}{$1998-2019$} & 48.2 & 27.0 & & 24.8 & 12.9 & 30.9 & & 56.2 & 31.8 & 18.0 & & 50.3 & 2.4 & 30.8 & 66.8 \\
\hline & \multicolumn{15}{|c|}{ Model 4} \\
\hline $1985-2019$ & 49.8 & 27.6 & & 22.7 & 15.5 & 27.4 & & 57.1 & 35.3 & 20.4 & & 44.3 & 1.1 & 23.8 & 75.0 \\
\hline $1985-2007$ & 44.7 & 29.8 & & 25.5 & 19.5 & 25.7 & & 54.7 & 35.1 & 22.1 & & 42.8 & 1.6 & 23.4 & 75.0 \\
\hline 1998-2019 & 52.5 & 24.5 & & 23.0 & 15.6 & 28.7 & & 55.7 & 35.5 & 17.0 & & 47.6 & 1.8 & 30.2 & 68.0 \\
\hline
\end{tabular}

Notes: In each cell, the variance share attributable to the relevant factor at a horizon of 30th quarter is reported. The variance contributions are attributed to: $\mathrm{W}$ (global macro factor), $\mathrm{C}$ (country-specific macro factor), SF (spillovers from financial to macro factors), SR (spillover from global financial factor), F (global financial factor), and I (idiosyncratic factor). Combined Model 1 and 2 captures spillovers to the global macro factor (Model 1) and to country-specific macro factor (Model 2) through which the financial factor affects macro activity. Combined Model 3 and 4, which captures spillovers from the global macro factor (Model 3) and from the U.S. country factor (Model 4) through which the financial sector is affected. 
Table A8. Variance Decompositions: Models with Only Macroeconomic Variables

A. $1985-2019$

\begin{tabular}{|c|c|c|c|c|c|c|c|c|c|}
\hline \multirow[b]{3}{*}{ Canada } & \multicolumn{3}{|c|}{ Output } & \multicolumn{3}{|c|}{ Consumption } & \multicolumn{3}{|c|}{ Investment } \\
\hline & \multirow{2}{*}{$\begin{array}{c}\text { Global } \\
39.4\end{array}$} & \multicolumn{2}{|c|}{ Variable Idios yncratic } & \multirow{2}{*}{$\begin{array}{c}\text { Global } \\
40.4\end{array}$} & \multicolumn{2}{|c|}{ Variable Idios yncratic } & \multirow{2}{*}{$\begin{array}{c}\text { Global } \\
8.3\end{array}$} & \multirow{2}{*}{$\begin{array}{c}\text { Variable } \\
55.8\end{array}$} & \multirow{2}{*}{$\begin{array}{c}\text { Idios yncratic } \\
35.9\end{array}$} \\
\hline & & 0.2 & 60.4 & & 18.7 & 40.9 & & & \\
\hline France & 32.9 & 19.6 & 47.5 & 13.5 & 11.8 & 74.6 & 46.3 & 0.2 & 53.5 \\
\hline Germany & 43.8 & 0.3 & 55.9 & 26.9 & 0.3 & 72.8 & 11.6 & 13.8 & 74.6 \\
\hline Italy & 0.0 & 83.6 & 16.4 & 12.8 & 1.7 & 85.5 & 1.6 & 0.4 & 98.0 \\
\hline Japan & 31.5 & 0.1 & 68.4 & 34.9 & 0.3 & 64.9 & 31.7 & 0.5 & 67.8 \\
\hline United Kingdom & 38.9 & 15.9 & 45.2 & 5.4 & 59.5 & 35.1 & 12.1 & 8.6 & 79.3 \\
\hline United States & 7.6 & 6.0 & 86.4 & 13.9 & 0.6 & 85.5 & 38.7 & 0.3 & 61.0 \\
\hline Average & 27.7 & 18.0 & 54.3 & 21.1 & 13.3 & 65.6 & 21.5 & 11.4 & 67.2 \\
\hline Median & 32.9 & 6.0 & 55.9 & 13.9 & 1.7 & 72.8 & 12.1 & 0.5 & 67.8 \\
\hline
\end{tabular}

B. $1985-2007$

\begin{tabular}{|c|c|c|c|c|c|c|c|c|c|}
\hline \multirow[b]{3}{*}{ Canada } & \multicolumn{3}{|c|}{ Output } & \multicolumn{3}{|c|}{ Consumption } & \multicolumn{3}{|c|}{ Investment } \\
\hline & \multirow{2}{*}{$\begin{array}{c}\text { Global } \\
55.3\end{array}$} & \multicolumn{2}{|c|}{ Variable Idios yncratic } & \multirow{2}{*}{$\begin{array}{c}\text { Global } \\
3.6\end{array}$} & \multicolumn{2}{|c|}{ Variable Idios yncratic } & \multirow{2}{*}{$\begin{array}{c}\text { Global } \\
11.1\end{array}$} & \multirow{2}{*}{$\begin{array}{c}\text { Variable } \\
3.3\end{array}$} & \multirow{2}{*}{$\begin{array}{c}\text { Idios yncratic } \\
85.7\end{array}$} \\
\hline & & 24.8 & 19.8 & & 1.9 & 94.5 & & & \\
\hline France & 63.8 & 0.4 & 35.9 & 0.1 & 1.0 & 98.9 & 0.3 & 35.5 & 64.2 \\
\hline Germany & 62.3 & 17.1 & 20.5 & 0.1 & 1.3 & 98.6 & 0.2 & 1.3 & 98.5 \\
\hline Italy & 42.2 & 40.7 & 17.1 & 1.2 & 5.2 & 93.6 & 0.2 & 2.9 & 96.9 \\
\hline Japan & 15.4 & 0.1 & 84.6 & 1.0 & 42.5 & 56.5 & 0.1 & 0.1 & 99.8 \\
\hline United Kingdom & 62.9 & 26.3 & 10.8 & 0.1 & 3.6 & 96.3 & 0.8 & 3.5 & 95.7 \\
\hline United States & 69.3 & 0.8 & 29.8 & 3.8 & 23.6 & 72.6 & 2.3 & 0.3 & 97.4 \\
\hline Average & 53.0 & 15.7 & 31.2 & 1.4 & 11.3 & 87.3 & 2.1 & 6.7 & 91.2 \\
\hline Median & 62.3 & 17.1 & 20.5 & 1.0 & 3.6 & 94.5 & 0.3 & 2.9 & 96.9 \\
\hline
\end{tabular}

C. $1998-2019$

\begin{tabular}{|c|c|c|c|c|c|c|c|c|c|}
\hline \multirow[b]{3}{*}{ Canada } & \multicolumn{3}{|c|}{ Output } & \multicolumn{3}{|c|}{ Consumption } & \multicolumn{3}{|c|}{ Investment } \\
\hline & \multirow{2}{*}{$\begin{array}{c}\text { Global } \\
37.4\end{array}$} & \multicolumn{2}{|c|}{ Variable Idiosyncratic } & \multirow{2}{*}{$\begin{array}{c}\text { Global } \\
23.6\end{array}$} & \multicolumn{2}{|c|}{ Variable Idiosyncratic } & \multirow{2}{*}{$\begin{array}{c}\text { Global } \\
37.5\end{array}$} & \multirow{2}{*}{$\begin{array}{c}\text { Variable } \\
7.1\end{array}$} & \multirow{2}{*}{$\begin{array}{c}\text { Idios yncratic } \\
55.4\end{array}$} \\
\hline & & 4.3 & 58.3 & & 3.7 & 72.7 & & & \\
\hline France & 60.7 & 0.8 & 38.5 & 12.3 & 0.3 & 87.4 & 50.9 & 0.8 & 48.3 \\
\hline Germany & 50.9 & 5.7 & 43.4 & 0.1 & 1.4 & 98.5 & 27.2 & 0.6 & 72.2 \\
\hline Italy & 51.5 & 9.3 & 39.3 & 17.4 & 2.2 & 80.5 & 26.5 & 21.6 & 51.9 \\
\hline Japan & 25.3 & 0.7 & 74.0 & 0.8 & 1.0 & 98.1 & 17.8 & 1.4 & 80.8 \\
\hline United Kingdom & 45.5 & 1.2 & 53.3 & 14.8 & 42.2 & 42.9 & 17.4 & 0.3 & 82.3 \\
\hline United States & 40.0 & 18.9 & 41.1 & 33.0 & 4.8 & 62.2 & 41.1 & 11.3 & 47.6 \\
\hline Average & 44.5 & 5.8 & 49.7 & 14.6 & 8.0 & 77.5 & 31.2 & 6.1 & 62.7 \\
\hline Median & 45.5 & 4.3 & 43.4 & 14.8 & 2.2 & 80.5 & 27.2 & 1.4 & 55.4 \\
\hline
\end{tabular}

Notes: In each cell, the variance share attributable to the relevant factor is reported. The variance contributions are attributed to: Global (global factor), Variable (variable-specific factor), and Idiosyncratic (idiosyncratic factor). The row marked "Average" represents unweighted averages of the variance contributions shown in each column. 
Table A9. Variance Decompositions:

Models with Macroeconomic and Financial variables (1985-2019)

\section{A. Equity prices}

\begin{tabular}{|c|c|c|c|c|c|c|c|c|}
\hline & \multicolumn{2}{|c|}{ Output } & \multicolumn{2}{|c|}{ Consumption } & \multicolumn{2}{|c|}{ Investment } & \multicolumn{2}{|c|}{ Equity price } \\
\hline & Global & Idiosyncratic & Global & Idiosyncratic & Global & Idiosyncratic & Global & Idiosyncratic \\
\hline Canada & 4.6 & 95.4 & 12.0 & 88.0 & 12.7 & 87.3 & 68.3 & 31.7 \\
\hline France & 7.1 & 92.9 & 1.5 & 98.5 & 3.6 & 96.4 & 49.6 & 50.4 \\
\hline Germany & 3.0 & 97.0 & 0.1 & 99.9 & 0.4 & 99.6 & 53.1 & 46.9 \\
\hline Italy & 7.8 & 92.2 & 4.8 & 95.2 & 1.1 & 98.9 & 34.2 & 65.8 \\
\hline Japan & 5.0 & 95.0 & 0.8 & 99.2 & 0.1 & 99.9 & 33.6 & 66.4 \\
\hline United Kingdom & 9.9 & 90.1 & 5.2 & 94.8 & 0.1 & 99.9 & 72.0 & 28.0 \\
\hline United States & 16.2 & 83.8 & 14.4 & 85.6 & 15.1 & 84.9 & 76.5 & 23.5 \\
\hline Average & 7.6 & 92.4 & 5.5 & 94.5 & 4.7 & 95.3 & 55.3 & 44.7 \\
\hline Median & 7.1 & 92.9 & 4.8 & 95.2 & 1.1 & 98.9 & 53.1 & 46.9 \\
\hline
\end{tabular}

\section{B. House prices}

\begin{tabular}{|c|c|c|c|c|c|c|c|c|}
\hline & \multicolumn{2}{|c|}{ Output } & \multicolumn{2}{|c|}{ Consumption } & \multicolumn{2}{|c|}{ Investment } & \multicolumn{2}{|c|}{ House prices } \\
\hline & Global & Idiosyncratic & Global & Idiosyncratic & Global & Idiosyncratic & Global & Idiosyncratic \\
\hline Canada & 26.4 & 73.6 & 14.8 & 85.2 & 30.2 & 69.8 & 11.7 & 88.3 \\
\hline France & 63.4 & 36.6 & 9.7 & 90.3 & 59.9 & 40.1 & 29.2 & 70.8 \\
\hline Germany & 35.3 & 64.7 & 0.5 & 99.5 & 20.8 & 79.2 & 0.1 & 99.9 \\
\hline Italy & 50.4 & 49.6 & 16.2 & 83.8 & 20.6 & 79.4 & 12.4 & 87.6 \\
\hline Japan & 22.9 & 77.1 & 2.7 & 97.3 & 10.0 & 90.0 & 2.9 & 97.1 \\
\hline United Kingdom & 29.7 & 70.3 & 10.9 & 89.1 & 9.2 & 90.8 & 16.6 & 83.4 \\
\hline United States & 26.5 & 73.5 & 16.2 & 83.8 & 30.0 & 70.0 & 0.3 & 99.7 \\
\hline Average & 36.4 & 63.6 & 10.1 & 89.9 & 25.8 & 74.2 & 10.5 & 89.5 \\
\hline Median & 29.7 & 70.3 & 10.9 & 89.1 & 20.8 & 79.2 & 11.7 & 88.3 \\
\hline
\end{tabular}




\section{Interest Rates}

\begin{tabular}{|c|c|c|c|c|c|c|c|c|}
\hline & \multicolumn{2}{|c|}{ Output } & \multicolumn{2}{|c|}{ Consumption } & \multicolumn{2}{|c|}{ Investment } & \multicolumn{2}{|c|}{ Interest rates } \\
\hline & Global & Idiosyncratic & Global & Idiosyncratic & Global & Idiosyncratic & Global & Idiosyncratic \\
\hline Canada & 24.8 & 75.2 & 15.8 & 84.2 & 27.3 & 72.7 & 2.7 & 97.3 \\
\hline France & 23.6 & 76.4 & 13.2 & 86.8 & 28.2 & 71.8 & 2.6 & 97.4 \\
\hline Germany & 63.5 & 36.5 & 9.6 & 90.4 & 57.1 & 42.9 & 0.5 & 99.5 \\
\hline Italy & 34.9 & 65.1 & 0.6 & 99.4 & 20.9 & 79.1 & 1.1 & 98.9 \\
\hline Japan & 48.9 & 51.1 & 16.4 & 83.6 & 20.9 & 79.1 & 1.1 & 98.9 \\
\hline United Kingdom & 22.0 & 78.0 & 2.2 & 97.8 & 9.4 & 90.6 & 1.6 & 98.4 \\
\hline United States & 27.1 & 72.9 & 9.5 & 90.5 & 7.6 & 92.4 & 5.6 & 94.4 \\
\hline Average & 35.0 & 65.0 & 9.6 & 90.4 & 24.5 & 75.5 & 2.2 & 97.8 \\
\hline Median & 27.1 & 72.9 & 9.6 & 90.4 & 20.9 & 79.1 & 1.6 & 98.4 \\
\hline
\end{tabular}

Notes: In each cell, the variance share attributable to the relevant factor is reported. The variance contributions are attributed to: Global (global factor) and Idiosyncratic (idiosyncratic factor). The row marked "Average" represents unweighted averages of the variance contributions in each column. 
Table A10. Variance Decompositions: Models with Financial Variables

A. $1985-2019$

\begin{tabular}{|c|c|c|c|c|c|c|c|c|c|}
\hline \multirow[b]{3}{*}{ Canada } & \multicolumn{3}{|c|}{ Equity prices } & \multicolumn{3}{|c|}{ House prices } & \multicolumn{3}{|c|}{ Interest rates } \\
\hline & \multirow{2}{*}{$\begin{array}{c}\text { Global } \\
61.0\end{array}$} & \multicolumn{2}{|c|}{$\overline{\text { Country Idiosyncratic }}$} & \multirow{2}{*}{$\begin{array}{c}\text { Global } \\
0.0\end{array}$} & \multicolumn{2}{|c|}{ Country Idiosyncratic } & \multirow{2}{*}{$\begin{array}{c}\text { Global } \\
0.0\end{array}$} & \multicolumn{2}{|c|}{ Country Idiosyncratic } \\
\hline & & 26.2 & 12.8 & & 70.6 & 29.3 & & 0.1 & 99.9 \\
\hline France & 5.5 & 0.8 & 93.7 & 0.0 & 0.1 & 99.8 & 70.3 & 21.0 & 8.6 \\
\hline Germany & 2.0 & 5.8 & 92.2 & 47.1 & 40.9 & 12.0 & 4.7 & 1.1 & 94.3 \\
\hline Italy & 64.7 & 0.2 & 35.1 & 0.0 & 3.1 & 96.8 & 0.1 & 3.5 & 96.3 \\
\hline Japan & 0.6 & 0.9 & 98.5 & 0.1 & 2.4 & 97.6 & 71.9 & 19.5 & 8.6 \\
\hline United Kingdom & 0.1 & 48.0 & 51.9 & 29.6 & 54.8 & 15.6 & 1.1 & 1.1 & 97.8 \\
\hline United States & 65.0 & 0.4 & 34.6 & 0.9 & 0.0 & 99.0 & 4.1 & 0.3 & 95.6 \\
\hline Average & 28.4 & 11.8 & 59.8 & 11.1 & 24.6 & 64.3 & 21.7 & 6.7 & 71.6 \\
\hline Median & 5.5 & 0.9 & 51.9 & 0.1 & 3.1 & 96.8 & 4.1 & 1.1 & 95.6 \\
\hline
\end{tabular}

B. $1985-2007$

\begin{tabular}{|c|c|c|c|c|c|c|c|c|c|}
\hline \multirow[b]{3}{*}{ Canada } & \multicolumn{3}{|c|}{ Equity prices } & \multicolumn{3}{|c|}{ House prices } & \multicolumn{3}{|c|}{ Interest rates } \\
\hline & \multirow{2}{*}{$\begin{array}{c}\text { Global } \\
55.3\end{array}$} & \multicolumn{2}{|c|}{ Country Idiosyncratic } & \multirow{2}{*}{$\begin{array}{c}\text { Global } \\
0.1\end{array}$} & \multicolumn{2}{|c|}{ Country Idiosyncratic } & \multirow{2}{*}{$\begin{array}{c}\text { Global } \\
0.1\end{array}$} & \multicolumn{2}{|c|}{ Country Idiosyncratic } \\
\hline & & 24.8 & 19.8 & & 1.3 & 98.6 & & 0.1 & 99.8 \\
\hline France & 3.6 & 1.9 & 94.5 & 0.2 & 1.3 & 98.5 & 62.9 & 26.3 & 10.8 \\
\hline Germany & 11.1 & 3.3 & 85.7 & 42.2 & 40.7 & 17.1 & 0.1 & 3.6 & 96.3 \\
\hline Italy & 63.8 & 0.4 & 35.9 & 1.2 & 5.2 & 93.6 & 0.8 & 3.5 & 95.7 \\
\hline Japan & 0.1 & 1.0 & 98.9 & 0.2 & 2.9 & 96.9 & 69.3 & 0.8 & 29.8 \\
\hline United Kingdom & 0.3 & 35.5 & 64.2 & 15.4 & 0.1 & 84.6 & 3.8 & 23.6 & 72.6 \\
\hline United States & 62.3 & 17.1 & 20.5 & 1.0 & 42.5 & 56.5 & 2.3 & 0.3 & 97.4 \\
\hline Average & 28.1 & 12.0 & 59.9 & 8.6 & 13.4 & 78.0 & 19.9 & 8.3 & 71.8 \\
\hline Median & 11.1 & 3.3 & 64.2 & 1.0 & 2.9 & 93.6 & 2.3 & 3.5 & 95.7 \\
\hline
\end{tabular}

C. $1998-2019$

\begin{tabular}{|c|c|c|c|c|c|c|c|c|c|}
\hline \multirow[b]{3}{*}{ Canada } & \multicolumn{3}{|c|}{ Equity prices } & \multicolumn{3}{|c|}{ House prices } & \multicolumn{3}{|c|}{ Interest rates } \\
\hline & \multirow{2}{*}{$\begin{array}{c}\text { Global } \\
66.4\end{array}$} & \multicolumn{2}{|c|}{ Country Idios yncratic } & \multirow{2}{*}{$\begin{array}{c}\text { Global } \\
0.6\end{array}$} & \multicolumn{2}{|c|}{ Country Idiosyncratic } & \multirow{2}{*}{$\begin{array}{c}\text { Global } \\
1.0\end{array}$} & \multicolumn{2}{|c|}{ Country Idiosyncratic } \\
\hline & & 2.7 & 30.9 & & 49.3 & 50.1 & & 1.6 & 97.4 \\
\hline France & 7.4 & 6.2 & 86.5 & 2.6 & 1.1 & 96.3 & 78.1 & 6.2 & 15.6 \\
\hline Germany & 1.3 & 69.8 & 28.8 & 51.4 & 1.4 & 47.2 & 5.2 & 4.3 & 90.5 \\
\hline Italy & 67.7 & 0.5 & 31.8 & 6.6 & 0.3 & 93.1 & 0.5 & 1.3 & 98.2 \\
\hline Japan & 4.6 & 1.9 & 93.5 & 0.1 & 57.9 & 42.0 & 76.2 & 3.5 & 20.3 \\
\hline United Kingdom & 3.3 & 63.3 & 33.4 & 49.1 & 35.6 & 15.3 & 0.2 & 40.7 & 59.1 \\
\hline United States & 67.9 & 0.5 & 31.6 & 0.1 & 0.7 & 99.2 & 5.8 & 0.5 & 93.6 \\
\hline Average & 31.2 & 20.7 & 48.1 & 15.8 & 20.9 & 63.3 & 23.9 & 8.3 & 67.8 \\
\hline Median & 7.4 & 2.7 & 31.8 & 2.6 & 1.4 & 50.1 & 5.2 & 3.5 & 90.5 \\
\hline
\end{tabular}

Notes: In each cell, the variance share attributable to the relevant factor is reported. The variance contributions are attributed to: Global (global factor), Country (country-specific factor), and Idiosyncratic (idiosyncratic factor). 
Table A11. Variance Decompositions: Credit Growth as the Financial Variable (G-7 Averages)

\section{A. Models 1, 2 and 1\&2}

\begin{tabular}{|c|c|c|c|c|c|c|c|c|c|c|c|c|c|c|}
\hline & \multicolumn{4}{|c|}{ Output } & \multicolumn{4}{|c|}{ Consumption } & \multicolumn{4}{|c|}{ Investment } & \multicolumn{2}{|c|}{ Credit } \\
\hline & $\mathbf{W}$ & $\mathbf{C}$ & SF & I & $\mathbf{W}$ & $\mathbf{C}$ & SF & I & W & $\mathbf{C}$ & SF & I & $\mathbf{F}$ & I \\
\hline & \multicolumn{14}{|c|}{ Model 1} \\
\hline $1985-2019$ & 36.4 & 34.5 & 2.6 & 26.6 & 8.7 & 29.0 & 0.6 & 61.7 & 23.3 & 23.3 & 1.6 & 51.8 & 13.5 & 86.5 \\
\hline $1985-2007$ & 21.9 & 40.9 & 2.4 & 34.8 & 6.8 & 29.4 & 0.7 & 63.1 & 17.1 & 23.6 & 1.9 & 57.4 & 11.5 & 88.5 \\
\hline \multirow[t]{2}{*}{ 1998-2019 } & 46.6 & 23.5 & 4.8 & 25.0 & 12.8 & 30.1 & 1.3 & 55.7 & 31.6 & 17.0 & 3.3 & 48.2 & 9.6 & 90.4 \\
\hline & \multicolumn{14}{|c|}{ Model 2} \\
\hline $1985-2019$ & 39.9 & 32.4 & 1.9 & 25.9 & 10.2 & 27.0 & 1.6 & 61.2 & 26.1 & 23.0 & 1.4 & 49.5 & 15.9 & 84.1 \\
\hline $1985-2007$ & 44.0 & 28.9 & 3.0 & 24.1 & 19.2 & 26.6 & 2.5 & 51.7 & 38.6 & 17.7 & 2.1 & 41.6 & 18.8 & 81.2 \\
\hline \multirow[t]{2}{*}{$1998-2019$} & 61.9 & 17.5 & 1.5 & 19.1 & 21.5 & 26.5 & 2.1 & 49.9 & 45.5 & 14.3 & 1.2 & 39.1 & 14.5 & 85.5 \\
\hline & \multicolumn{14}{|c|}{ Model 1\&2 } \\
\hline $1985-2019$ & 38.8 & 31.8 & 4.2 & 25.3 & 10.0 & 27.2 & 2.2 & 60.6 & 25.5 & 22.8 & 2.9 & 48.8 & 16.0 & 84.0 \\
\hline $1985-2007$ & 19.7 & 42.6 & 6.5 & 31.2 & 7.1 & 28.1 & 3.7 & 61.0 & 13.3 & 31.7 & 5.0 & 50.0 & 18.7 & 81.3 \\
\hline $1998-2019$ & 50.1 & 21.1 & 6.4 & 22.4 & 15.2 & 28.0 & 3.7 & 53.1 & 35.2 & 15.4 & 4.6 & 44.8 & 14.4 & 85.6 \\
\hline
\end{tabular}

Notes: In each cell, the variance share attributable to the relevant factor is reported. The share is averaged across the G-7 countries at a horizon of 30 quarters. The variance contributions are attributed to: W (global macro factor), C (country-specific macro factor), F (global financial factor), SF (spillovers from financial to macro factors), and I (idiosyncratic factor). In Model 1, the financial factor spills over to the global macro factor. In Model 2, the financial factor spills over directly to country-specific macro factor. Models 1 and 2 combined capture both channels through which the financial factor affects macro activity.

\section{Models 3, 4 and $3 \& 4$}

\begin{tabular}{|c|c|c|c|c|c|c|c|c|c|c|c|c|}
\hline & \multicolumn{3}{|c|}{ Output } & \multicolumn{3}{|c|}{ Consumption } & \multicolumn{3}{|c|}{ Investment } & \multicolumn{3}{|c|}{ Credit } \\
\hline & $\mathbf{W}$ & $\mathbf{C}$ & I & $\mathbf{W}$ & C & $\mathbf{I}$ & $\mathbf{W}$ & $\mathbf{C}$ & I & SR & $\mathbf{F}$ & $\mathbf{I}$ \\
\hline & \multicolumn{12}{|c|}{ Model 3} \\
\hline $1985-2019$ & 31.7 & 37.9 & 30.4 & 13.7 & 41.3 & 44.9 & 19.8 & 41.9 & 38.2 & 0.5 & 6.0 & 93.5 \\
\hline $1985-2007$ & 13.8 & 52.7 & 33.4 & 6.8 & 31.2 & 62.1 & 8.0 & 48.4 & 43.6 & 0.5 & 11.1 & 88.4 \\
\hline \multirow[t]{2}{*}{$1998-2019$} & 42.4 & 30.9 & 26.7 & 12.1 & 32.0 & 55.8 & 27.0 & 29.3 & 43.7 & 0.6 & 8.3 & 91.1 \\
\hline & \multicolumn{12}{|c|}{ Model 4} \\
\hline 1985-2019 & 35.2 & 33.0 & 31.9 & 13.9 & 31.4 & 54.7 & 21.3 & 37.8 & 40.9 & 0.8 & 9.4 & 89.7 \\
\hline $1985-2007$ & 13.6 & 48.0 & 38.4 & 6.6 & 36.4 & 57.0 & 7.8 & 46.6 & 45.6 & 0.5 & 5.7 & 93.9 \\
\hline \multirow[t]{2}{*}{$1998-2019$} & 13.6 & 48.0 & 38.4 & 6.6 & 36.4 & 57.0 & 7.8 & 46.6 & 45.6 & 0.5 & 5.7 & 93.9 \\
\hline & \multicolumn{12}{|c|}{ Model 3\&4 } \\
\hline $1985-2019$ & 33.9 & 36.3 & 29.8 & 12.9 & 31.8 & 55.3 & 20.0 & 38.3 & 41.7 & 0.5 & 5.8 & 93.7 \\
\hline $1985-2007$ & 14.6 & 50.8 & 34.6 & 8.0 & 31.0 & 61.1 & 8.8 & 46.9 & 44.3 & 0.6 & 5.6 & 93.8 \\
\hline $1998-2019$ & 43.0 & 31.8 & 25.2 & 12.4 & 27.9 & 59.7 & 27.1 & 28.3 & 44.6 & 0.8 & 7.4 & 91.8 \\
\hline
\end{tabular}

Notes: In each cell, the variance share attributable to the relevant factor is reported. The share is averaged across the G-7 countries at a horizon of 30 quarters. The variance contributions are attributed to: W (global macro factor), C (country-specific macro factor), F (global financial factor), SR (spillovers from macro to financial factor), and I (idiosyncratic factor). In Model 3, the global macro factor spills over to the financial factor. In Model 4, the U.S. country factor spills over to the financial factor. Models 3 and 4 combined capture both channels through which the macro factors affect financial sector. 


\section{Table A12. Variance Decompositions: Long-term Interest Rates (G-7 Average; Model 1\&2 and Model 3\&4)}

\begin{tabular}{|c|c|c|c|c|c|c|c|c|c|c|c|c|c|c|c|}
\hline & \multicolumn{4}{|c|}{ Output } & \multicolumn{4}{|c|}{ Consumption } & \multicolumn{4}{|c|}{ Investment } & \multicolumn{3}{|c|}{ Interest rates } \\
\hline & $\mathbf{W}$ & $\mathbf{C}$ & SF & $\mathbf{I}$ & $\mathbf{W}$ & $\mathbf{C}$ & SF & I & $\mathbf{W}$ & C & SF & $\mathbf{I}$ & SR & $\mathbf{F}$ & I \\
\hline & \multicolumn{15}{|c|}{ Models 1 \& 2} \\
\hline $1985-2019$ & 38.7 & 32.4 & 2.5 & 26.4 & 9.8 & 27.8 & 1.4 & 61.0 & 25.3 & 23.5 & 1.8 & 49.4 & & 32.6 & 67.4 \\
\hline $1985-2007$ & 25.2 & 37.9 & 4.6 & 32.3 & 8.4 & 29.3 & 2.5 & 59.8 & 20.9 & 22.0 & 3.5 & 53.7 & & 31.0 & 69.0 \\
\hline \multirow[t]{2}{*}{$1998-2019$} & 47.7 & 21.1 & 10.1 & 21.0 & 14.1 & 28.2 & 4.6 & 53.1 & 33.7 & 15.1 & 7.3 & 43.9 & & 40.7 & 59.3 \\
\hline & \multicolumn{15}{|c|}{ Models 3 \& 4} \\
\hline $1985-2019$ & 34.4 & 41.7 & & 23.8 & 8.0 & 44.1 & & 47.9 & 22.2 & 34.2 & & 43.6 & 2.3 & 22.6 & 75.1 \\
\hline $1985-2007$ & 27.6 & 46.4 & & 26.0 & 18.1 & 33.6 & & 48.3 & 23.2 & 36.6 & & 40.3 & 1.9 & 19.8 & 78.3 \\
\hline $1998-2019$ & 40.7 & 36.0 & & 23.3 & 9.9 & 41.2 & & 48.9 & 27.0 & 27.6 & & 45.4 & 7.7 & 31.0 & 61.2 \\
\hline
\end{tabular}

Notes: In each cell, the variance share attributable to the relevant factor is reported. The shares are averaged across the G-7 countries at a horizon of 30 quarters. The variance contributions are attributed to: W (global macro factor), C (country-specific macro factor), F (global financial factor), SF (spillovers from financial to macro factor), SR (spillovers from macro to financial factor), and I (idiosyncratic factor). The results in the upper panel are based on the combined Model 1\&2, which captures spillovers of the global financial factor to macro variables through both the global macro factor and the country-specific macro factor. The results in the lower panel are based on the combined Model 3\&4, which captures spillovers of the global macro factor and the U.S. country factor onto the global factor for long-term interest rates. 
Table A13. Variance Decompositions: Alternative House Price Indicator (G-7 Averages)

\section{A. Model 1 and 2}

\begin{tabular}{|c|c|c|c|c|c|c|c|c|c|c|c|c|c|c|}
\hline & \multicolumn{4}{|c|}{ Output } & \multicolumn{4}{|c|}{ Consumption } & \multicolumn{4}{|c|}{ Investment } & \multicolumn{2}{|c|}{ House prices } \\
\hline & $\mathbf{W}$ & C & SF & I & W & C & SF & I & $\mathbf{W}$ & $\mathbf{C}$ & SF & I & $\mathbf{F}$ & $\mathbf{I}$ \\
\hline & \multicolumn{14}{|c|}{ Model 1} \\
\hline $1985-2019$ & 35.6 & 33.8 & 4.1 & 26.5 & 8.7 & 28.6 & 1.0 & 61.7 & 22.8 & 23.0 & 2.6 & 51.5 & 9.1 & 90.9 \\
\hline $1985-2007$ & 22.9 & 40.5 & 3.4 & 33.2 & 7.7 & 29.0 & 1.2 & 62.2 & 17.0 & 25.2 & 2.6 & 55.2 & 8.5 & 91.5 \\
\hline \multirow[t]{2}{*}{ 1998-2019 } & 41.0 & 24.9 & 8.1 & 26.1 & 10.4 & 31.3 & 2.1 & 56.3 & 27.2 & 17.4 & 5.4 & 50.0 & 9.8 & 90.2 \\
\hline & \multicolumn{14}{|c|}{ Model 2} \\
\hline $1985-2019$ & 39.2 & 32.8 & 1.7 & 26.3 & 10.1 & 27.7 & 1.4 & 60.8 & 25.3 & 23.4 & 1.2 & 50.2 & 12.7 & 87.3 \\
\hline $1985-2007$ & 24.1 & 40.4 & 1.8 & 33.7 & 7.7 & 30.2 & 0.6 & 61.5 & 19.6 & 23.0 & 1.5 & 55.9 & 6.3 & 93.7 \\
\hline \multirow[t]{2}{*}{ 1998-2019 } & 52.2 & 23.0 & 2.0 & 22.8 & 15.5 & 27.6 & 2.3 & 54.6 & 36.3 & 16.6 & 1.3 & 45.9 & 16.3 & 83.7 \\
\hline & \multicolumn{14}{|c|}{ Model 1\&2 } \\
\hline 1985-2019 & 34.8 & 31.8 & 5.8 & 27.6 & 8.5 & 28.3 & 2.2 & 61.0 & 22.3 & 24.4 & 3.9 & 49.4 & 15.6 & 84.4 \\
\hline $1985-2007$ & 19.1 & 40.4 & 6.4 & 34.1 & 5.6 & 29.9 & 3.2 & 61.3 & 14.9 & 22.1 & 4.4 & 58.7 & 9.8 & 90.2 \\
\hline 1998-2019 & 36.6 & 22.8 & 16.7 & 23.8 & 9.7 & 30.2 & 6.4 & 53.7 & 25.0 & 16.0 & 11.4 & 47.6 & 16.6 & 83.4 \\
\hline
\end{tabular}

Notes: In each cell, the variance share attributable to the relevant factor is reported. The share is averaged across the G-7 countries at a horizon of 30 quarters. The variance contributions are attributed to: W (global macro factor), C (country-specific macro factor), $\mathrm{F}$ (global financial factor), SF (spillovers from financial to macro factors), and I (idiosyncratic factor). In Model 1, the financial factor spills over to the global macro factor. In Model 2, the financial factor spills over directly to country-specific macro factor. Models 1 and 2 combined capture both channels through which the financial factor affects macro fluctuations.

\section{B. Model 3 and 4}

\begin{tabular}{|c|c|c|c|c|c|c|c|c|c|c|c|c|}
\hline & \multicolumn{3}{|c|}{ Output } & \multicolumn{3}{|c|}{ Consumption } & \multicolumn{3}{|c|}{ Investment } & \multicolumn{3}{|c|}{ House prices } \\
\hline & $\mathbf{W}$ & $\mathbf{C}$ & I & $\mathbf{W}$ & $\mathbf{C}$ & I & $\mathbf{W}$ & $\mathbf{C}$ & I & SR & $\mathbf{F}$ & I \\
\hline & \multicolumn{12}{|c|}{ Model 3} \\
\hline 1985-2019 & 35.2 & 37.6 & 27.2 & 7.7 & 40.2 & 52.1 & 21.8 & 31.0 & 47.1 & 1.2 & 9.1 & 89.7 \\
\hline $1985-2007$ & 24.1 & 43.5 & 32.5 & 10.6 & 35.2 & 54.2 & 21.4 & 28.3 & 50.3 & 1.5 & 10.0 & 88.6 \\
\hline \multirow[t]{2}{*}{ 1998-2019 } & 44.6 & 31.0 & 24.4 & 10.3 & 35.9 & 53.8 & 28.2 & 23.6 & 48.2 & 1.6 & 9.3 & 89.0 \\
\hline & \multicolumn{12}{|c|}{ Model 4} \\
\hline 1985-2019 & 43.0 & 34.9 & 22.1 & 12.4 & 40.4 & 47.2 & 29.1 & 30.7 & 40.2 & 1.0 & 9.8 & 89.2 \\
\hline $1985-2007$ & 24.0 & 42.5 & 33.5 & 14.9 & 26.5 & 58.6 & 13.6 & 39.9 & 46.6 & 1.0 & 9.7 & 89.3 \\
\hline \multirow[t]{2}{*}{ 1998-2019 } & 44.7 & 29.8 & 25.4 & 10.3 & 34.9 & 54.7 & 27.7 & 23.1 & 49.2 & 0.8 & 7.5 & 91.7 \\
\hline & \multicolumn{12}{|c|}{ Model 3\&4 } \\
\hline 1985-2019 & 34.2 & 40.4 & 25.4 & 7.6 & 42.7 & 49.7 & 21.7 & 32.9 & 45.4 & 1.3 & 6.9 & 91.9 \\
\hline $1985-2007$ & 28.5 & 40.4 & 31.1 & 15.1 & 32.8 & 52.0 & 26.6 & 25.2 & 48.2 & 1.0 & 5.9 & 93.1 \\
\hline 1998-2019 & 46.5 & 28.5 & 25.0 & 11.4 & 35.1 & 53.5 & 29.3 & 22.5 & 48.2 & 1.5 & 6.4 & 92.1 \\
\hline
\end{tabular}

Notes: In each cell, the variance share attributable to the relevant factor is reported. The share is averaged across the G-7 countries at a horizon of 30 quarters. The variance contributions are attributed to: W (global macro factor), C (country-specific macro factor), F (global financial factor), SR (spillovers from macro to financial factor), and I (idiosyncratic factor). In Model 3, the global macro factor spills over to the financial factor. In Model 4, the U.S. country factor spills over to the financial factor. Models 3 and 4 combined capture both channels through which the macro factors affect financial markets. 
Table A14. Variance Decompositions: Dataset Excluding the U.S.

(G-7 Averages)

\section{A. Model 1}

\begin{tabular}{|c|c|c|c|c|c|c|c|c|c|c|c|c|c|c|}
\hline & \multicolumn{4}{|c|}{ Output } & \multicolumn{4}{|c|}{ Consumption } & \multicolumn{4}{|c|}{ Investment } & \multicolumn{2}{|c|}{ Financial } \\
\hline & $\mathbf{W}$ & $\mathrm{C}$ & SF & I & $\mathbf{W}$ & C & SF & I & $\mathbf{W}$ & C & SF & I & $\mathbf{F}$ & $\mathbf{I}$ \\
\hline & \multicolumn{14}{|c|}{ Equity prices } \\
\hline $1985-2019$ & 31.4 & 36.4 & 5.0 & 27.2 & 4.6 & 40.0 & 0.8 & 54.6 & 18.3 & 26.6 & 3.0 & 52.2 & 47.3 & 52.7 \\
\hline $1985-2007$ & 19.7 & 44.2 & 1.7 & 34.4 & 6.6 & 38.1 & 0.6 & 54.8 & 19.1 & 29.0 & 1.6 & 50.2 & 43.3 & 56.7 \\
\hline \multirow[t]{2}{*}{ 1998-2019 } & 34.7 & 29.9 & 10.2 & 25.2 & 6.1 & 37.3 & 1.8 & 54.8 & 19.3 & 18.3 & 5.7 & 56.6 & 50.6 & 49.4 \\
\hline & \multicolumn{14}{|c|}{ House prices } \\
\hline $1985-2019$ & 34.3 & 35.1 & 2.8 & 27.8 & 5.6 & 39.5 & 0.5 & 54.4 & 19.9 & 25.6 & 1.6 & 52.9 & 11.6 & 88.4 \\
\hline $1985-2007$ & 20.6 & 43.4 & 1.9 & 34.1 & 7.3 & 36.7 & 0.7 & 55.3 & 20.2 & 26.7 & 1.9 & 51.3 & 12.9 & 87.1 \\
\hline \multirow[t]{2}{*}{ 1998-2019 } & 41.5 & 28.8 & 4.4 & 25.3 & 8.2 & 34.3 & 0.9 & 56.6 & 22.5 & 18.4 & 2.4 & 56.6 & 6.6 & 93.4 \\
\hline & \multicolumn{14}{|c|}{ Interest rates } \\
\hline $1985-2019$ & 36.4 & 36.1 & 1.4 & 26.1 & 6.5 & 38.6 & 0.3 & 54.6 & 22.4 & 23.0 & 0.9 & 53.8 & 18.8 & 81.2 \\
\hline $1985-2007$ & 22.1 & 42.7 & 1.6 & 33.6 & 8.2 & 36.2 & 0.6 & 54.9 & 21.7 & 24.4 & 1.5 & 52.4 & 18.1 & 81.9 \\
\hline 1998-2019 & 41.8 & 30.2 & 1.9 & 26.1 & 7.9 & 35.2 & 0.4 & 56.5 & 23.0 & 19.5 & 1.1 & 56.4 & 26.5 & 73.5 \\
\hline
\end{tabular}

Notes: In each cell, the variance share attributable to the relevant factor is reported. The results are based on Model 1, which captures spillovers from the financial sector to the macroeconomy through the global macro factor. The dataset for this exercise comprises six of the G-7 countries; the U.S. is excluded.

\section{B. Model 3}

\begin{tabular}{|c|c|c|c|c|c|c|c|c|c|c|c|c|}
\hline & \multicolumn{3}{|c|}{ Output } & \multicolumn{3}{|c|}{ Consumption } & \multicolumn{3}{|c|}{ Investment } & \multicolumn{3}{|c|}{ Financial } \\
\hline & $\mathbf{W}$ & $\mathbf{C}$ & I & W & $\mathbf{C}$ & I & W & $\mathbf{C}$ & I & SR & $\mathbf{F}$ & I \\
\hline & \multicolumn{12}{|c|}{ Equity prices } \\
\hline $1985-2019$ & 37.0 & 37.9 & 25.1 & 6.3 & 38.2 & 55.5 & 22.3 & 26.1 & 51.6 & 0.4 & 47.2 & 52.4 \\
\hline $1985-2007$ & 20.6 & 47.6 & 31.7 & 7.2 & 40.2 & 52.6 & 20.8 & 31.8 & 47.4 & 0.4 & 43.3 & 56.3 \\
\hline \multirow[t]{2}{*}{$1998-2019$} & 55.1 & 25.0 & 19.9 & 13.2 & 33.3 & 53.5 & 32.1 & 17.7 & 50.2 & 0.8 & 51.6 & 47.6 \\
\hline & \multicolumn{12}{|c|}{ House prices } \\
\hline $1985-2019$ & 37.7 & 35.7 & 26.6 & 6.6 & 40.4 & 53.0 & 23.1 & 24.5 & 52.4 & 0.6 & 11.2 & 88.2 \\
\hline $1985-2007$ & 20.3 & 47.6 & 32.1 & 7.2 & 38.8 & 54.0 & 20.3 & 31.9 & 47.8 & 0.5 & 11.9 & 87.6 \\
\hline \multirow[t]{2}{*}{ 1998-2019 } & 46.2 & 30.2 & 23.6 & 9.1 & 36.0 & 54.9 & 26.2 & 19.5 & 54.2 & 0.5 & 8.2 & 91.3 \\
\hline & \multicolumn{12}{|c|}{ Interest rates } \\
\hline $1985-2019$ & 38.9 & 33.6 & 27.5 & 7.5 & 41.7 & 50.9 & 24.7 & 21.6 & 53.7 & 0.9 & 19.2 & 79.9 \\
\hline $1985-2007$ & 21.4 & 46.1 & 32.5 & 7.3 & 38.4 & 54.3 & 20.5 & 31.4 & 48.2 & 1.0 & 19.2 & 79.8 \\
\hline 1998-2019 & 48.2 & 28.4 & 23.4 & 9.9 & 35.5 & 54.5 & 27.4 & 18.9 & 53.7 & 1.0 & 26.5 & 72.5 \\
\hline
\end{tabular}

Notes: In each cell, the variance share attributable to the relevant factor is reported. The share is averaged across the G-7 countries at a horizon of 30 quarters. The variance contributions are attributed to: W (global macro factor), C (country-specific macro factor), F (global financial factor), SR (spillovers from macro to financial factor), and I (idiosyncratic factor). In Model 3, the global macro factor spills over to the financial factor. 
Table A15. Variance Decompositions: Alternative Sub-Samples

(G-7 Averages)

\section{A. Model 1\&2}

\begin{tabular}{|c|c|c|c|c|c|c|c|c|c|c|c|c|c|c|}
\hline & \multicolumn{4}{|c|}{ Output } & \multicolumn{4}{|c|}{ Consumption } & \multicolumn{4}{|c|}{ Investment } & \multicolumn{2}{|c|}{ Financial variable } \\
\hline & $\mathbf{W}$ & $\mathbf{C}$ & SF & $\mathbf{I}$ & $\mathbf{W}$ & $\mathbf{C}$ & SF & I & $\mathbf{W}$ & $\mathbf{C}$ & SF & $\mathbf{I}$ & $\mathbf{F}$ & I \\
\hline & \multicolumn{14}{|c|}{ Equity prices } \\
\hline $1985-2000$ & 29.8 & 32.4 & 8.6 & 29.2 & 12.6 & 28.4 & 5.0 & 54.0 & 25.9 & 21.1 & 6.9 & 46.1 & 43.7 & 56.3 \\
\hline \multirow[t]{2}{*}{ 2001-2019 } & 50.4 & 13.5 & 23.2 & 12.9 & 23.8 & 18.8 & 13.9 & 43.4 & 33.2 & 18.9 & 16.3 & 31.5 & 60.6 & 39.4 \\
\hline & \multicolumn{14}{|c|}{ House prices } \\
\hline $1985-2000$ & 17.8 & 39.2 & 7.7 & 35.4 & 7.8 & 27.8 & 4.7 & 59.7 & 13.2 & 28.7 & 6.0 & 52.1 & 9.8 & 90.2 \\
\hline \multirow[t]{2}{*}{ 2001-2019 } & 40.5 & 21.8 & 18.9 & 18.7 & 12.7 & 26.3 & 7.7 & 53.3 & 27.9 & 16.9 & 13.1 & 42.1 & 20.3 & 79.7 \\
\hline & \multicolumn{14}{|c|}{ Interest rates } \\
\hline $1985-2000$ & 13.4 & 45.7 & 6.0 & 34.9 & 7.8 & 27.8 & 3.5 & 60.9 & 8.3 & 36.8 & 5.1 & 49.8 & 19.6 & 80.4 \\
\hline $2001-2019$ & 55.8 & 18.1 & 9.2 & 16.9 & 20.9 & 22.9 & 4.7 & 51.5 & 36.6 & 17.8 & 6.5 & 39.1 & 29.7 & 70.3 \\
\hline
\end{tabular}

Notes: In each cell, the variance share attributable to the relevant factor is reported. The share is averaged across the G-7 countries at a horizon of 30 quarters. The variance contributions are attributed to: W (global macro factor), C (country-specific macro factor), F (global financial factor), SF (spillovers from financial to macro factors), and I (idiosyncratic factor). The results are based on the combined Models 1 and 2, which capture financial market spillovers to macro aggregates through the global macro factor and country-specific macro factors.

\section{B. Model $3 \& 4$}

\begin{tabular}{|c|c|c|c|c|c|c|c|c|c|c|c|c|}
\hline & \multicolumn{3}{|c|}{ Output } & \multicolumn{3}{|c|}{ Consumption } & \multicolumn{3}{|c|}{ Investment } & \multicolumn{3}{|c|}{ Financial variable } \\
\hline & $\mathbf{W}$ & $\mathbf{C}$ & $\mathbf{I}$ & $\mathbf{W}$ & $\mathbf{C}$ & $\mathbf{I}$ & $\mathbf{W}$ & $\mathbf{C}$ & $\mathbf{I}$ & SR & $\mathbf{F}$ & I \\
\hline & \multicolumn{12}{|c|}{ Equity prices } \\
\hline $1985-2000$ & 25.2 & 45.4 & 29.4 & 15.6 & 33.9 & 50.5 & 16.9 & 38.3 & 44.8 & 1.1 & 37.9 & 61.1 \\
\hline \multirow[t]{2}{*}{ 2001-2019 } & 69.2 & 17.2 & 13.6 & 31.3 & 26.1 & 42.5 & 40.3 & 24.4 & 35.2 & 1.5 & 54.6 & 43.8 \\
\hline & \multicolumn{12}{|c|}{ House prices } \\
\hline $1985-2000$ & 25.9 & 45.5 & 28.6 & 16.4 & 33.7 & 49.8 & 17.5 & 39.1 & 43.3 & 1.2 & 5.5 & 93.3 \\
\hline \multirow[t]{2}{*}{ 2001-2019 } & 67.4 & 18.2 & 14.5 & 32.7 & 24.0 & 43.3 & 37.3 & 27.6 & 35.1 & 0.4 & 3.6 & 96.1 \\
\hline & \multicolumn{12}{|c|}{ Interest rates } \\
\hline $1985-2000$ & 31.6 & 41.4 & 27.1 & 22.7 & 29.4 & 47.8 & 21.1 & 37.6 & 41.3 & 2.6 & 12.4 & 85.1 \\
\hline 2001-2019 & 46.0 & 29.2 & 24.8 & 12.4 & 33.2 & 54.4 & 30.1 & 24.1 & 45.9 & 5.3 & 26.3 & 68.4 \\
\hline
\end{tabular}

Notes: In each cell, the variance share attributable to the relevant factor is reported. The share is averaged across the G-7 countries at a horizon of 30 quarters. The variance contributions are attributed to: W (global macro factor), C (country-specific macro factor), F (global financial factor), SR (spillovers from macro to financial factor), and I (idiosyncratic factor). The results are based on the combined Models 3 and 4, which capture spillovers of macro fluctuations onto financial markets through the global macro factor and the U.S. country factor. 
Table A16. Variance Decompositions:

(Monthly Industrial Production and Financial Variables; Percent)

A. Models with Only Monthly Financial Variables

\begin{tabular}{lcccccccc}
\hline & \multicolumn{2}{c}{ Equity price } & & \multicolumn{2}{c}{ House price } & & \multicolumn{2}{c}{ Interest rate } \\
\cline { 2 - 3 } \cline { 7 - 8 } \cline { 7 - 8 } \cline { 7 - 8 } Canada & Global & Idiosyncratic & & Global & Idiosyncratic & & Global & Idiosyncratic \\
\hline \hline France & 47.8 & 52.2 & & 0.0 & 100.0 & & 0.4 & 99.6 \\
Germany & 93.0 & 7.0 & & & 100.0 & & 3.4 & 96.6 \\
Italy & 84.3 & 15.7 & & & 100.0 & & 0.0 & 100.0 \\
Japan & 76.4 & 23.6 & & & 100.0 & & 0.0 & 100.0 \\
United Kingdom & 72.8 & 27.2 & & 2.4 & 97.6 & & 0.1 & 99.9 \\
United States & 69.2 & 30.8 & & 0.6 & 99.4 & & 0.8 & 99.2 \\
Average & 69.8 & 30.2 & & 0.8 & 99.5 & & 0.8 & 99.2 \\
\hline
\end{tabular}

B. Models with Industrial Production and Financial Variables

\begin{tabular}{|c|c|c|c|c|c|c|c|c|c|c|c|c|}
\hline & \multicolumn{2}{|r|}{ IP } & \multicolumn{2}{|c|}{ Equity prices } & \multicolumn{2}{|r|}{ IP } & \multicolumn{2}{|c|}{ House prices } & \multicolumn{2}{|r|}{ IP } & \multicolumn{2}{|c|}{ Interest rates } \\
\hline & Global & Idiosyncratic & Global & Idiosyncratic & Global & Idiosyncratic & Global & Idiosyncratic & Global & Idiosyncratic & Global & Idiosyncratic \\
\hline Canada & 0.1 & 99.9 & 46.1 & 53.9 & 6.5 & 93.5 & 10.6 & 89.4 & 9.4 & 90.6 & 0.2 & 99.8 \\
\hline France & 1.1 & 98.9 & 96.6 & 3.4 & 12.7 & 87.3 & & & 16.7 & 83.3 & 0.1 & 99.9 \\
\hline Germany & 0.9 & 99.1 & 86.7 & 13.3 & 22.1 & 77.9 & & & 22.5 & 77.5 & 3.1 & 96.9 \\
\hline Italy & 0.6 & 99.4 & 78.1 & 21.9 & 14.3 & 85.7 & & & 17.5 & 82.5 & 1.4 & 98.6 \\
\hline Japan & 0.4 & 99.6 & 44.5 & 55.5 & 22.3 & 77.7 & 1.0 & 99.0 & 24.2 & 75.8 & 0.2 & 99.8 \\
\hline United Kingdom & 0.3 & 99.7 & 71.2 & 28.8 & 7.0 & 93.0 & 9.9 & 90.1 & 8.7 & 91.3 & 0.1 & 99.9 \\
\hline United States & 1.5 & 98.5 & 65.1 & 34.9 & 12.6 & 87.4 & 3.8 & 96.2 & 12.5 & 87.5 & 1.5 & 98.5 \\
\hline Average & 0.7 & 99.3 & 69.8 & 30.2 & 13.9 & 86.1 & 6.3 & 93.7 & 15.9 & 84.1 & 0.9 & 99.1 \\
\hline Median & 0.6 & 99.4 & 71.2 & 28.8 & 12.7 & 87.3 & 6.9 & 93.1 & 16.7 & 83.3 & 0.2 & 99.8 \\
\hline
\end{tabular}

Notes: In each cell, the variance share attributable to the relevant factor is reported. The variance contributions are attributed to: Global (global factor) and Idiosyncratic (idiosyncratic factor). 
Table A17. Variance Decompositions:

Spillover Model 1 with Industrial Production and Financial Variables (1998-2019)
A. Equity Price

\begin{tabular}{lcccccc}
\hline & \multicolumn{2}{c}{ Industrial Production } & & \multicolumn{2}{c}{ Equity prices } \\
\cline { 2 - 3 } \cline { 6 - 7 } & Global & Spillover Idiosyncratic & & Global & Idiosyncratic \\
\hline \hline Canada & 12.5 & 5.6 & 81.9 & & 45.7 & 54.3 \\
France & 11.0 & 4.8 & 84.1 & & 93.2 & 6.8 \\
Ge rmany & 21.1 & 9.3 & 69.7 & & 84.6 & 15.4 \\
Italy & 15.7 & 6.9 & 77.4 & & 76.5 & 23.5 \\
Japan & 18.0 & 7.9 & 74.1 & & 47.6 & 52.4 \\
United Kingdom & 8.4 & 3.7 & 87.8 & & 73.4 & 26.6 \\
United States & 22.3 & 9.9 & 67.8 & & 69.8 & 30.2 \\
Average & 15.6 & 6.9 & 77.6 & & 70.1 & 29.9 \\
\hline
\end{tabular}

B. House Price

\begin{tabular}{lcccccc}
\hline & \multicolumn{3}{c}{ Industrial Production } & & \multicolumn{2}{c}{ Interest rates } \\
\cline { 2 - 3 } \cline { 6 - 7 } & Global & Spillover Idiosyncratic & & Global & Idiosyncratic \\
\hline \hline Canada & 18.9 & 0.4 & 80.7 & & 51.8 & 48.2 \\
France & 17.7 & 0.4 & 81.9 & & 8.6 & 91.4 \\
Germany & 32.3 & 0.7 & 67.1 & & 18.7 & 81.3 \\
Italy & 25.1 & 0.5 & 74.3 & & 8.1 & 91.9 \\
Japan & 29.2 & 0.6 & 70.1 & & 11.2 & 88.8 \\
United Kingdom & 14.3 & 0.3 & 85.4 & & 13.5 & 86.5 \\
United States & 32.2 & 0.7 & 67.1 & & 83.5 & 16.5 \\
Average & 24.2 & 0.5 & 75.2 & & 27.9 & 72.1 \\
\hline
\end{tabular}




\section{Interest Rates}

\begin{tabular}{lcccccc}
\hline & \multicolumn{2}{c}{ Industrial Production } & & \multicolumn{2}{c}{ House prices } \\
\cline { 2 - 3 } \cline { 6 - 7 } & Global & Spillover Idios yncratic & & Global & Idios yncratic \\
\hline \hline Canada & 16.7 & 2.6 & 80.7 & & 2.1 & 97.9 \\
France & 15.6 & 2.4 & 82.0 & & \\
Ge rmany & 28.6 & 4.3 & 67.1 & & \\
Italy & 22.2 & 3.4 & 74.4 & & \\
Japan & 25.5 & 3.9 & 70.6 & & 22.2 & 77.8 \\
United Kingdom & 12.3 & 1.9 & 85.8 & & 57.4 & 42.6 \\
United States & 28.1 & 4.3 & 67.6 & & 2.6 & 97.4 \\
Ave rage & 21.3 & 3.2 & 75.5 & & 21.1 & 78.9 \\
\hline
\end{tabular}

Notes: In each cell, the variance share attributable to the relevant factor is reported at a horizon of 30 quarters. The variance contributions are attributed to: Global (global macro factor), Financial (global financial factor), Spillover (spillovers from financial to macro factors), and Idiosyncratic (idiosyncratic factor). In Model 1, the global financial factor influences macroeconomic aggregates through its spillover onto the global macro factor. 
Table A18. Variance decompositions:

Spillover Model 3 with Industrial Production and Financial Variables (1998-2019)

A. Equity Price

\begin{tabular}{lccccccc}
\hline & \multicolumn{2}{c}{ Industrial Production } & & \multicolumn{3}{c}{ Equity prices } \\
\cline { 2 - 3 } \cline { 6 - 7 } \cline { 6 - 7 } Canada & Global & Idiosyncratic & & Global & Spillover & Idiosyncratic \\
\hline \hline France & 19.1 & 80.9 & & 44.0 & 1.3 & 54.7 \\
Germany & 18.0 & 82.0 & & 90.7 & 2.7 & 6.6 \\
Italy & 32.5 & 67.5 & & 82.0 & 2.4 & 15.6 \\
Japan & 25.3 & 74.7 & & 74.2 & 2.2 & 23.6 \\
United Kingdom & 14.7 & 85.3 & & 71.1 & 2.1 & 26.8 \\
United States & 33.0 & 67.0 & & 67.5 & 2.0 & 30.6 \\
Average & 24.6 & 70.4 & & 45.5 & 1.3 & 53.2 \\
\hline
\end{tabular}

B. House Price

\begin{tabular}{lcccccc}
\hline & \multicolumn{2}{c}{ Industrial Production } & & \multicolumn{3}{c}{ House prices } \\
\cline { 2 - 3 } \cline { 5 - 7 } \cline { 5 - 7 } & Global & Idiosyncratic & & Global & Spillover & Idiosyncratic \\
\hline \hline Canada & 18.8 & 81.2 & & 3.2 & 0.3 & 96.5 \\
France & 17.8 & 82.2 & & & & \\
Germany & 33.0 & 67.0 & & & \\
Italy & 25.4 & 74.6 & & & \\
Japan & 29.8 & 70.2 & & 1.3 & 0.1 & 98.5 \\
United Kingdom & 14.4 & 85.6 & & 59.4 & 4.3 & 36.3 \\
United States & 32.9 & 67.1 & & 0.3 & 0.0 & 99.7 \\
Average & 24.6 & 75.4 & & 16.0 & 1.2 & 82.8 \\
\hline
\end{tabular}




\section{Interest Rates}

\begin{tabular}{lcccccc}
\hline & \multicolumn{2}{c}{ Industrial Production } & & \multicolumn{3}{c}{ Interest rates } \\
\cline { 2 - 3 } \cline { 5 - 7 } \cline { 5 - 7 } & Global & Idiosyncratic & & Global & Spillover & Idiosyncratic \\
\hline \hline Canada & 19.9 & 80.1 & & 47.9 & 3.1 & 49.0 \\
France & 18.9 & 81.1 & & 7.7 & 0.5 & 91.7 \\
Germany & 33.9 & 66.1 & & 16.8 & 1.1 & 82.1 \\
Italy & 26.5 & 73.5 & & 7.3 & 0.5 & 92.2 \\
Japan & 30.2 & 69.8 & & 10.8 & 0.7 & 88.5 \\
United Kingdom & 14.9 & 85.1 & & 12.8 & 0.8 & 86.4 \\
United States & 34.2 & 65.8 & & 79.7 & 5.2 & 15.0 \\
Average & 25.5 & 74.5 & & 26.1 & 1.7 & 72.1 \\
\hline
\end{tabular}

Notes: In each cell, the variance share attributable to the relevant factor is reported at a horizon of 30 quarters. The variance contributions are attributed to: Global (global macro factor), Financial (global financial factor), Spillover (spillovers from macro to financial factors), and Idiosyncratic (idiosyncratic factor). In Model 3, the global macro factor spills over to the global financial factor. 


\section{Figure A1. Country-Specific Variance Decompositions:}

Spillovers From Financial Sector to Macroeconomy

(Model 1\&2; Output; 1998-2019)
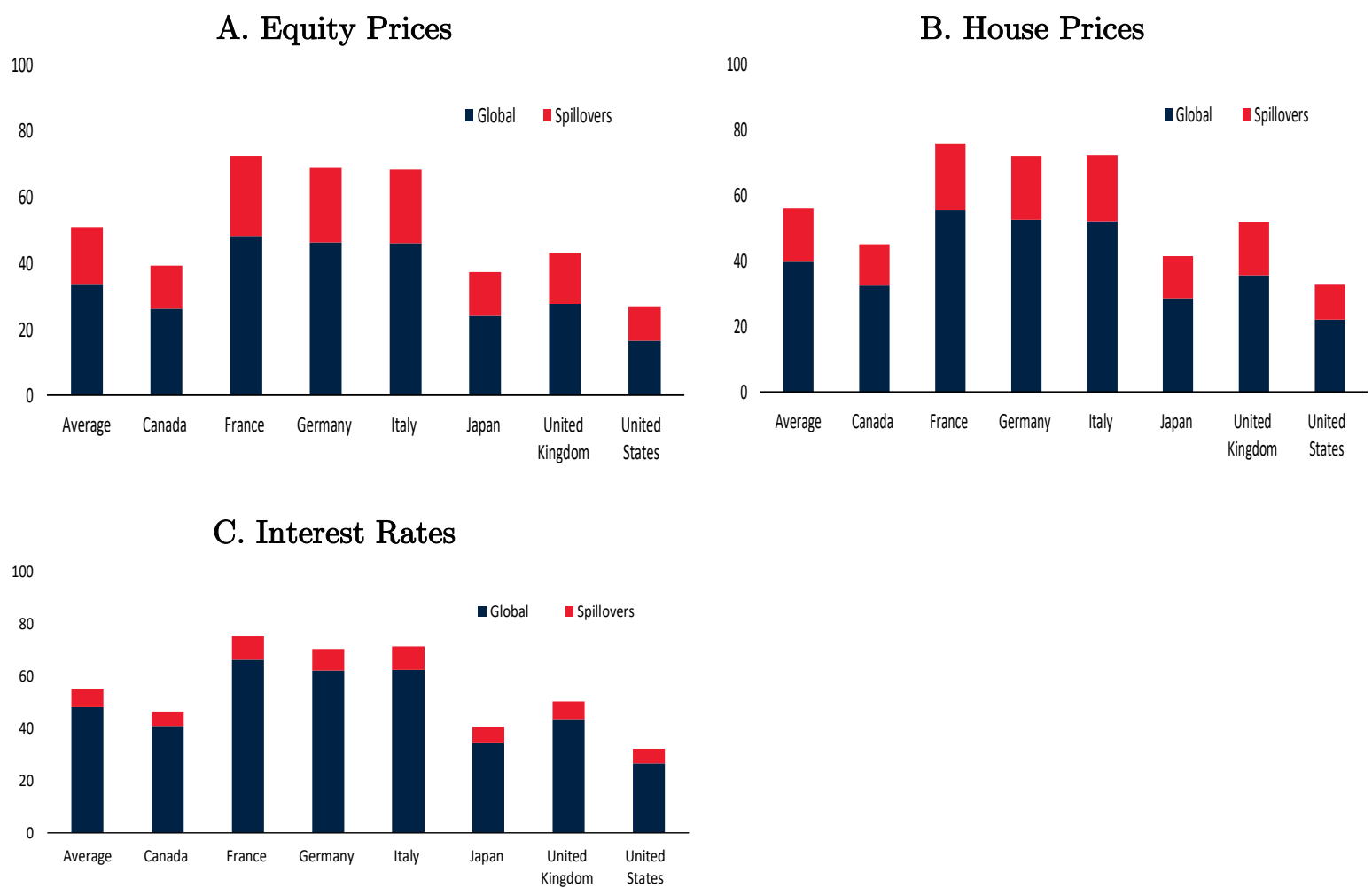

Notes: The bars show the shares of output variance in each country accounted for by the global macro factor ("global") and spillovers from financial factors ("spillovers"). The results are based on the combined Model 1 and 2, which captures spillovers of the financial factor on output fluctuations through the global macro factor (Model 1) and the country-specific macro factor (Model 2). 
Figure A2. Variance Decompositions: Spillovers From Macroeconomy to Financial Sector (15-Year Rolling Windows; Model 3\&4; G-7 Averages; 1985-2019)

\section{A. Equity Prices}

100

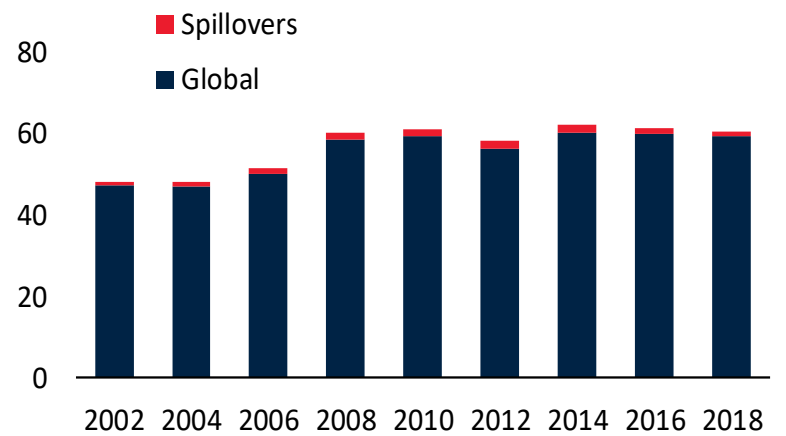

\section{B. House Prices}

100

$80 \quad$ Spillovers

60

40

20

0

200220042006200820102012201420162018

\section{Interest Rates}

100

- Spillovers

80

$$
\text { - Global }
$$

60

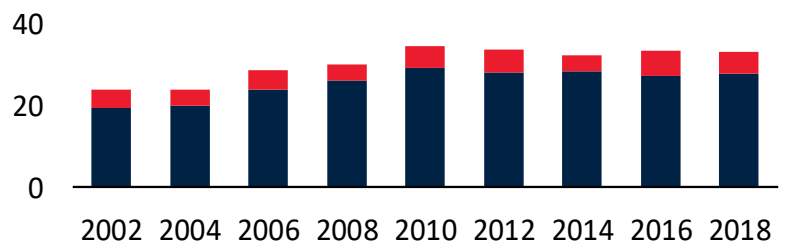

Notes: These figures are based on variance decompositions from model estimates over 15-year (trailing) rolling windows. The bars show the average (for the G-7 countries) shares of the variance in fluctuations of financial variables accounted for by the global financial factor ("global") and by spillovers from macroeconomic aggregates. The results are based on the combined Model 3 and 4, which captures spillovers of macro fluctuations onto financial markets through the global macro factor (Model 3) and the U.S. country factor. 
Figure A3. Country-Specific Variance Decompositions: Spillovers From Macroeconomy to Financial Sector (Model 3\&4; 1998-2019)

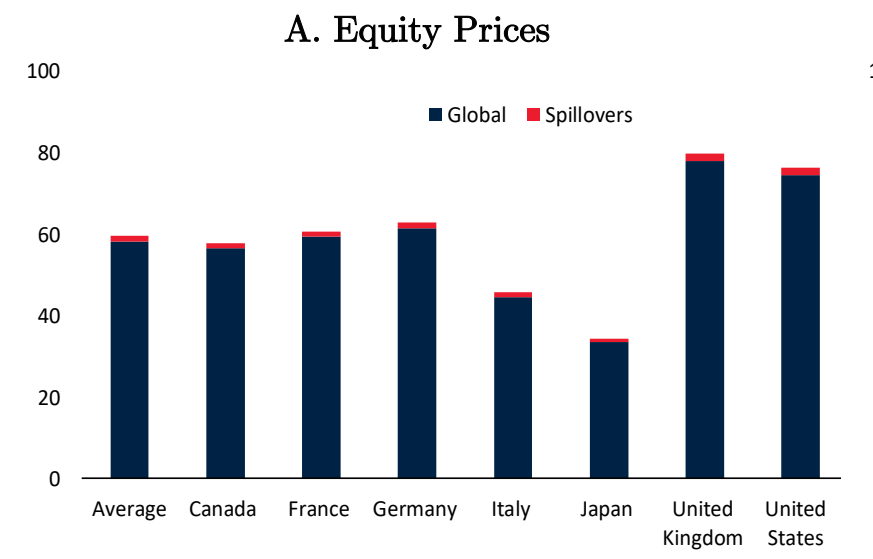

B. House Prices
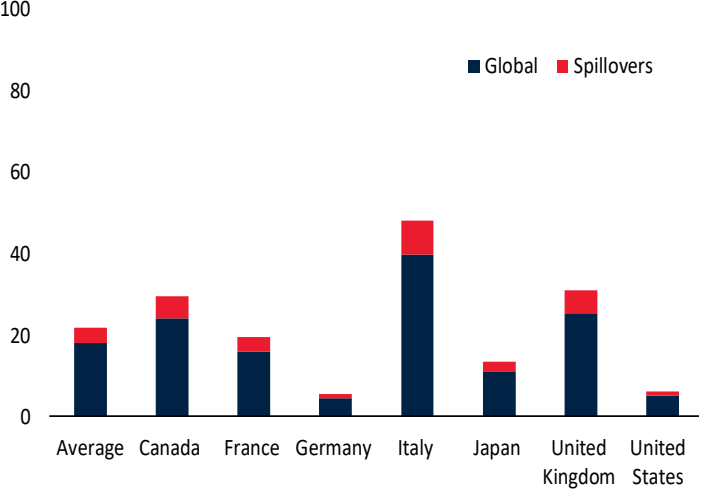

C. Interest Rates

100

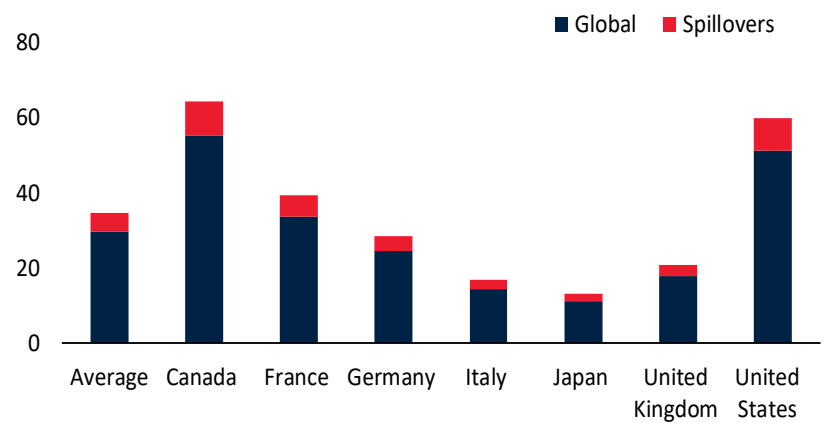

Notes: In each panel, the bars show the country-specific shares of the variance of the relevant financial variable that is accounted for by the global financial factor ("global") and spillovers from macro variables to financial factors ("spillovers"). The results are based on the combined Model 3 and 4, which captures spillovers from the macroeconomy onto financial markets through the global macro factor (Model 3) and the U.S. country factor (Model 4). 
Figure A4. Dynamic Factor Estimation Results with Credit Growth

\section{A. Global Credit Factor \\ (1985-2019)}

4

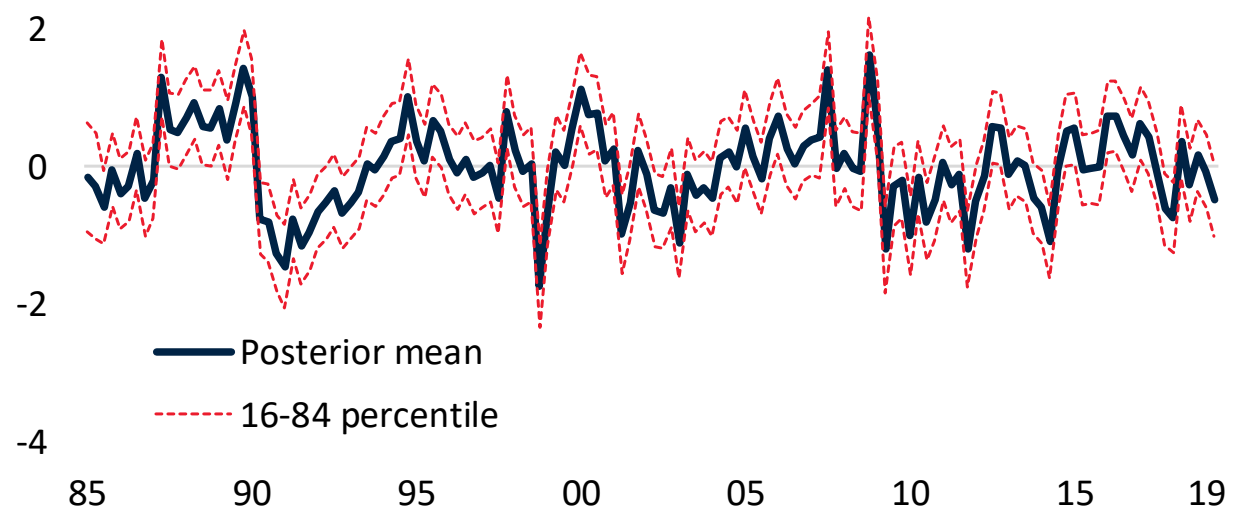

Notes: The factors shown as solid lines are posterior medians based on the combined Model $3 \& 4$ estimated over the full sample (1985-2019). The dashed lines represent the 16 and 84 percent posterior quantile bands. In Model 3, the global macro factor spills over to the financial factor. In Model 4, the U.S. country factor spills over to the financial factor. Models 3 and 4 combined capture both channels through which the macro factors affect the financial sector.

\section{B. Variance Decompositions: Spillovers From Financial Sector to Macroeconomy}

(1998-2019)

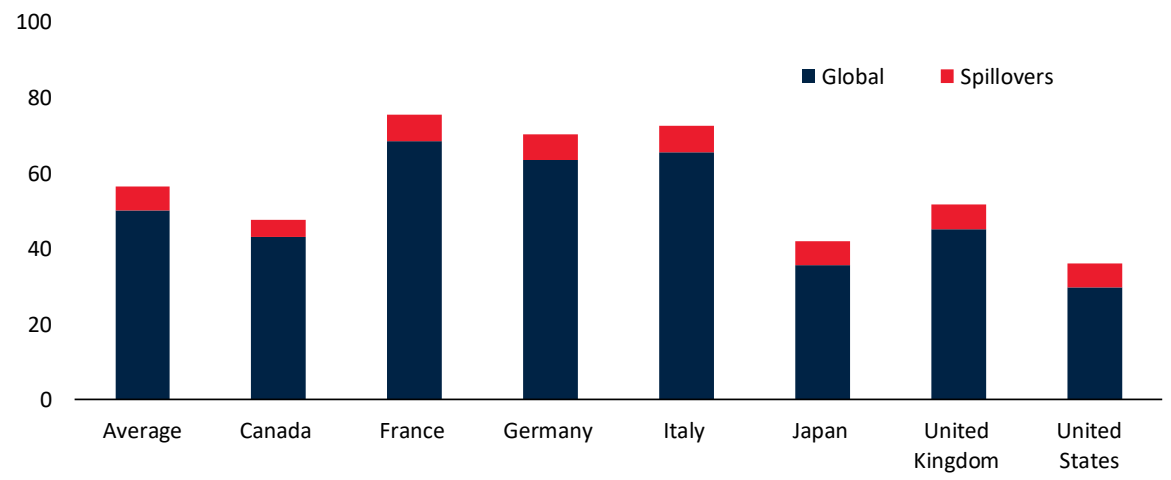

Notes: These figures show the variance decompositions for the global macro factor ("global") and spillovers from the credit factor to fluctuations in macro variables ("spillovers"). The results are based on the combined Model 1 and 2, which captures spillovers to the global macro factor (Model 1) and to country-specific macro factor (Model 2) through which the financial factor affects macro activity. 


\section{Variance Decompositions: Spillovers From Macroeconomy to Financial Sector \\ (1998-2019)}

100

80

- Global a Spillovers

60

40

20

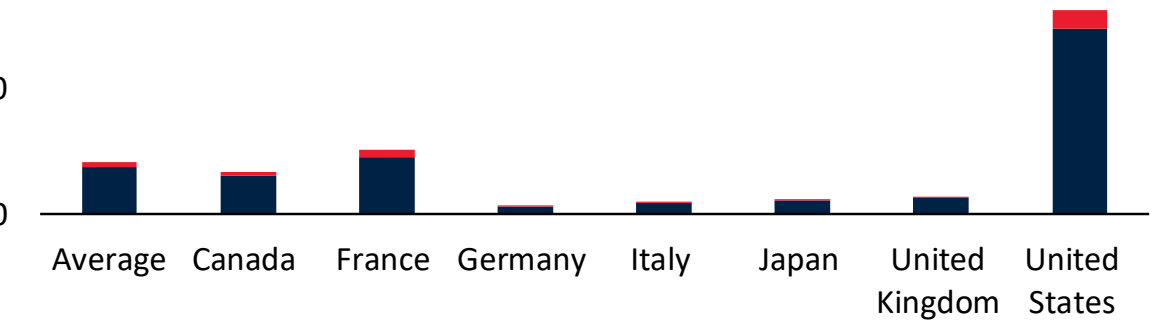

Notes: These figures show the variance decompositions for the global financial factor ("global") and spillovers from macro to financial factors ("spillovers"). The results are based on the combined Model 3 and 4, which captures spillovers from the global macro factor (Model 3) and from the U.S. country factor (Model 4) through which the financial sector is affected 